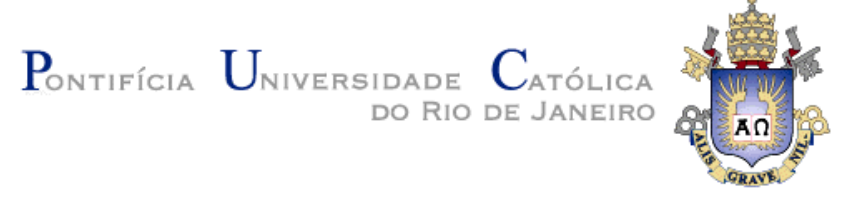

Bruno Jordão Lopes

\title{
Desenvolvimento e Caracterização de Compósitos Termoplásticos Reforçados por \\ Fibras de Carbono
}

Dissertação de Mestrado

Dissertação apresentada ao Programa de Pós-graduação em Engenharia de Materiais e de Processos Químicos e Metalúrgicos da PUC-Rio como requisito parcial para obtenção do grau de Mestre em Engenharia de Materiais e de Processos Químicos e Metalúrgicos.

Orientador: Prof. José Roberto Moraes d'Almeida 


\section{BRUNO JORDAO LOPES}

\section{Desenvolvimento e Caracterização de Compósitos Termoplásticos Reforçados por Fibras de \\ Carbono}

Dissertação apresentada como requisito parcial para a obtenção do grau de Mestre pelo Programa de Pósgraduação em Engenharia de Materiais e de Processos Químicos e Metalúrgicos da PUC-Rio. Aprovada pela Comissão Examinadora abaixo assinada.

Prof. José Roberto Moraes d'Almeida Orientador

Departamento de Engenharia Química e de Materiais - PUC-Rio

Profa. Marysilvia Ferreira da Costa Universidade Federal do Rio de Janeiro - UFRJ

Profa. Marisa Cristina Guimarães Rocha Universidade Estadual do Rio de Janeiro - UERJ

Prof. Marcio da Silveira Carvalho Coordenador Setorial do Centro Técnico Científico - PUC-Rio 
Todos os direitos reservados. É proibida a reprodução total ou parcial do trabalho sem autorização da universidade, do autor e do orientador.

\section{Bruno Jordão Lopes}

Graduou-se em Engenharia Mecânica na UERJ (Universidade do Estado do Rio de Janeiro) em 2015. Tem como linha de pesquisa o desenvolvimento, caracterização e certificação de materiais compósitos, possuindo artigo sobre o tema. É bolsista de pesquisa pelo $\mathrm{CNPq}$ já tendo atuado na área de certificação de materiais e componentes para a indústria offshore.

\section{Ficha Catalográfica}

\section{Lopes, Bruno Jordão}

Desenvolvimento e caracterização de compósitos termoplásticos reforçados por fibras de carbono / Bruno Jordão Lopes ; orientador: José Roberto Moraes d'Almeida. - 2018.

108 f. : il. color. ; $30 \mathrm{~cm}$

Dissertação (mestrado)-Pontifícia Universidade Católica do Rio de Janeiro, Departamento de Engenharia Química e de Materiais, 2018.

Inclui bibliografia

1. Engenharia de Materiais - Teses. 2. Engenharia Química - Teses. 3. Compósitos. 4. Fibra de carbono. 5. ABS. 6. Extrusão. 7. Manufatura aditiva. I. Almeida, José Roberto Moraes d'. Il. Pontifícia Universidade Católica do Rio de Janeiro. Departamento de Engenharia Química e de Materiais. III. Título. 
Para a minha madrinha Martha e meus avós Fernando e Therezinha. 


\section{Agradecimentos}

À minha madrinha Martha, por uma vida inteira de ensinamentos, carinho e paciência.

Aos meus avós por todo o incentivo e apoio, mesmo, muitas vezes em condições adversas.

À minha mãe e irmão por sempre acreditarem na minha capacidade e por confiarem nas minhas decisões.

Aos meus amigos e roomates, sem os quais certamente toda esta experiência teria sido muito mais difícil.

À PUC-Rio e ao CNPq que possibilitaram o desenvolvimento desta pesquisa.

À Toho Tenax America, Inc., na figura do Sr. Carlos Leutewiler, que acreditou no projeto, nos doou as fibras de carbono e estava sempre disponível para nos dar suporte.

À professora Marisa, à professora Verônica e ao professor Nicolás que disponibilizaram seus laboratórios para a realização de ensaios deste projeto.

Ao técnico Jorge, à Nancy, ao Bruno, às alunas Raquel e Nathalia do IPRJ, às alunas Anna, Jessica e Daphne do LABIO, ao aluno Geovane e ao Marcos Henrique da PUC. A todos que ajudaram de alguma forma a realização deste projeto.

Por último e mais importante ao meu orientador professor José Roberto que aceitou fazer este projeto do zero e que sempre incentivou e acreditou mesmo com todos os obstáculos encontrados. 


\section{Resumo}

Lopes, Bruno Jordão; Moraes d'Almeida, José Roberto. Desenvolvimento e Caracterização de Compósitos Termoplásticos Reforçados por Fibras de Carbono. Rio de Janeiro, 2018. 108p. Dissertação de Mestrado Departamento de Engenharia Química e de Materiais, Pontifícia Universidade Católica do Rio de Janeiro.

O objetivo deste trabalho foi produzir, caracterizar e avaliar o comportamento mecânico de um compósito de matriz termoplástica (ABS) reforçado por fibras de carbono para uso futuro em manufatura aditiva. Misturas foram produzidas contendo diferentes quantidades $(0 \%, 5 \%$ e $16,7 \%)$ e comprimentos (3 $\mathrm{mm}$ e $6 \mathrm{~mm}$ ) de fibras. Cada mistura foi processada através de uma extrusora dupla rosca para a produção de pellets. Os pellets de cada mistura (incluindo pellets de ABS puro) foram analisados para a caracterização do material processado. Posteriormente, corpos de prova foram extrusados para a determinação das propriedades mecânicas e análise da superfície de fratura. As técnicas utilizadas para a caracterização do material foram: espectroscopia no infravermelho (FTIR), análise termogravimétrica (TGA), reometria capilar e microscopia eletrônica de varredura (MEV). Para a avaliação do comportamento mecânico, os corpos de prova extrusados foram ensaiados para a determinação da resistência à tração, módulo de elasticidade e ductilidade. Em seguida, as superfícies de fratura dos corpos de prova foram analisadas no MEV. Foi verificada a possibilidade de degradação da matriz polimérica e formação de vazios durante o processamento inicial do material, que foram eliminados após a segunda extrusão. As fibras de carbono causaram aumento no módulo de elasticidade e diminuição da ductilidade do compósito, apesar de pouco influenciarem as propriedades reológicas. Além disto, pequenas variações na estabilidade térmica foram observadas. Ao final, em anexo, foi elaborado um panorama sobre a Manufatura Aditiva (MA) e a oportunidade de utilização de compósitos em técnicas de impressão 3D.

\section{Palavras chave}

Compósitos; Fibra de carbono; ABS; Extrusão; Manufatura Aditiva. 


\section{Abstract}

Lopes, Bruno Jordão; Moraes D’Almeida, José Roberto (Advisor). Development and Characterization of Carbon Fiber Reinforced Thermoplastic Composites. Rio de Janeiro, 2018. 108p. Dissertação de Mestrado - Departamento de Engenharia Química e de Materiais, Pontifícia Universidade Católica do Rio de Janeiro.

The goal of this work was to produce, characterize and analyze the mechanical behavior of a carbon fiber reinforced thermoplastic composite with future applications in additive manufacturing. Mixtures were produced with varying carbon fiber content $(0 \%, 5 \%$, and $16,7 \%)$ and initial length $(3 \mathrm{~mm}$ and 6 $\mathrm{mm})$. Each mixture was processed via a twin-screw extruder to produce pellets. Pellets from each mixture (including pure $\mathrm{ABS}$ ) were analyzed to investigate the processed material properties. Afterwards, test specimens were extruded from each mixture's pellets for mechanical testing and fracture surface analysis. The following techniques were used for material characterization: Fourrier-Transform Infrared Spectroscopy (FTIR), Thermogravimetric Analysis (TGA), capillary rheology and Scanning Electron Microscopy (SEM). For the evaluation of mechanical properties, the extruded test specimens' yield strength, Young's modulus and ductility were determined. Also, the fracture surfaces were observed using SEM. The effects of processing parameters and of the introduction of carbon fibers in the ABS polymer were determined. Results pointed out the possibility of degradation during initial processing and the formation of voids in the pellets' structure, which were eliminated during the second extrusion. Results also showed an increase in modulus and a decrease in ductility of the composite, whereas rheological properties seemed largely unaffected. Additionally, small variations in thermal stability were observed with varying carbon fiber content and length. Finally, as an annex, a brief overview of Additive Manufacturing and the opportunities for using carbon fiber reinforced thermoplastics in 3D printing techniques is presented.

\section{Keywords}

Composites; Carbon fiber; ABS; Extrusion, Additive Manufacturing. 


\section{Sumário}

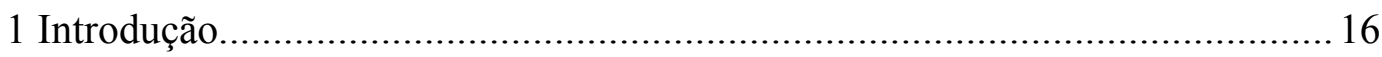

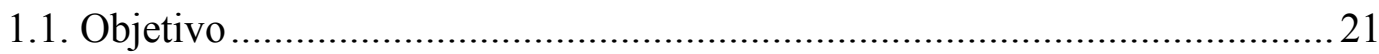

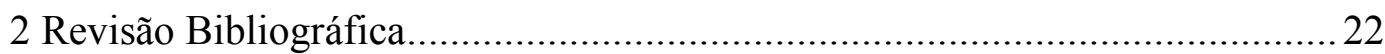

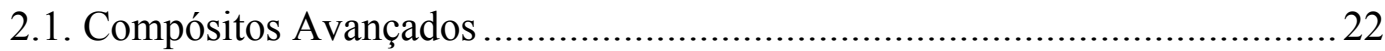

2.1.1. Termoplásticos vs. Termorrígidos ....................................................................

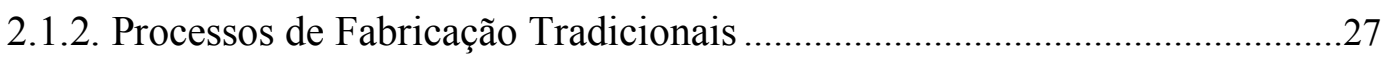

2.1.2.1. Processos de Fabricação para Compósitos Termoplásticos .........................29

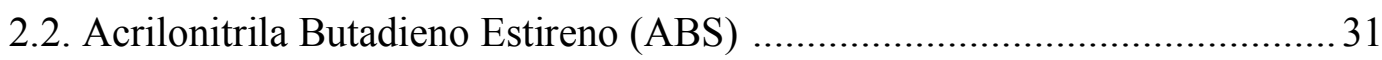

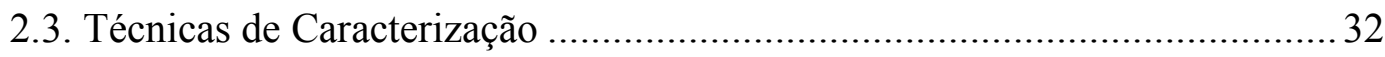

2.3.1. Espectroscopia no Infravermelho por Transformada de Fourrier...................32

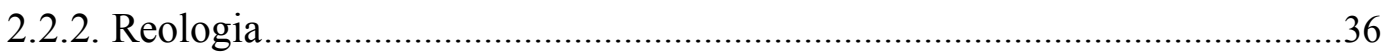

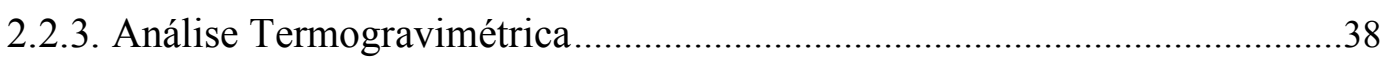

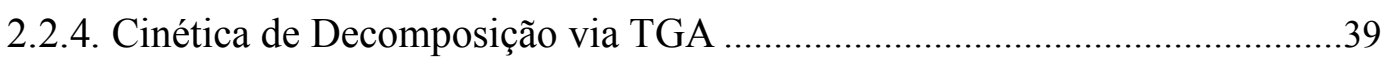

3 Materiais e Métodos Experimentais .............................................................. 41

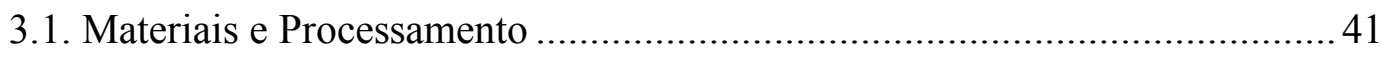

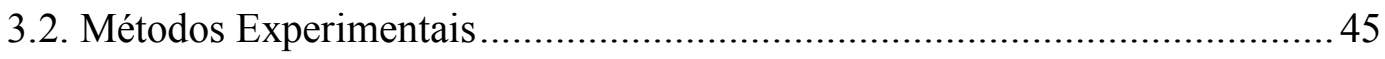

3.2.1. Ensaio de Infravermelho (FTIR) .............................................................

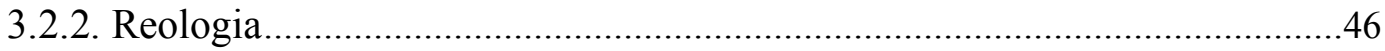

3.2.3. Análise Termogravimétrica (TGA) ............................................................46

3.2.3.1. Cinética de Decomposição via TGA ............................................................4

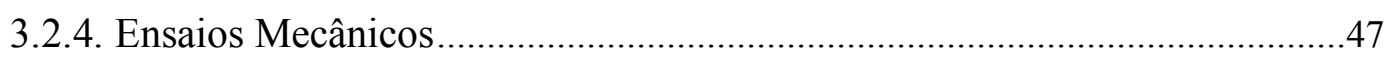

3.2.5. Análise Microestrutural ...............................................................................

4 Resultados e Discussão ............................................................................... 50

4.1. Degradação da Matriz Polimérica................................................................ 50

4.2. Análise Termogravimétrica ………………………................................... 55

4.2.1. Influência das Fibras na Estabilidade Térmica .................................................56

4.2.2. Fração Real de Fibras nas Misturas ..............................................................60

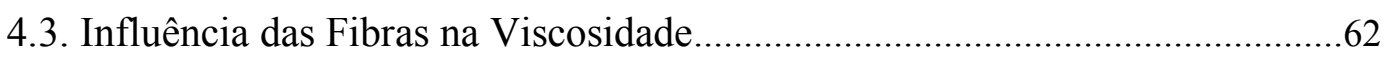

4.4. Variação das Propriedades em Função da Fração e do

Comprimento Inicial de Fibras.......................................................................................63 


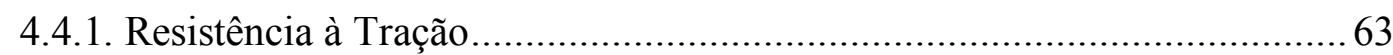

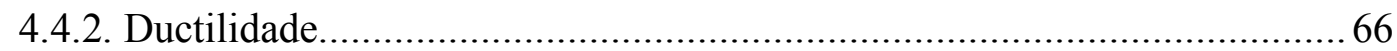

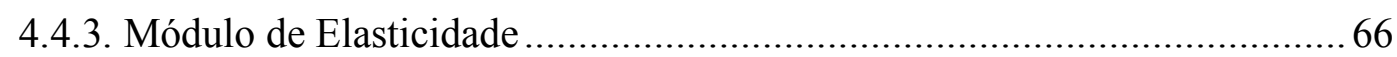

4.4.4. Influência do Comprimento Incial das Fibras.................................................67

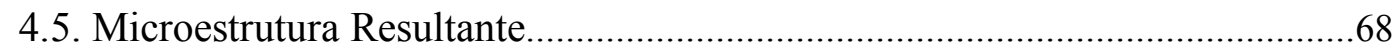

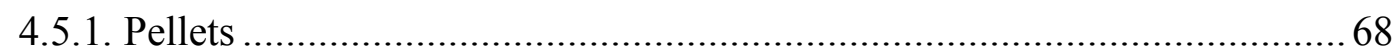

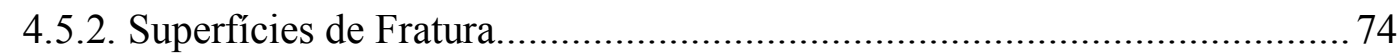

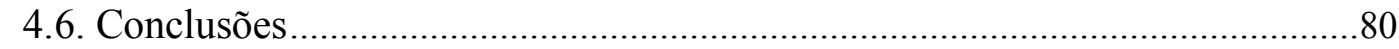

4.6.1. Comportamento Mecânico …………….............................................................. 80

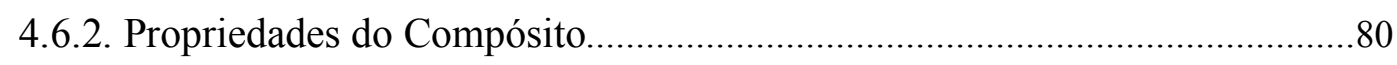

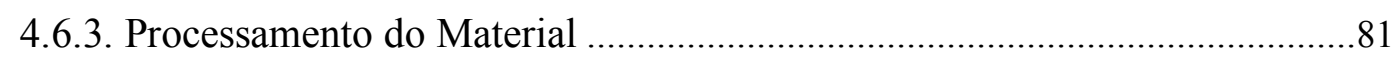

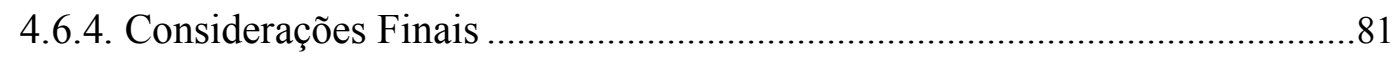

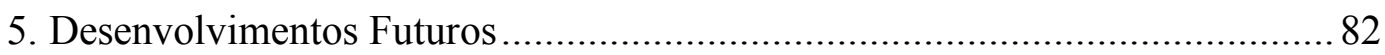

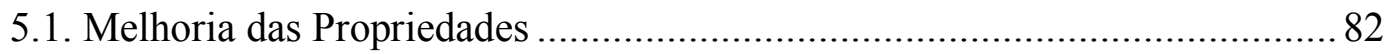

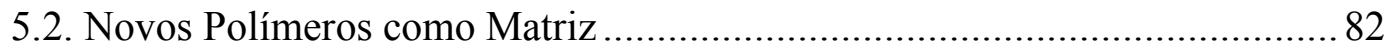

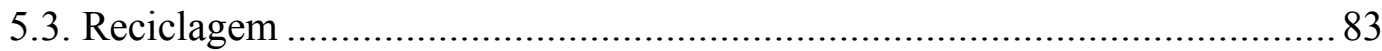

5.4. Manufatura Aditiva em Grande Escala ...................................................... 83

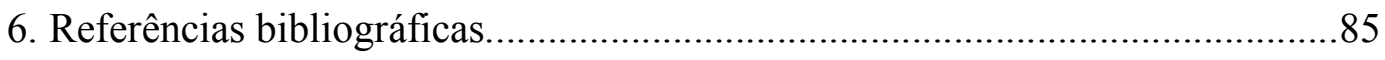




\section{Lista de figuras}

Figura 1: Evolução dos Materiais de Engenharia [1] 16

Figura 2: Monocoque produzido a partir da técnica Forged

Composite ${ }^{\circledR}$, desenvolvida por Feraboli et al. [4-9] em parceria

com a Lamborghini Automobili S.p.A. e Callaway Golf Company e

Boeing. Fonte da imagem: Divulgação 17

Figura 3:Projeção do mercado de fibra de carbono no Brasil [11] 18

Figura 4: Distribuição do mercado de compósitos por processo,

(a) na América Latina [12]; e (b) no Brasil [13] 19

Figura 5: TCPs produzidos pela Airborne Oil \& Gas [26] 20

Figura 6: Molde para pá de turbina eólica fabricado por manufatura aditiva [24]. 22

Figura 7: (a) tecido prepreg unidirecional; (b) sheet molding compound;

(c) fios contínuos; (d) fibras descontínuas [32, 33] 24

Figura 8: Estrutura molecular do ABS 31

Figura 9: Esquematização de um interferômetro de Michelson. Fonte: wikipedia.org 33

Figura 10: Principais bandas de absorção para materiais poliméricos.

Fonte: Billmeyer Jr., F. como visto em Novoa [45] 35 
Figura 11: Representação esquemática de um reômetro capilar.

(1) base do equipamento; (2) Cilindro de ensaio; (3) Pistão; (4/5) Suporte

do pistão com transdutor de força; (6) Conjunto motriz com carenagem;

(7) Vidro de proteção; (8) Painel de controle; (9) Suporte do equipamento.

Fonte: Manual do Usuário do Reômetro Göttfert Rheograph 25 ......................... 36

Figura 12: Fluxograma do procedimento experimental..................................... 41

Figura 13: Fibras de Carbono em dois comprimentos: $3 \mathrm{~mm}$ e $6 \mathrm{~mm}$................ 42

Figura 14: Corpos de prova da Mistura I, como extrusados (antes de serem cortados nas dimensões do equipamento de medição).

Dimensões: Aprox. $3 \mathrm{~mm}$ de diâmetro por aprox. $15 \mathrm{~cm}$ de comprimento. 44

Figura 15: Amostras metalizadas posicionadas no porta-amostras do MEV 49

Figura 16: Gráfico resultante do FTIR, gerado pelo software

Spectrum (Perkin Elmer), para ABS puro

Figura 17: Comparação da região indicativa de oxidação do ABS

processado em diferentes temperaturas 51

Figura 18: Comparação da Região F para as 5 misturas processadas. .52

Figura 19: Espectro de FTIR destacado para a região A. 53

Figura 20: Espectro de FTIR destacado para a região B 53

Figura 21: Espectro de FTIR destacado para a região C 54

Figura 22: Espectro de FTIR destacado para a região D .54

Figura 23: Espectro de FTIR destacado para a região E 55 
Figura 24: Termograma em função da \% de perda de massa para as três taxas de aquecimento utilizadas. Exemplo para a Mistura I 56

Figura 25: Gráfico dos níveis de degradação em função da taxa de aquecimento e temperatura 57

Figura 26: Gráfico das energias de ativação em função das misturas. .58

Figura 27: Gráfico resultante do TGA para o óleo de semente de uva........ .59

Figura 28: Comparativo das temperaturas de cada mistura à 5\% de perda de massa. 60

Figura 29: Gráfico resultante do TGA para o ABS puro (Mistura I). 61

Figura 30: Gráfico resultante do TGA para a mistura III. 61

Figura 31: Gráfico Viscosidade x Taxa de Cisalhamento para as 5

misturas analisadas. 63

Figura 32: Comparação do gráfico Tensão x Deformação para um corpo de prova de cada mistura. 65

Figura 33: Comparação da resistência à tração entre as misturas. 65

Figura 34: Comparação da ductilidade entre as misturas. 67

Figura 35: Comparação do módulo de elasticidade entre as misturas. 68

Figura 36: Visão geral da superfície dos pellets da mistura (a) II;

(b) III; (c) IV; (d) V. 71 
Figura 37: (a) Vazios na região central da mistura IV; (b) \&

(c) Vazios e fibras com fraca interface na mistura II;

(d) Fibras dentro de vazios e interação entre fibras na mistura V

Figura 38: Superfície de fratura das misturas (a) I; (b) II; (c) III; (d) IV; (e)V . ... 77

Figura 39: (a) ponto inicial da fratura - mistura I; (b) fibra arrancada

- mistura IV; (c) buraco deixado por fibra arrancada - mistura V;

(d) fibras desalinhadas - mistura III; (e) interação entre fibras - mistura V. 79 


\section{Lista de tabelas}

Tabela 1: Propriedades do ABS e outros polímeros utilizados em manufatura aditiva [30-32]

Tabela 2: Misturas utilizadas para a etapa experimental. 43

Tabela 3: Resultados do TGA para uma taxa de aquecimento de $10^{\circ} \mathrm{C} / \mathrm{min}$. ........55

Tabela 4: Resultados do TGA para uma taxa de aquecimento de $20^{\circ} \mathrm{C} / \mathrm{min}$. .......56

Tabela 5: Resultados do TGA para uma taxa de aquecimento de $30^{\circ} \mathrm{C} / \mathrm{min}$. .......56

Tabela 6: Temperaturas de degradação para a Mistura II................................... 57

Tabela 7: Energia de ativação em função do nível de degradação e mistura.........58

Tabela 8: Quadro comparativo das \% wt real e calculada 62 
Simplify and then, add lightness.

Colin Chapman, Lotus Cars 


\section{Introdução}

Do final do século XIV a meados do século XX, o material estrutural mais importante foi o ferro. $\mathrm{O}$ ferro e suas ligas, à medida que foram sendo desenvolvidas, dominaram os projetos de engenharia. Economistas eram capazes de correlacionar o nível de desenvolvimento de um país pela quantidade de aço produzida per capita [1].

Desde então, o ritmo de desenvolvimento de novas ligas metálicas, tem diminuído, Figura 1 [1]. Após um pico, ao final dos anos 1940, impulsionado sobretudo pelas demandas da indústria de defesa e aeroespacial, por conta em grande parte das Grandes Guerras, o crescente de inovação perdeu força. Recentemente, o desenvolvimento dos metais tem sido lento e tange basicamente a melhoras no processo de produção e controle de qualidade [1].

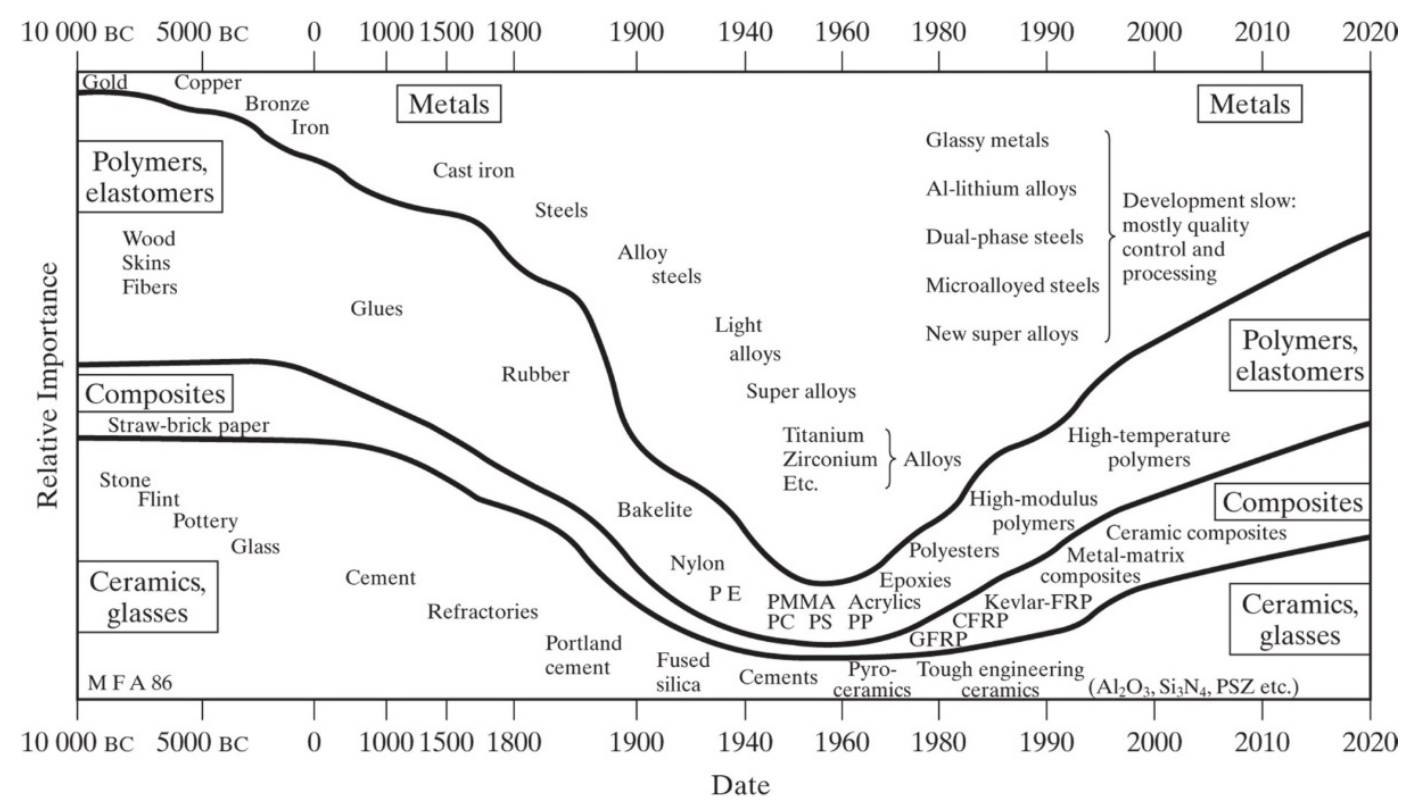

Figura 1: Evolução dos Materiais de Engenharia [1]

A forma de produção também pouco mudou ao longo do século XX. Fábricas cresceram, saíram de seus países de origem em busca de mão-de-obra barata e se especializaram cada vez mais em um mesmo tipo de produto. Muitas foram as tentativas de revitalizar um modelo de produção proposto no início do século passado. Hoje, este modelo já está esgotado e uma nova revolução da manufatura está acontecendo neste exato momento [2]. 
Segundo Scalabre [2], esta revolução acontece baseada em avanços tecnológicos aplicados, dentre outras áreas, ao desenvolvimento de novos materiais e processos de manufatura. Neste cenário, os materiais compósitos, desempenham um papel central por conta de suas propriedades mecânicas aliadas a baixa densidade e versatilidade de projeto. A utilização destes materiais, numa indústria antes dominada por metais e suas ligas, demanda uma nova abordagem sobre o desenvolvimento e processamento de materiais.

Tratando-se de compósitos de matriz polimérica, os compósitos ditos avançados apresentam como reforço fibras de alta performance, principalmente as fibras de carbono, que garantem ao material altas relações resistência/densidade e rigidez/densidade [3]. Este tipo de material é utilizado apenas onde a alta performance justifica os altos custos associados à sua produção [3].

Dito isto, com o avanço dos processos de fabricação e novas resinas, além do constante aumento da demanda de mercado, os materiais compósitos avançados estão se tornando cada vez mais acessíveis. Antes, este tipo de material era restrito praticamente só à indústria aeroespacial, mas hoje, pesquisas permitem a sua aplicação em outros nichos, como por exemplo, a indústria automotiva (Figura 2), como mostrado pelos estudos de Feraboli et al. [4-9].

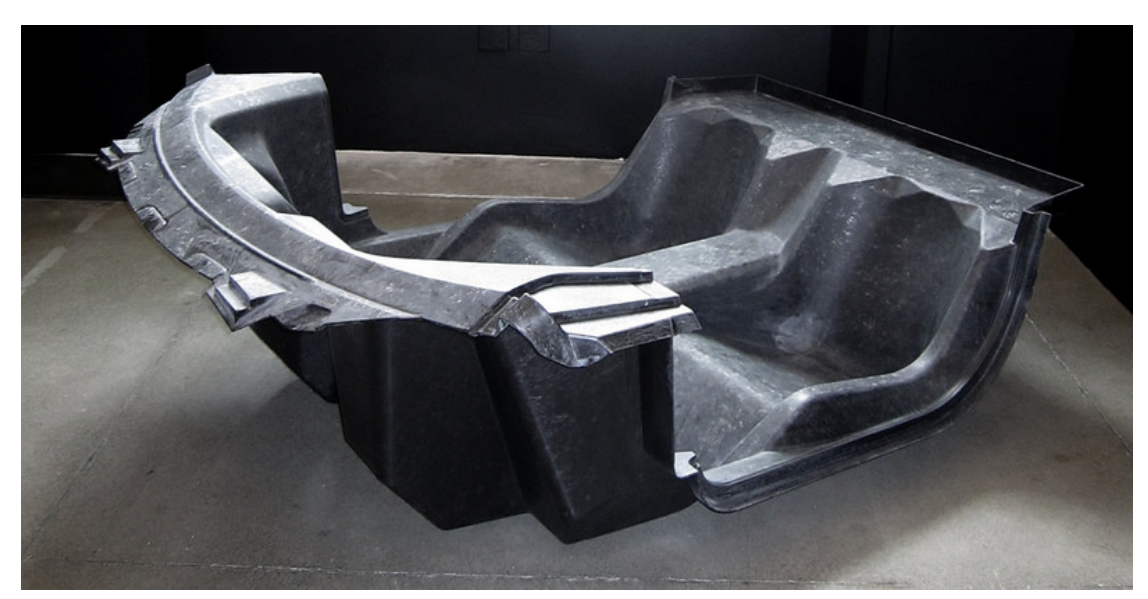

Figura 2: Monocoque produzido a partir da técnica Forged Composite ${ }^{\circledR}$, desenvolvida por Feraboli et al. [4-9] em parceria com a Lamborghini Automobili S.p.A. e Callaway Golf Company e Boeing. Fonte da imagem: Divulgação

Desde os anos 2000, a indústria de materiais compósitos reforçados por fibras de carbono aumentou significativamente. No começo daquela década, o mercado global movimentava menos de 20.000 toneladas por ano. Atualmente, este volume 
já ultrapassou as 60.000 toneladas/ano e previsões indicam que no começo da próxima década este número deve saltar para um valor entre 100.000 e 140.000 toneladas/ano. [10].

No Brasil, o mercado de fibra de carbono foi fortemente dominado pela demanda da energia eólica nos últimos anos e espera-se um crescimento contínuo pelo menos até 2020. Só em 2012 o consumo de fibra de carbono atingiu mais de 3500 toneladas (Figura 3) e movimentou quase 100 milhões de dólares, sobretudo por conta da produção de pás de turbinas eólicas. O cenário para os próximos anos é de que o mercado volte a crescer depois de uma forte queda em 2015, para se estabelecer em um patamar de 70 milhões de dólares/ano e por volta de 2500 toneladas/ano nos próximos 4 anos, estimulado principalmente por demandas das indústrias eólica, óleo \& gás e aeroespacial [11].

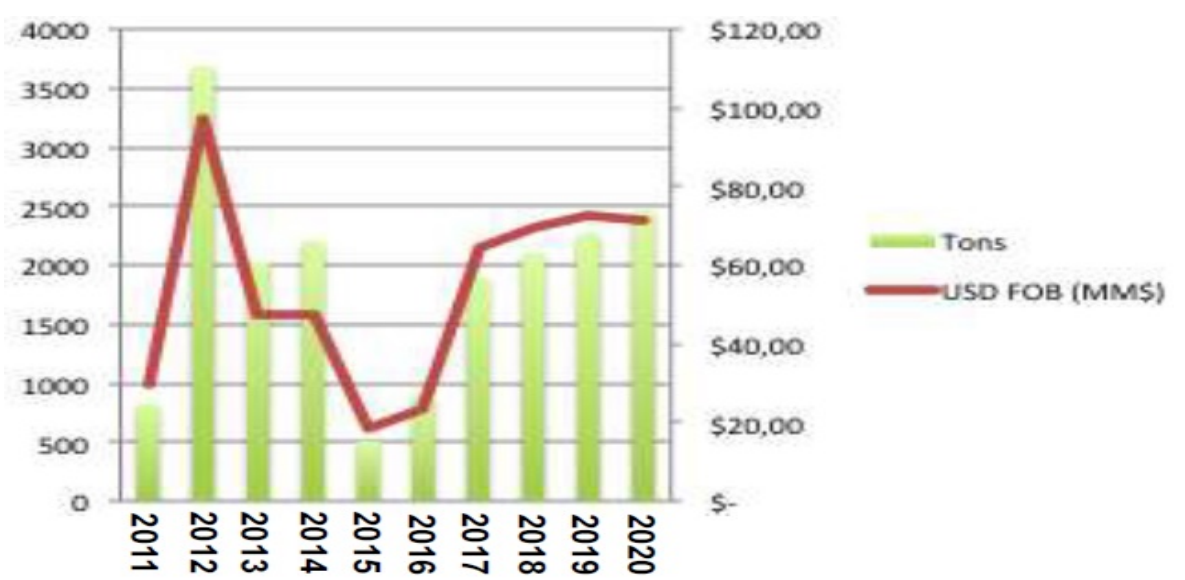

Figura 3:Projeção do mercado de fibra de carbono no Brasil [11].

Em termos de processo, a maior parte dos componentes produzidos a partir de materiais compósitos (avançados e não avançados), no Brasil e na América Latina, é produzida por técnicas manuais [12]. No Brasil, 49\% dos compósitos na indústria são produzidos por técnicas manuais [13]. Quando se trata da América Latina, esse número chega a 50\% (Figura 4) [12]. 


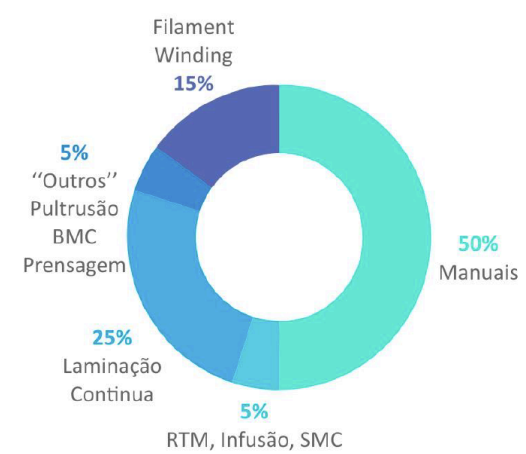

(a)

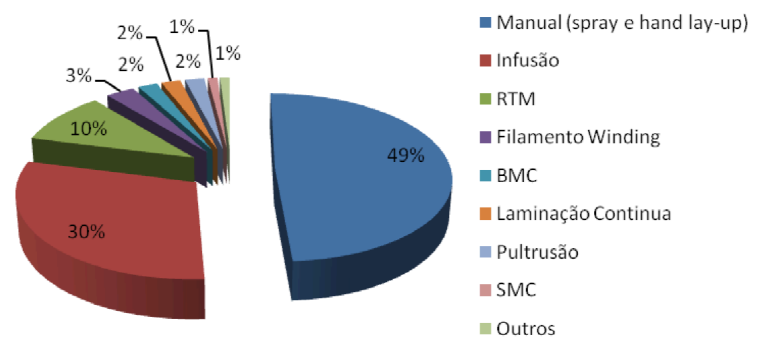

(b)

Figura 4: Distribuição do mercado de compósitos por processo,(a) na América Latina [12]; e (b) no Brasil [13]

Por outro lado, em países mais tecnologicamente desenvolvidos, a indústria de compósitos se mostra bastante avançada. Dados de 2009 mostram que, na Europa, o consumo de compósitos naquele ano era da ordem de $6 \mathrm{~kg} / \mathrm{habitante}$ por ano. Nos Estados Unidos, maior mercado consumidor, este número chegava a 10 $\mathrm{kg} /$ habitantes ano, enquanto no Brasil, este número chegava apenas a 0,95 $\mathrm{kg} /$ habitantes ano, ou seja, menos do que $10 \%$ do mercado americano [13].

O maior volume de mercado destes países os permite investir no avanço da tecnologia associada a este tipo de material e seus processos. Nas últimas décadas, compósitos de matriz termoplástica têm sido o objeto de estudo de diversos consórcios, institutos de pesquisa e universidades, em conjunto com a indústria. Este tipo de compósito apresenta uma série de vantagens em relação aos termorrígidos: maior ductilidade, maior facilidade de reparo, melhor resistência a impacto, maior shelf-life, maior possibilidade de reciclagem e reaproveitamento e novos processos de fabricação, para citar alguns.

Consórcios como o Thermoplastic Composites Research Center (TPRC), em Enschede, Holanda, são exemplo. O TPRC é um consórcio apoiado pela Boeing, diversos fornecedores da indústria e universidades holandesas com o único objetivo de desenvolver materiais e processos com este tipo de material [14, 15]. Na Europa, outros exemplos podem ser encontrados como o TAPAS - Thermoplastic Affordable Primary Aircraft Structure, criado para desenvolver materiais e processos para a Airbus [16].

Laboratórios financiados por governos, como o Oak Ridge National Laboratory (ORNL) no Tennessee, EUA, ilustram a importância também 
estratégica do desenvolvimento das tecnologias que envolvem compósitos termoplásticos. Nos últimos anos, o ORNL desenvolveu pesquisas que tratam da utilização deste tipo de compósito em técnicas de manufatura aditiva em larga escala $[17,18]$. Trabalhando em conjunto com a indústria, esta pesquisa já rompeu barreiras da impressão 3D, conseguindo produzir componentes de grandes dimensões e prontos para aplicações práticas, tais como veículos [9-21], estruturas e moldes [22-24]. Além disto, o ORNL em parceria com a Cincinnatti Inc., desenvolveu a primeira impressora 3D por extrusão de polímeros em larga escala do mundo [25]. No Anexo I são apresentados aspectos sobre as perspectivas e impacto que a manufatura aditiva de compósitos está trazendo ao setor industrial.

Atualmente, a Petrobrás estuda a viabilidade da utilização de tubos flexíveis, produzidos a partir de compósitos termoplásticos (Thermoplastic Composite Pipes - TCP) no campo de Libra [26]. A empresa contratada para o serviço é a holandesa Airborne Oil \& Gas (AOG), que, no seu portfólio, oferece tubos de polietileno (PE) ou polipropileno (PP) reforçados por fibra de vidro e tubos de náilon 12 (PA 12) ou de fluoreto de polivinilideno (PVDF) reforçados por fibras de carbono. Tubos produzidos pela AOG já são utilizados por empresas como Saipem, Chevron, Shell, Petronas e Total, conforme mostrado na Figura 5 [27].

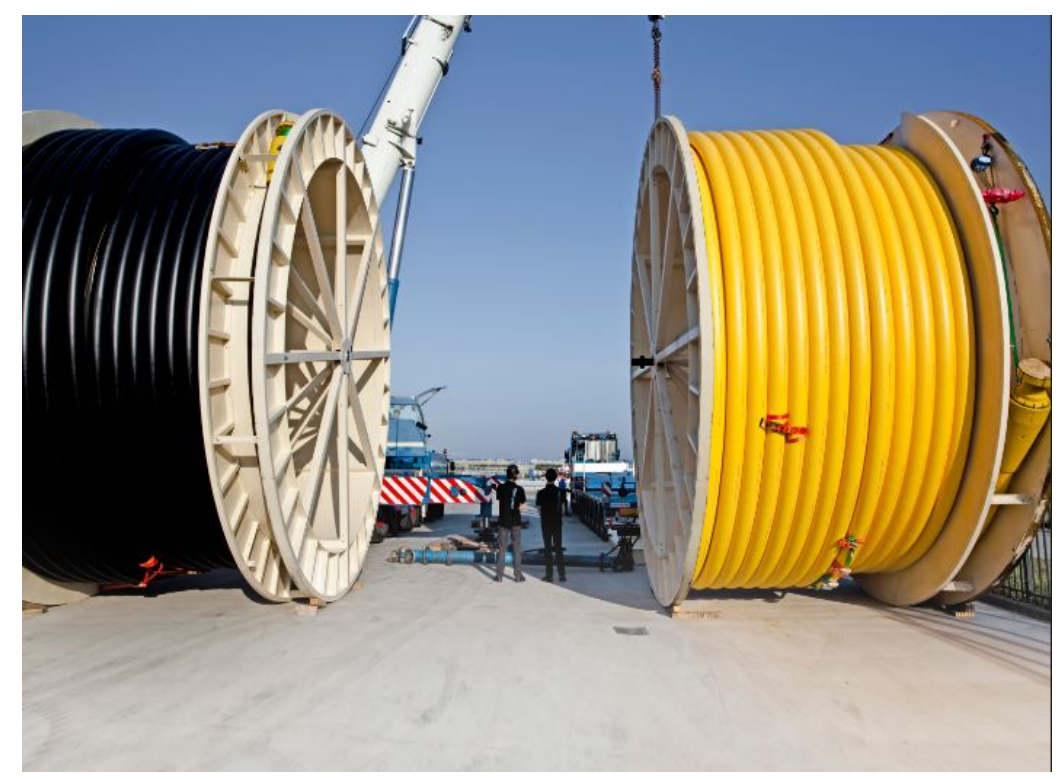

Figura 5: TCPs produzidos pela Airborne Oil \& Gas [26]

Apesar do baixo nível de investimento no país ser um entrave, o investimento em tecnologias relativas aos materiais compósitos é uma necessidade. 
As fronteiras do desenvolvimento vão, cada vez mais, exigir estruturas mais leves e resistentes, além de sustentáveis. A demanda já existe, hoje, principalmente por projetos relacionados a exploração de petróleo offshore, mas toda a indústria - e o país, tem muito a se beneficiar com o desenvolvimento das tecnologias relativas aos materiais compósitos e seus processos.

\section{1}

Objetivo

Este trabalho tem por objetivos:

I) produzir, caracterizar e analisar o comportamento mecânico de um compósito termoplástico avançado reforçado por fibra de carbono.

II) avaliar os desafios encontrados na fabricação e determinação das propriedades deste tipo de material, durante as etapas de seu desenvolvimento, para utilização como matéria prima em manufatura aditiva. 


\section{2 \\ Revisão Bibliográfica}

2.1

\section{Compósitos Avançados}

Segundo Gibson [3], compósitos avançados são os materiais compósitos feitos a partir de carbono, carbeto de silício, aramida, boro ou outras fibras de alto módulo, que são usados em aplicações de maior demanda estrutural, onde o alto custo pode ser justificado pela elevada performance.

Comparadas a reforços convencionais, como a fibra de vidro, por exemplo, estas fibras, ditas avançadas, apresentam inúmeras vantagens, dentre elas as mais importantes são: maior módulo de elasticidade, maior resistência e menor densidade [3]. A relação entre as propriedades mecânicas e o peso é bastante alta nessas fibras, o que as tornam muito interessantes para aplicações onde exige-se alta performance e baixo peso. Exemplos deste tipo de aplicação podem ser encontrados cada vez mais frequentemente em projetos das áreas aeroespacial [28], automotiva [7, 29], de energias renováveis [3, 24, 29] (como observado na Figura 6), construção civil e fins recreativos.

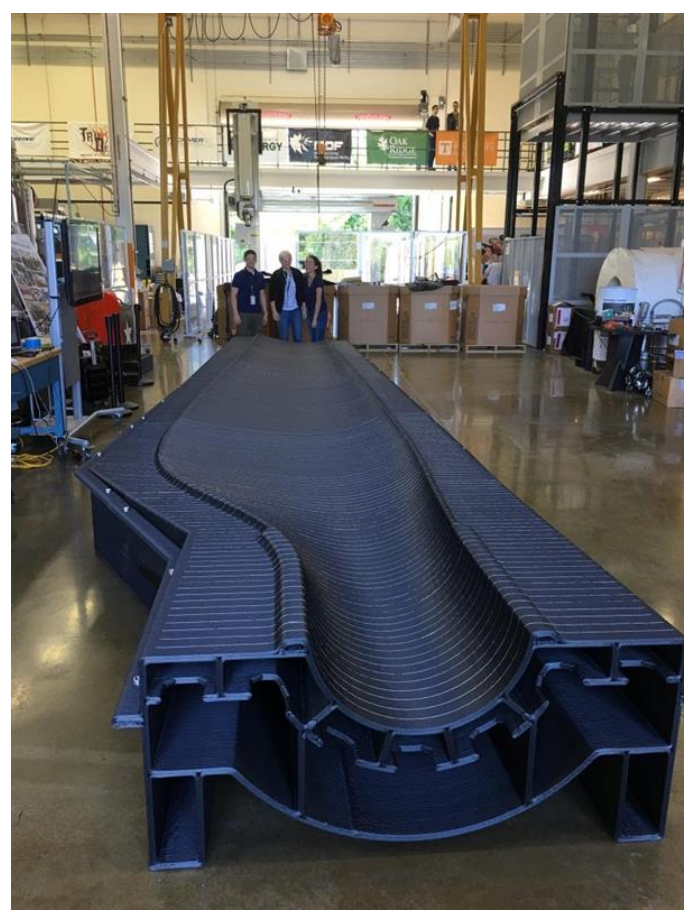

Figura 6: Molde para pá de turbina eólica fabricado por manufatura aditiva [24]. 
As matrizes desempenham funções importantes nos materiais compósitos. São elas as responsáveis por unir as fibras e protege-las do ambiente e de contatos que causem danos por abrasão ou impacto. Elas também são responsáveis por distribuir a carga aplicada e prover ductilidade ao componente [30].

Diversos materiais podem constituir a fase da matriz em um compósito, tais como: ligas metálicas, materiais cerâmicos e polímeros. A escolha do tipo de matriz influencia diretamente nas propriedades finais do compósito e no processo de fabricação, que será usado para produzir o componente desejado. As matrizes mais largamente utilizadas na indústria são as poliméricas, em função das suas propriedades, como ductilidade e fácil processabilidade, além do seu menor custo $[3,30]$.

Os compósitos avançados estão comercialmente disponíveis em inúmeras formas, sendo as principais: tecidos, mantas, fitas e fios. A escolha irá variar de acordo com a necessidade de cada projeto, em função de parâmetros como: direção das cargas aplicadas, facilidade de conformação em superfícies, custo e processo de manufatura.

O tipo mais comumente utilizado para aplicações de alta performance é o tecido, mostrado na Figura 7(a). Os tecidos podem ser encontrados secos, isto é, sem nenhum tipo de resina (matriz) impregnada, ou pré-impregnados de resina polimérica (prepreg). Prepregs são finas camadas de fibras impregnadas com quantidades predeterminadas de matriz polimérica distribuídas uniformemente [29]. Nesta configuração o material apresenta uma alta proporção fibra/resina, gerando valores de fração volumétrica altos ao fim do processo. Os tecidos são constituídos de fibras contínuas que podem estar dispostas de maneira uni ou multidirecional.

As mantas, por sua vez, são constituídas de fibras descontínuas aleatoriamente orientadas, como pode ser observado na Figura 7(b). Nelas, fios contínuos ou tecidos são cortados e prensados com o auxílio de rolos para formar uma manta. As fibras são mantidas juntas com o uso de um agente aglutinante e/ou por uma resina polimérica. As mantas apresentam como vantagens: baixo custo, facilidade de conformação com superfícies irregulares e um alto grau de isotropia [9].

As fitas são estruturas planas que contém filamentos contínuos unidirecionais, distribuídos igualmente e embebidos na matriz polimérica [31]. O material na forma de fita é geralmente utilizado em técnicas de posicionamento automático de fibras, 
tais como o Automated Tape Laying (ATL) e o Automatic Fiber Placement (AFP), bastante comuns na indústria aeroespacial e na produção de vasos de pressão [31].

Os fios podem ser encontrados na forma contínua, enrolados em bobinas (roving) - Figura 7(c), ou na forma descontínua (chopped tow) - Figura 7(d). Quando contínuos, os fios são encontrados em feixes com quantidades que variam normalmente entre 1.000 e 48.000 filamentos [32]. Nesta configuração, o reforço é geralmente utilizado em processos como enrolamento filamentar e pultrusão. Quando descontínuos, além da variação de filamentos por feixe, o comprimento das fibras também pode ser definido. Em ambos os casos, os fios podem vir com tratamento superficial (sizing) para melhor aderirem à matriz desejada [32].

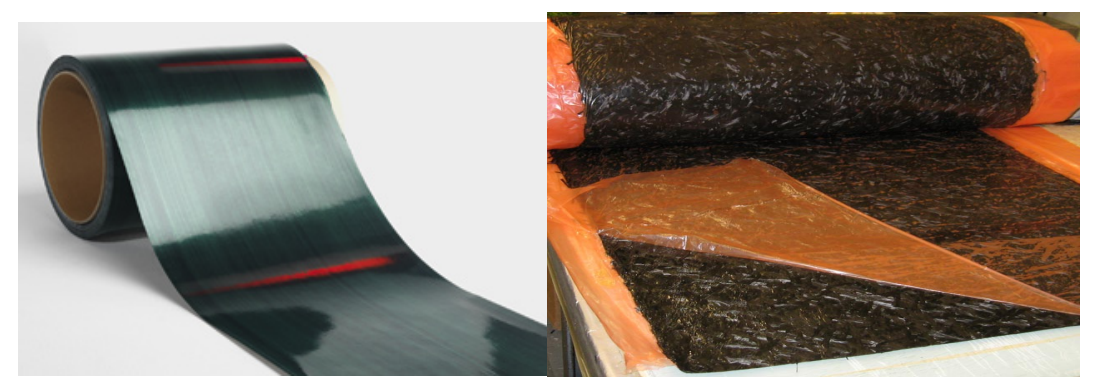

(a)

(b)

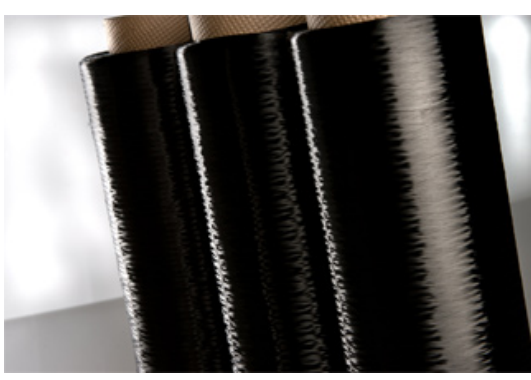

(c)

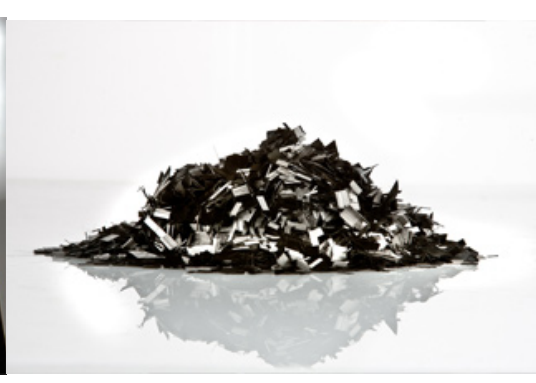

(d)

Figura 7: (a) tecido prepreg unidirecional; (b) sheet molding compound; (c) fios contínuos; (d) fibras descontínuas $[32,33]$

\subsection{1}

\section{Termoplásticos vs. Termorrígidos}

As matrizes de origem polimérica são constituídas de resinas termorrígidas ou de polímeros termoplásticos. Os termorrígidos endurecem durante o processo de formação e não amolecem com um aumento de temperatura. Neste caso, o grande 
número de ligações covalentes intercadeias impede o movimento de cadeias adjacentes. Para os termorrígidos, apenas uma temperatura excessiva causará degradação, que será permanente. O processo de cura do material polimérico é de grande importância para as propriedades mecânicas finais do compósito. Uma cura feita fora de parâmetros precisos, principalmente de temperatura e tempo, pode prejudicar a capacidade estrutural de um componente [34].

Estes polímeros são geralmente mais resistentes, rígidos e apresentam melhor estabilidade dimensional, quando comparados aos termoplásticos [30]. Além disso, apresentam viscosidade bastante baixa, da ordem de menos de 100 Pa.s [35]. Esta baixa viscosidade proporciona uma alta impregnabilidade perante as fibras e uma alta fluidez. Desta forma, este tipo de resina é bastante utilizado em processos de transferência de resina, como os processos da família RTM (do inglês Resin Transfer Molding) e infusão à vácuo. Alguns exemplos mais utilizados são as resinas epóxi, poliéster e vinil éster.

Já os termoplásticos são constituídos de longas cadeias poliméricas, com alto peso molecular e alta viscosidade. Uma de suas principais características é a de amolecerem quando aquecidos até eventualmente se liquefazerem, em um processo totalmente reversível. Isto ocorre pela quebra das ligações secundárias entre cadeias poliméricas que constituem o material. Caso a temperatura seja muito alta, pode haver degradação permanente [30].

A maior utilização de compósitos termoplásticos atualmente é fruto de desenvolvimentos recentes de polímeros e processos, principalmente a partir das décadas de 1980 e 1990. Assim, nas últimas décadas, com o desenvolvimento de novos polímeros mais resistentes à altas temperaturas, tais como PEEK (poliéteréter-cetona) e PPS (sulfeto de polifenileno), os compósitos termoplásticos vem ganhando espaço na indústria [35].

Com isso há um constante estudo de novas técnicas e aplicações para compósitos termoplásticos [14]. Alguns exemplos são: o desenvolvimento de resinas termoplásticas de baixa viscosidade para utilização em processos de RTM, onde a baixa viscosidade dos termorrígidos é essencial para a impregnação das fibras [36]; o desenvolvimento de técnicas de soldagem termoplástica [36]; possibilidade da utilização de compósitos em manufatura aditiva [18].

Os compósitos termoplásticos apresentam inúmeras vantagens, quando comparados aos tradicionais termorrígidos: menores ciclos de processamento, 
matrizes que permitem um shelf life (tempo o qual o material pode permanecer a temperatura ambiente sem que haja degradação) infinito - o que elimina a necessidade de refrigeração, normalmente associada a termorrígidos, melhor ductilidade, maior resistência a impacto [37], maior facilidade de reparo e a possibilidade de serem reaproveitados e reciclados [35, 38].

No caso de compósitos de matriz termoplástica, também é possível encontralos no mercado de diversas formas. Na sua maioria, estes materiais se encontram em uma forma denominada semi-consolidada. Esta forma é semelhante a um prepreg tradicional: as fibras são impregnadas com uma quantidade prédeterminada de resina e a consolidação ocorre mediante altas temperaturas e/ou pressão. Além das tradicionais formas de tecidos, fitas e fios, algumas das formas em que os termoplásticos estão disponíveis fazem uso da capacidade deste tipo de matriz fundir e solidificar sem degradação. São exemplos: pellets e laminados préfabricados.

Os pellets são grânulos - geralmente de 7 a $23 \mathrm{~mm}$. Na forma de pellets, o material é normalmente utilizado para técnicas de moldagem por injeção ou compressão e a fração volumétrica é da ordem de 30 a 40\% de fibras [31]. Nesta forma, os compósitos termoplásticos também se mostram uma alternativa aos filamentos utilizados atualmente em técnicas de manufatura aditiva [39].

Os laminados pré-fabricados (também conhecidos como organo sheets) são constituídos de um número pré-determinado de camadas, denominadas lâminas, que podem conter fibras contínuas ou descontínuas em uma matriz termoplástica. Assim como os laminados tradicionais, estes pré-fabricados podem ter cada camada orientada na mesma direção, em direções diferentes ou sem nenhuma orientação específica. Esta forma traz inúmeras vantagens tanto em termos de processabilidade quanto de velocidade de produção de peças finais que utilizam processos de termoformagem $[31,38]$

Além do tipo de polímero constituinte da matriz, a diferença mais importante entre compósitos termoplásticos e termorrígidos é o tipo de tratamento superficial dado às fibras. Este tratamento superficial, também conhecido como sizing, é responsável em grande parte pela estabilidade da interface entre fibra e matriz, sendo assim de suma importância para as propriedades do compósito.

Algumas considerações devem ser levadas em conta ao se trabalhar com matrizes termoplásticas. Apesar de não haver um processo de cura na forma de uma 
reação química neste tipo de material, o processo de consolidação também exige a aplicação de calor e/ou pressão para ocorrer. As temperaturas para que isto ocorra são geralmente mais altas que as necessárias para a cura de termorrígidos e o controle do resfriamento deve ser feito de forma mais controlada, por conta das características de cristalinidade presentes em termoplásticos [37].

Ao contrário dos compósitos termorrígidos, estruturas produzidas a partir de termoplásticos ainda possuem valor mesmo após o fim de seu ciclo de vida. A possibilidade de reciclagem e reutilização do material é também uma forma de amortizar os custos do processo. Porém, para que isso ocorra, os parâmetros de processo devem ser cuidadosamente controlados para evitar ao máximo qualquer tipo de degradação nas etapas de fabricação e reutilização [38].

Como o estudo deste tipo de material é recente, sobretudo para a aplicação visada neste projeto (manufatura aditiva), a literatura ainda é pequena e em constante desenvolvimento. Desta forma, os resultados já presentes na literatura, bem como sua discussão com os resultados obtidos neste projeto serão apresentados no Capítulo 4.

\subsection{2}

\section{Processos de Fabricação Tradicionais}

Quando se deseja produzir componentes de alta performance, geralmente são usados processos que promovem a cura da matriz polimérica com o auxílio de autoclaves. Em processos que utilizam este tipo de cura, o componente é posicionado em um molde metálico, onde aplicam-se as camadas de material préimpregnado, cortadas no formato adequado. O molde então é envolto de uma bolsa plástica (vacuum bag), acoplada a linhas de vácuo para que todo o ar seja retirado. O conjunto é então colocado dentro da autoclave. As altas temperaturas e pressão fazem com que a resina polimérica sofra o processo de cura, no caso dos termorrígidos e consolidação, no caso dos termoplásticos, e ao final obtém-se um componente com propriedades mecânicas excelentes, com um alto volume de fibras, além de um ótimo acabamento superficial [3, 29, 40].

As etapas de lay-up, isto é, de preparação e posicionamento do material, que ocorrem previamente à cura em autoclave, podem ser feitas de diversas formas. Existem técnicas como o Automatic Tape Laying (ATL) e o Automatic Fiber 
Placement (AFP), que realizam o lay-up de forma completamente automática e muito precisa. Ambas as técnicas utilizam robôs que posicionam, aplicam e cortam o material pré-impregnado - na forma de fitas no caso do ATL e pequenos feixes, no caso do AFP. Muitas vezes, porém, o layup é feito de forma manual com nenhuma ou pouca automatização, apenas com cortes e dimensionamentos programados digitalmente.

Todos os processos que utilizam autoclave são bastante onerosos. Sua utilização só é justificada em casos onde existe uma necessidade de propriedades mecânicas elevadas e não existe demanda de um volume grande de peças produzidas. Os altos custos de instalação e operação da autoclave, os custos envolvidos em processos automatizados de layup, a utilização, muitas vezes, de processos manuais durante o layup e os longos ciclos de processamento, contribuem para os elevados custos finais dos componentes produzidos [3, 29]

Existem esforços no sentido de utilizar os processos de posicionamento de fibras e fitas automatizados sem a cura em autoclave. Processos que viabilizam a utilização destas técnicas com compósitos termorrígidos, através da utilização de resinas especialmente desenvolvidas, com temperaturas de cura mais baixas já existem. Desta forma, é possível utilizar todo o processo de layup normalmente usado para curas em autoclave, mas, ao final realizar a cura em um forno - sem a aplicação de pressão. A fração de fibras e as propriedades mecânicas são comparáveis aos equivalentes curados em autoclave, a custos de investimento e operação menores [41].

Quando existe necessidade de um maior volume de produção, processos que utilizam transferência de resina, fora de autoclave, envolvem menos custos operacionais, apresentam ciclos menores de processamento e também obtém boas propriedades mecânicas. Processos, como a família de processos de RTM (Resin Transfer Molding), são bastante utilizados na produção de componentes para a indústria automotiva, por exemplo.

Neste processo, a resina é impregnada ao material e curada durante a fabricação das peças, geralmente com o uso de vácuo e/ou moldes (que podem ser aquecidos para auxiliar no processo de cura). Outra técnica que permite um grande volume de produção é a pultrusão. Neste processo, as fibras na forma de fios e mantas são puxadas através de um molde de forma contínua. Durante o processo, as fibras são impregnadas com resina e curadas dentro do molde aquecido. A 
pultrusão é bastante utilizada para a fabricação de perfis para a construção civil e estruturas como escadas e guarda-corpos.

Estes processos, apesar do elevado custo de instalação e operação, não necessitam de autoclave, o que por si só representa uma oportunidade de redução de custos. Outro fator favorável a este tipo de processo é não ter a necessidade de utilização de prepregs. Além de mais caros, prepregs exigem uma série de cuidados no transporte e armazenamento, devido ao seu curto shelf life, no caso das resinas termorrígidas. Além disso, estes processos permitem um alto grau de automatização das etapas de layup, diminuindo consideravelmente os ciclos de processamento e melhorando o controle de qualidade dos componentes produzidos.

Processos completamente manuais também existem e são, ainda, muito utilizados na indústria [12]. O hand layup, consiste em cortar, posicionar e manualmente impregnar as fibras em tecido sobre um molde. A cura ocorre geralmente à temperatura ambiente, com o auxílio de catalisadores. Este processo, quando utilizado em aplicações industriais, gera peças com baixo volume de fibras e de difícil controle de qualidade. Uma técnica semelhante é o spray-up, onde uma mistura de fibras descontínuas e resina é aplicada com o auxílio de uma pistola de pulverização. Esta técnica sofre dos mesmos problemas do hand lay-up e de outras pouco automatizadas, como baixo volume de fibras, difícil controle de qualidade e áreas de trabalho muito sujas. Além disso, a grande geração de resíduos e emissão de voláteis, especialmente o monômero estireno, causam preocupações também no aspecto socioambiental [13].

\subsubsection{1}

\section{Processos de Fabricação para Compósitos Termoplásticos}

Diferentemente dos pre-pregs baseados em resinas termorrígidas, que precisam ser curados - um processo químico, a consolidação dos termoplásticos é um processo físico, que, muitas vezes necessita de temperaturas mais altas, acima de $300^{\circ} \mathrm{C}$ [37], o que exige adaptações aos processos. É possível utilizar compósitos termoplásticos com praticamente todos os métodos de fabricação onde normalmente utiliza-se pre-pregs. A diferença é que, no caso dos termoplásticos, o material é utilizado em um estado semi-consolidado. 
Este estado semi-consolidado faz com que o custo da matéria prima seja inicialmente maior, por conta da etapa de impregnação. Porém, ganhos em tempo de produção e ciclos de processamento menores tendem a reduzir o custo final por peça produzida [35]. Além disso, a utilização destes termoplásticos semiconsolidados elimina a necessidade de processos de layup no ambiente de produção, o que aumenta o nível de qualidade das peças produzidas [38].

Estes compósitos também abrem novas possibilidades quanto a diferentes processos de fabricação. Com este tipo de material, e a sua capacidade de mudar de fase através da variação de temperatura, é possível utilizar mais facilmente processos como extrusão e injeção.

Outro exemplo, é o processo de termoformagem [38]. Esta técnica utiliza laminados pré-fabricados de polímeros termoplásticos reforçados como matéria prima e permite a produção rápida de peças finais. $\mathrm{Na}$ primeira etapa da termoformagem, o laminado é aquecido a temperaturas acima da sua temperatura de fusão, o que reduz a sua viscosidade. Na segunda etapa, o laminado é posicionado entre as duas metades de um molde. Ao fechar os moldes, ocorre a consolidação do material com a forma final do componente. A temperatura do molde é definida de forma a proporcionar um resfriamento controlado da peça, antes de sua retirada [38].

A utilização de compósitos termoplásticos em manufatura aditiva (MA), sobretudo na forma de pellets, visa proporcionar uma significativa mudança nas propriedades mecânicas, para que seja possível utilizar os benefícios da impressão 3D para a construção de estruturas de engenharia. MA e compósitos avançados se complementam em termos de simular a complexa e materialmente eficiente construção da natureza. A impressão 3D é extremamente boa em produzir formas complexas e pequenas, enquanto materiais compósitos são excelentes para produzir estruturas muito resistentes, simples e leves. Combinar estas duas tecnologias na fabricação de estruturas compósitas pode reduzir significativamente o tempo de manufatura, peso e custo de componentes complexos [17]. Processos de impressão 3D em larga escala por deposição de compósitos termoplásticos extrudados já estão em fase avançada de desenvolvimento, conforme descrito no Anexo I [17, 18, 21$23]$. 


\section{2.}

\section{Acrilonitrila Butadieno Estireno (ABS)}

O Acrilonitrilo Butadieno Estireno (ABS, do inglês Acrylonitrile Butadiene Styrene) é um copolímero termoplástico de larga utilização na indústria. $\mathrm{O}$ ABS é produzido através da copolimerização dos monômeros estireno e acrilonitrila na presença de polibutadieno (Figura 8). As principais formas de produção deste polímero são através de mistura mecânica, polimerização em massa e polimerização por emulsão, sendo esta última, a principal [29].

Dentre os polímeros plásticos, o ABS apresenta propriedades elevadas em termos de resistência e tenacidade [14]. A presença de um monômero de elastômero, o butadieno, confere ao ABS uma maior ductilidade e resistência ao impacto [29]. A tabela 1 [30-32] compara algumas propriedades do ABS com polímeros termoplásticos largamente empregados na indústria.

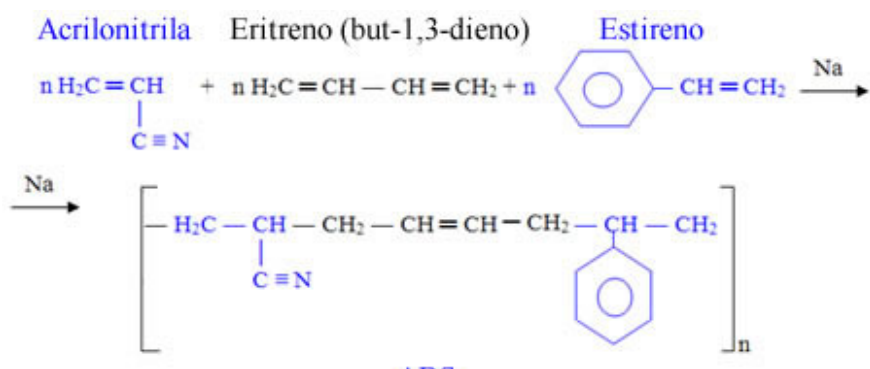

ABS

Figura 8: Estrutura molecular do ABS.

A gama de processamentos possíveis com o ABS é bastante vasta. O ABS pode ser usado em técnicas como moldagem por injeção, extrusão, moldagem por sopro e termoformagem, dentre outras. As principais aplicações do ABS são revestimentos e componentes que não exigem propriedades mecânicas elevadas. É possível encontrar aplicações de ABS em eletrodomésticos, calotas, brinquedos, tubos e carcaças de equipamentos $[14,29]$

Além disso, o ABS é também um dos materiais mais utilizados em técnicas de manufatura aditiva por extrusão de polímeros. Por conta de seu baixo custo e propriedades comparáveis a outros polímeros usados em técnicas de MA, como o PLA (poliácido lático) e a poliamida (PA), o ABS é largamente utilizado 
em impressões de componentes que necessitem de uma resistência ao impacto maior.

Tabela 1: Propriedades do ABS e outros polímeros utilizados em manufatura aditiva [30-32]

\begin{tabular}{cccccccc}
\hline & $\begin{array}{c}\text { Módulo de } \\
\text { elasticidade }(\mathrm{GPa})\end{array}$ & $\begin{array}{c}\text { Resistência à } \\
\text { tração }(\mathrm{MPa})\end{array}$ & $\begin{array}{c}\text { Deformação no } \\
\text { escoamento }(\%)\end{array}$ & $\begin{array}{c}\text { Deformação na } \\
\text { ruptura }(\%)\end{array}$ & $\begin{array}{c}\text { Impacto Charpy } \\
\text { com identação } \\
23^{\circ} \mathrm{C}\left(\mathrm{kJ} / \mathrm{m}^{\wedge} 2\right)\end{array}$ & $\begin{array}{c}\text { Densidade } \\
\left(\mathrm{kg} / \mathrm{m}^{\wedge} 3\right)\end{array}$ & $\begin{array}{c}\text { Temperatura } \\
\text { de fusão }\left({ }^{\circ} \mathrm{C}\right)\end{array}$ \\
\hline ABS & 2,3 & 44,0 & 2,4 & 12,0 & 19,0 & 1040 & $220-260$ \\
PA & 2,7 & 78,0 & 4,0 & 25,0 & 3,5 & 1130 & $240-285$ \\
PLA & 2,3 & 49,5 & 3,3 & 5,2 & - & 1250 & $145-160$ \\
\hline
\end{tabular}

Estudos recentes, sobretudo de pesquisadores do Oak Ridge National Laboratory [17, 18, 21-23], tratam da utilização de ABS reforçado por fibras de carbono como matéria prima para a impressão 3D. Justamente por ser um dos materiais mais utilizados na manufatura aditiva, o ABS apresenta um grande potencial para constituir a matriz de compósitos a serem empregados neste tipo de técnica.

\section{3}

\section{Técnicas de Caracterização}

\subsection{1}

\section{Espectroscopia no Infravermelho por Transformada de Fourrier}

A espectroscopia no infravermelho por transformada de Fourrier (Fourrier Transform Infrared Spectroscopy - FTIR) é uma técnica de análise que utiliza a interação entre a luz e moléculas para identificar ou quantificar um material. Através da emissão de luz nos comprimentos de onda do espectro infravermelho (IR), é possível identificar componentes químicos presentes em uma amostra através da sua "identidade" molecular [42, 43].

Cada material e seus compostos apresentam um perfil que o identifica em função da absorção de energia em determinados comprimentos de onda. A absorção ocorre em frequências específicas, que variam em função da massa dos átomos envolvidos, da força da ligação entre eles e do meio ao redor das moléculas. Uma vez identificadas, é possível associar as frequências de absorção a comprimentos de onda específicos dentro do espectro IR. Através da catalogação dos espectros de 
diversos tipos de materiais, é possível fazer uma análise através da correlação e comparação de compostos em amostras [43].

O equipamento utilizado para este ensaio é baseado no interferômetro de Michelson (Figura 9) [42].

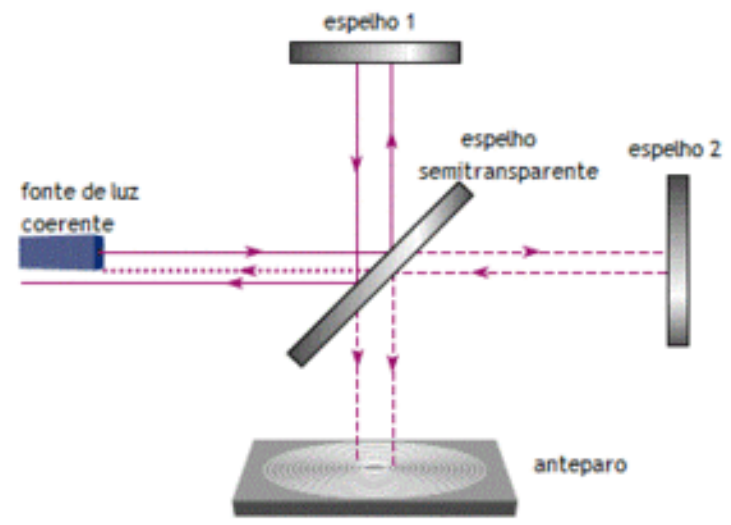

Figura 9: Esquematização de um interferômetro de Michelson. Fonte: wikipedia.org

Este interferômetro consiste de uma fonte de luz, que é responsável por emitir a radiação IR, que é direcionada a um espelho semitransparente, cuja função é separar o feixe emitido. Uma parte do feixe reflete no espelho fixo (espelho 1), enquanto a outra reflete no espelho móvel (espelho 2). As duas partes do feixe são refletidas de volta para o espelho semitransparente, onde são recombinadas e refletidas em direção a um anteparo, onde fica localizado o detector.

Ao variar a distância do espelho móvel em relação ao espelho fixo, a distância percorrida pelos feixes refletidos também varia. Isto faz com que ocorra o fenômeno da interferência, causado pela diferença de fase entre as ondas que compõem os feixes no momento em que se recombinam. À medida em que as ondas ficam mais defasadas entre si, menor é o sinal captado devido à interferência destrutiva entre elas. Logo, o sinal resultante captado pelo detector é uma função da intensidade do sinal detectado, o qual varia com o tempo (visto que a posição do espelho móvel varia em função do tempo).

Em um ensaio de FTIR, todos os comprimentos de onda da radiação IR são utilizados ao mesmo tempo. Sem a transformada de Fourrier (TR), o gráfico resultante, chamado de interferograma, torna-se de difícil interpretação devido às complexas interações que ocorrem entre as frequências associadas aos 
comprimentos de onda que incidem simultaneamente. A função da TR é justamente transformar os dados do interferograma que são representados em função do tempo, em ocorrências em função do número de onda, que está associado ao comprimento de onda (e, consequentemente, à frequência).

Para obter o espectro final, o equipamento gera um interferograma e aplica a TR em uma corrida sem a amostra (baseline) e em uma corrida com a amostra. A diferença entre picos em determinadas regiões de números de onda nos gráficos, representa a quantidade de energia absorvida pela amostra naquela determinada frequência. $\mathrm{O}$ equipamento então faz uma relação dos dois gráficos e representa a quantidade de energia absorvida através da transmitância (\%), no caso da medição de energia que atravessa a amostra, ou absorvância (\%), no caso da medição da diferença da energia que é emitida em função a energia captada pelo detector, em função no número de onda $\left(\mathrm{cm}^{-1}\right)$.

Para amostras opacas, onde não é possível medir a transmitância da radiação incidente, utiliza-se uma técnica denominada refletância total atenuada (ATR - do inglês Attenuated Total Reflectance). Nesta técnica, a amostra é colocada sobre um cristal, feito de material com índice de refração conhecido, tal como diamante ou germânio. A radiação penetra o cristal em um determinado ângulo incidente, e, ao refratar na superfície oposta, emite uma onda conhecida como onda evanescente. Esta onda interage com a amostra até uma certa profundidade, chamada de profundidade de penetração, que varia em função do comprimento de onda da radiação IR (e, consequentemente, do número de onda), do ângulo incidente da radiação e do índice de refração do cristal. Como tanto o índice de refração e o ângulo incidente são constantes, é possível identificar ou quantificar o material de uma amostra através da variação da profundidade de penetração ao longo da faixa de comprimentos de onda do IR [42, 43].

As principais vantagens deste método estão relacionadas ao uso da TR. Através da TR, é possível utilizar todos os comprimentos de onda do espectro desejado, o que torna o ensaio muito mais rápido quando comparado a outras técnicas de espectrometria. Outra vantagem é que o equipamento pode ser projetado de forma mais simples, com apenas uma parte móvel. Isto além de diminuir o custo final, diminui os eventuais custos de manutenção e operação [43].

Segundo Fischer et al. [44], para o polímero utilizado neste projeto (ABS), são esperados picos de absorção nas regiões $2242 \mathrm{~cm}^{-1}$ (Acrilonitrila), $1602 \mathrm{~cm}^{-1}$ 
(Estireno) e $971 \mathrm{~cm}^{-1}$ (Butadieno). Através da Figura 10, é possível observar que cada região de números de onda representa a presença de grupos funcionais específicos e a interação que ocorre entre seus átomos.

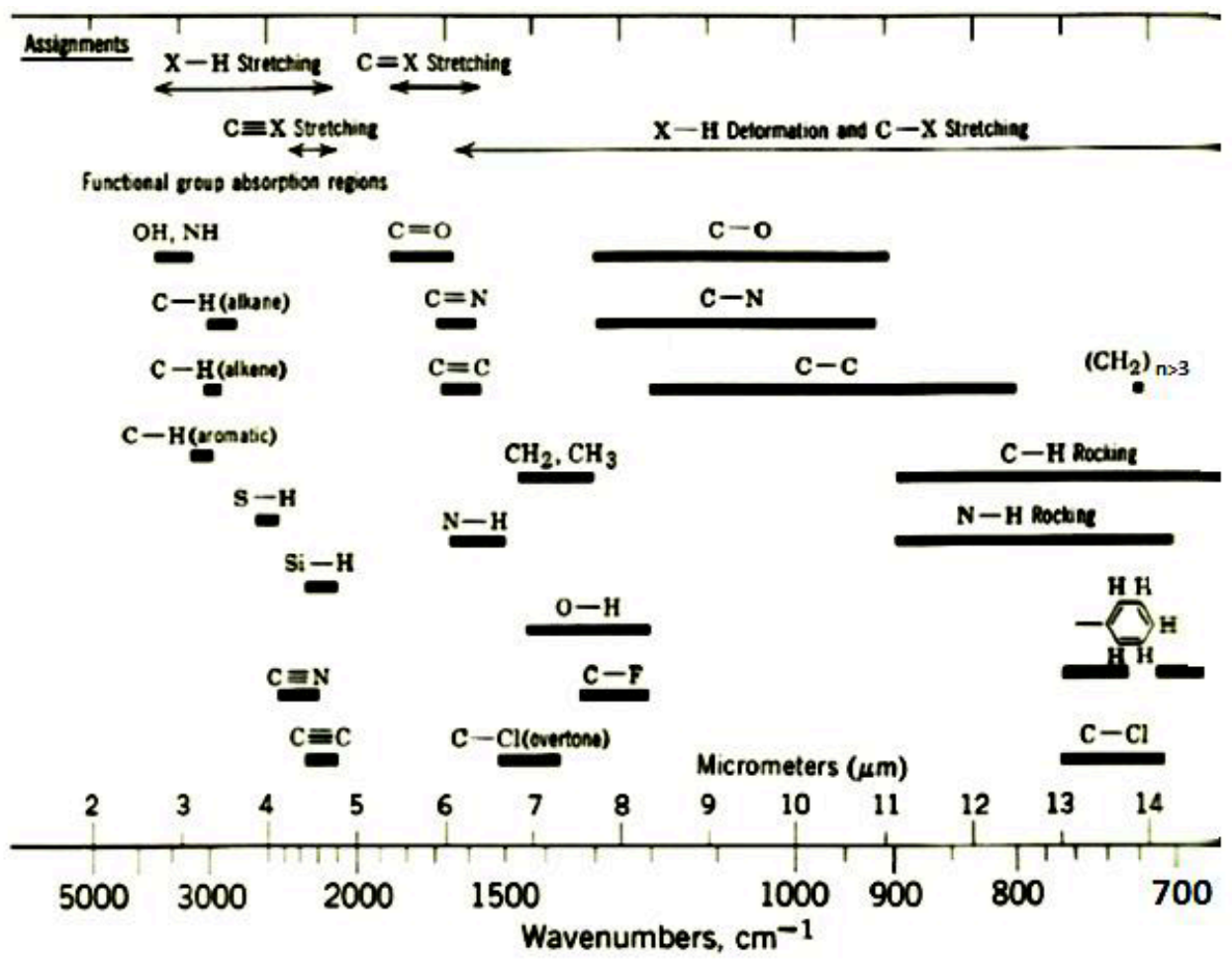

Figura 10: Principais bandas de absorção para materiais poliméricos. Fonte: Billmeyer Jr., F. como visto em [45]

Baseando-se na literatura [44-46], pode-se identificar na região entre 2200 e $2300 \mathrm{~cm}^{-1}$ a presença de ligações $\mathrm{C} \equiv \mathrm{N}$ com vibrações do tipo estiramento axial (stretching) que estão associadas ao grupo funcional nitrila. Como pode-se observar na Figura 8 , é possível correlacionar a presença da nitrila à acrilonitrila na estrutura molecular do ABS. Analogamente, a região entre 1500 e $1650 \mathrm{~cm}^{-1} 1$ está relacionada a vibrações de estiramento axial (stretching) de ligações $\mathrm{C}=\mathrm{C}$ (anel aromático), que podem ser relacionadas ao estireno, presente na estrutura molecular do ABS. Finalmente, pode-se fazer a mesma correlação com a região entre 850 e $1000 \mathrm{~cm}^{-1}$ com a presença de ligações $\mathrm{CH}=\mathrm{CH}_{2}$. $\mathrm{O}$ grupo funcional correspondente na estrutura molecular do ABS é o butadieno (but-1,3-dieno). 


\subsection{2 \\ Reologia}

Segundo Freire [47], a reologia é a parte da físico-química que investiga as propriedades dos corpos (sólidos elásticos) ou escoamentos (fluidos) que sofrem deformação. Estas propriedades são, principalmente: elasticidade, viscosidade e plasticidade de um corpo ou massa submetido a tensões [47], tempo de relaxação e compliância [48].

Para determinar estas propriedades, existem vários tipos de reômetro. Um dos mais comumente utilizados para ensaios em polímeros é o reômetro capilar (Figura 11), através de um método conhecido como viscosimetria capilar [49]. Segundo Winter [48], a viscosidade é determinada através da medição da vazão e do gradiente de pressão na região de escoamento totalmente desenvolvido no interior do capilar, a uma temperatura constante selecionada.

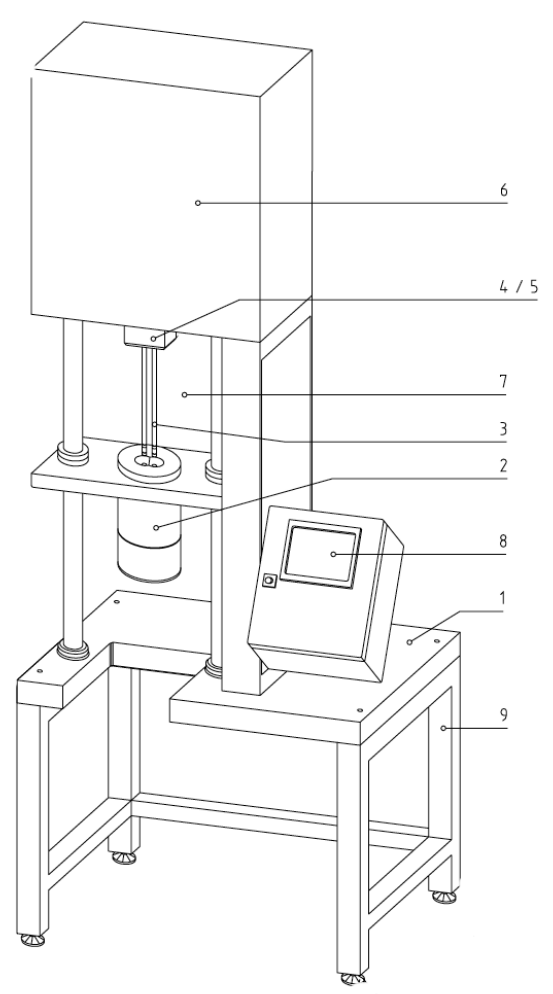

Figura 11: Representação esquemática de um reômetro capilar. (1) base do equipamento; (2) Cilindro de ensaio; (3) Pistão; (4/5) Suporte do pistão com transdutor de força; (6) Conjunto motriz com carenagem; (7) Vidro de proteção; (8) Painel de controle; (9) Suporte do equipamento. Fonte: Manual do Usuário do Reômetro Göttfert Rheograph 25 
Como pode ser observado na Figura 11, o material é inserido no cilindro aquecido do equipamento, onde um pistão o pressionará, elevando a pressão do sistema. Esta pressão, que é medida por um sensor localizado logo acima da entrada do capilar, força o material para que ele atravesse o capilar e, então, seja extrusado na saída. No reômetro capilar, o material testado permanece confinado durante o processo, o que evita interações com a atmosfera, principalmente a oxidação [49].

Reômetros capilares são projetados para a caracterização de polímeros fundidos a altas taxas de cisalhamento [48]. Estas altas taxas de cisalhamento também são aplicadas aos polímeros durante o seu processamento, como por exemplo nos processos de extrusão e injeção [48], o que permite ao experimento simular condições reais da indústria e ajudar na seleção de parâmetros de processo.

Porém, tanto as altas taxas de cisalhamento [48] quanto a geometria do capilar [49] causam efeitos que requerem atenção. Dentre eles: escoamento turbulento na região de entrada do capilar causado pela redução abrupta do diâmetro quando o fluido passa do reservatório para o capilar; aceleração sofrida pela massa do fluido ao passar do reservatório para o capilar; propriedades elásticas do material fundido que temporariamente absorve e armazena parte da energia que lhe é fornecida para que passe através do capilar; instabilidades do escoamento e dissipação viscosa [48, 49]. Existem correções matemáticas, que devem ser aplicadas no tratamento dos dados obtidos, que mitigam estes efeitos, como por exemplo, a correção de Bagley [48, 49].

Para fluidos não-Newtonianos, que é o caso dos polímeros fundidos, o comportamento elástico não-linear apresentado por este tipo de material também requer um tratamento matemático dos dados obtidos. Para estes fluidos, não é possível medir diretamente a tensão cisalhante nem a taxa de deformação [48]. Neste caso, a relação particular entre tensão aplicada e a vazão volumétrica, característica deste tipo de fluido, gera medidas chamadas "aparentes", que consequentemente resultarão em um valor de viscosidade não verdadeiro. Porém, existem correções, como a correção de Weissemberg-Rabinowitsch, que permitem, a partir das medições de pressão e vazão, obter os valores reais [48, 49].

Ajinjeru et al. [50] investigou as propriedades reológicas do ABS puro e de ABS com $20 \%$ em peso de fibras carbono. Três diferentes temperaturas foram utilizadas $\left(230,250\right.$ e $\left.270^{\circ} \mathrm{C}\right)$ a taxas de cisalhamento variando de 0,1 a $1000 \mathrm{rad} / \mathrm{s}$ (equivalente a 100 a $250 \mathrm{~s}^{-1}$ ). Foram verificadas reduções de $50 \%$ na viscosidade 
com o aumento da temperatura para o ABS puro. Para o ABS com fibras de carbono, houve um aumento de $65 \%$ na viscosidade e uma intensificação do efeito de diminuição da viscosidade em função do aumento da taxa de cisalhamento.

\subsection{3}

\section{Análise Termogravimétrica}

A análise termogravimétrica (TGA) é uma técnica utilizada para caracterizar a estabilidade térmica de materiais sempre que a temperatura for uma variável essencial. Alguns exemplos destas aplicações estão nas indústrias alimentícia e farmacêutica e também na indústria petroquímica. A TGA consiste na avaliação da variação na massa da amostra de material em um aparelho que garante controle preciso da atmosfera e temperatura do experimento. Este aparelho apresenta geralmente um recipiente para a amostra que é apoiado em uma balança de alta precisão, que monitora a variação da massa do corpo de prova durante o experimento. Este recipiente está contido em uma câmara que será aquecida em função do objetivo da análise [51].

O equipamento pode trabalhar com temperatura constante ou variável, dependendo do tipo de experimento a ser realizado. Desta forma, a análise termogravimétrica é uma ferramenta muito versátil que pode ser utilizada para avaliar a perda de massa sofrida por um material em diversas condições, como uma simulação das condições em que o produto de onde veio aquela amostra irá operar durante a sua vida útil, por exemplo [51]. O ensaio utilizado neste trabalho utilizou um aquecimento constante da amostra, visando identificar os pontos críticos de degradação da fase polimérica no compósito.

Outra variável importante de controle ao realizar o TGA é o tipo de gás constituinte da atmosfera. $O$ gás utilizado pode ser o oxigênio ou o nitrogênio que conferem uma característica oxidante e neutra, respectivamente, à atmosfera de trabalho.

O resultado deste ensaio é plotado em um gráfico que apresenta sempre a perda de massa sofrida pelo material no eixo das ordenadas, enquanto o eixo das abscissas pode estar apresentado em função do tempo ou da temperatura. Este gráfico deverá apresentar degraus que representam o momento em que uma substância constituinte daquela amostra sofreu degradação [51]. 
Hull et al [52], em seu estudo, mostrou que o TGA pode ser uma ferramenta bastante eficaz para a determinação da quantidade de fibras presente em um compósito reforçado por fibras de carbono. Através da comparação da massa residual ao fim de corridas até $700^{\circ} \mathrm{C}$ de amostras de $\mathrm{ABS}$ puro e $\mathrm{ABS}$ com quantidades distintas de fibras de carbono, pode-se determinar a quantidade real de fibras presente no material final.

Ainda em seu estudo, Hull et al. [52] verificou que a maior parte da degradação ocorreu entre $400^{\circ} \mathrm{C}$ e $500^{\circ} \mathrm{C}$ e que, a partir desta temperatura, não houveram mudanças significativas na massa residual. Além disto, para todas as quantidades de fibras de carbono avaliadas, a quantidade final foi um pouco abaixo do esperado devido a perdas que ocorrem durante o processamento.

\subsection{4}

\section{Cinética de Decomposição via TGA}

A análise da cinética de decomposição de um material permite obter a relação dos parâmetros cinéticos de reação com a decomposição (conversão) verificada em análises térmicas, quando feitas em diferentes taxas de aquecimento. Esta técnica torna possível a análise de parâmetros cinéticos, sem a necessidade de investigar mais a fundo a ordem e os mecanismos de reações que ocorrem no material durante sua degradação [53].

Dentre os parâmetros que podem ser obtidos por esta técnica, a energia de ativação aparente (ou cinética) é de especial importância. A energia de ativação pode ser entendida como uma "barreira" para o início de reações em um material. Quanto maior for esta energia, mais difícil será para uma reação acontecer.

Apesar de que, para uma análise térmica completa, outros fatores devem ser levados em conta, tais como fator pré-exponencial e ordem e mecanismos de reação, a determinação apenas da energia de ativação pode fornecer informações importantes sobre a decomposição e estabilidade térmica do material [54].

$\mathrm{Na}$ análise da cinética de decomposição via TGA, as amostras de material são aquecidas a temperaturas suficientemente altas para que ocorra degradação, a diferentes taxas constantes de aquecimento. A partir das curvas geradas, selecionam-se níveis de decomposição (perda de massa), ou conversão, e verificase as temperaturas nas quais estes níveis ocorrem, nas curvas relativas a cada taxa 
de aquecimento. A energia de ativação cinética é obtida plotando-se o logaritmo das taxas de aquecimento vs. o recíproco da temperatura para cada nível de decomposição [54].

Uma das formas de obter o valor da energia de ativação, é através da equação do método de Flynn-Wall [55],

$$
E=\frac{-R}{b}\left[\frac{d \log \beta}{d\left(\frac{1}{T}\right)}\right] \quad \text { Equação } 1
$$

onde $E$ é a energia de ativação $(\mathrm{J} / \mathrm{mol}), R$ é a constate dos gases $(8,314 \mathrm{~J} / \mathrm{mol} \mathrm{K}), T$ é a temperatura de degradação $(\mathrm{K}), \beta$ é a taxa de aquecimento $\left({ }^{\circ} \mathrm{C} / \mathrm{min}\right)$ e $b$ é uma constante tabelada, que exige um processos iterativo, visto em detalhes em Flynn et al. [55] e Doyle [56], para a sua determinação. O valor da derivada entre colchetes é o coeficiente angular das retas plotadas para as taxas de aquecimento vs. temperatura [54].

Yang [57], em seu estudo, verificou a energia de ativação de resina ABS através da cinética de decomposição via TGA. No estudo, foram usadas taxas de aquecimento de $5,10,20$ e $40^{\circ} \mathrm{C} / \mathrm{min}$, sob atmosfera inerte. Através da equação do método de Flynn-Wall, foi encontrada uma energia média de ativação de 42,0 $\mathrm{kcal} / \mathrm{mol}$. 


\section{3}

\section{Materiais e Métodos Experimentais}

3.1

Materiais e Processamento

O processo experimental seguiu o fluxograma mostrado na Figura 12.

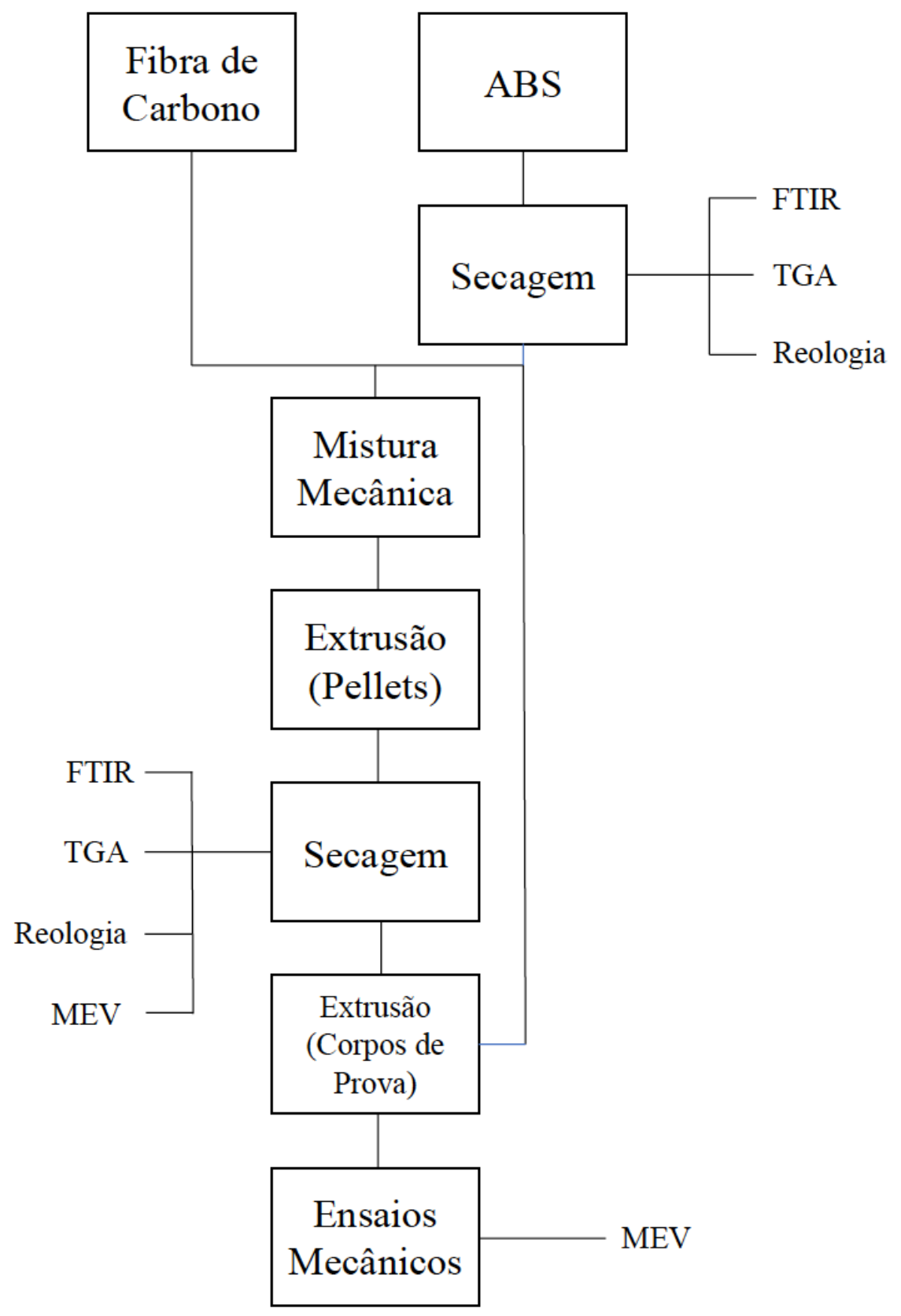

Figura 12: Fluxograma do procedimento experimental. 
Material utilizado:

- Pellets virgens de ABS GP-35 (INEOS Styrolution Terluran® GP-35);

- Fibras de carbono Tenax®-J HT C261(Toho Tenax) com 3 mm e 6 mm de comprimento, com sizing para epoxi (Figura 13). As fibras de carbono foram cedidas ao projeto pela Toho Tenax America, Inc.

- Óleo de semente de uva Quinaríß.

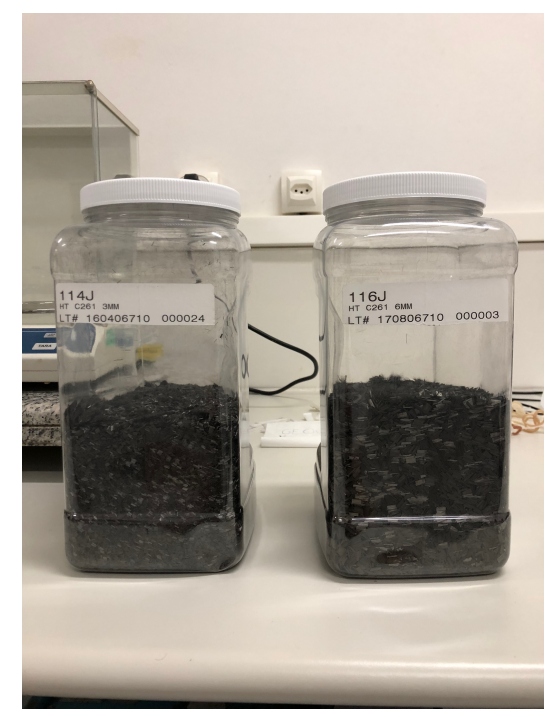

Figura 13: Fibras de Carbono em dois comprimentos: $3 \mathrm{~mm}$ e $6 \mathrm{~mm}$

O ABS foi utilizado como matriz polimérica, pois é um material muito utilizado em técnicas de manufatura aditiva, além de diversas outras aplicações em engenharia. As fibras de carbono foram escolhidas como reforço devido às suas propriedades de alto módulo e resistência, desejáveis para um compósito com capacidades estruturais. O sizing utilizado não é especificamente desenvolvido para aplicações em matrizes termoplásticas, porém sizings para termoplásticos ainda são pouco disponíveis no mercado, sobretudo no caso de fibras descontínuas. Levando isto em consideração, dentre as opções disponíveis, o epóxi era o que melhor se adequava às condições do processo utilizado. O óleo de semente de uva foi utilizado em caráter experimental, pois estava à disposição durante o processamento inicial.

Inicialmente os pellets de $\mathrm{ABS}$ puro foram secos em estufa a $80^{\circ} \mathrm{C}$ por aproximadamente $6 \mathrm{~h}$. Parte destes pellets foi utilizada para ensaios iniciais de FTIR, TGA e reologia. Pellets de ABS puro também foram extrusados para obtenção de 
corpos de prova nos quais foram realizados ensaios mecânicos e análise de imagem através de microscópio de varredura eletrônica (MEV) dos corpos de prova fraturados, com objetivo de estabelecer uma baseline para os resultados dos compósitos. O material extrusado obtido apenas com ABS foi denominado mistura I.

Outra parte do ABS seco foi misturada mecanicamente com as fibras de carbono, em proporções previamente definidas (Tabela 2). As misturas de II a V, tem como objetivo investigar a miscibilidade entre fibras e matriz, influência da fração em peso das fibras de carbono (\% wt CF) e a influência do comprimento inicial das fibras ( $3 \mathrm{~mm}$ vs. $6 \mathrm{~mm}$ ). A determinação dos valores foi baseada em estudos feitos por Love et al. [23] e Tekinalp et al [28], onde uma proporção entre $13 \%$ wt CF e $20 \%$ wt CF foi verificada como o ideal em termos de propriedades mecânicas e processabilidade.

As Misturas II e III foram produzidas com uma baixa \% wt CF como teste da miscibilidade entre o termoplástico e o reforço. A Mistura III foi produzida com a mesma \% wt CF da Mistura II, porém com adição de óleo de semente de uva. A introdução do óleo teve como objetivo melhorar a processabilidade da mistura na extrusora.

As Misturas IV e V foram produzidas com uma \% wt CF maior, da ordem de $16,7 \%$. Elas diferem entre si apenas no tipo de fibra de carbono utilizado. A utilização de dois comprimentos de fibra diferentes visa a investigação da influência do comprimento inicial das fibras no comportamento final do material.

Todas as misturas feitas estão listadas na Tabela 2:

Tabela 2: Misturas utilizadas para a etapa experimental.

\begin{tabular}{ccccc}
\hline & \multicolumn{5}{c}{ Fibra de Carbono } \\
Misturas & ABS & (CF) & Tipo CF & $\%$ wt CF \\
\hline I & $1000 \mathrm{~g}$ & - & - & - \\
II & $500 \mathrm{~g}$ & $25 \mathrm{~g}$ & $3 \mathrm{~mm}$ & $5 \%$ \\
III & $207,2 \mathrm{~g}$ & $10,6 \mathrm{~g}$ & $3 \mathrm{~mm}$ & $5 \%$ \\
IV & $1000 \mathrm{~g}$ & $200 \mathrm{~g}$ & $3 \mathrm{~mm}$ & $16,70 \%$ \\
V & $1000 \mathrm{~g}$ & $200 \mathrm{~g}$ & $6 \mathrm{~mm}$ & $16,70 \%$ \\
\hline
\end{tabular}

Todas as misturas foram produzidas em uma extrusora dupla rosca, com 10 zonas de aquecimento (Leistritz ZSE 18 MAXX) no Laboratório de Tecnologia de 
Polímeros (TECPOL) do Instituto Politécnico do Rio de Janeiro (IPRJ-UERJ). O processo seguiu as seguintes etapas:

- Deposição da mistura em um alimentador mecânico (Brabender) com rosca para material particulado;

- Processamento do material na extrusora a temperatura constante de $200^{\circ} \mathrm{C}$, rotação de 500 RPM e taxa de alimentação velocidade de $5 \mathrm{~kg} / \mathrm{h}$;

- Peletização do filamento extrusado.

Após este processo, todos os pellets produzidos foram secos em estufa a $80^{\circ} \mathrm{C}$ por aproximadamente $12 \mathrm{~h}$ para a eliminação de qualquer umidade presente. Os pellets secos de cada mistura foram utilizados para ensaios de FTIR, TGA, reologia e MEV.

Após a secagem, corpos de prova foram extrusados na forma de filamentos de aproximadamente $3 \mathrm{~mm}$ de diâmetro e cortados no tamanho adequado para os ensaios mecânicos no Laboratório de Microcaracterização de Materiais da PUCRio. Para cada mistura, entre 14 e 15 corpos de prova foram extrusados, Figura 14.

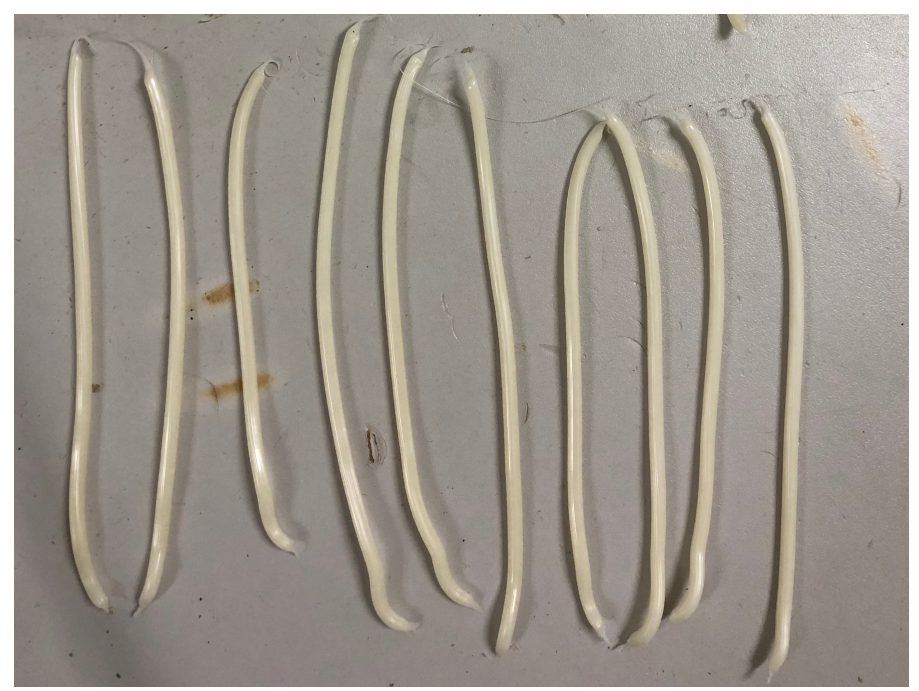

Figura 14: Corpos de prova da Mistura I, como extrusados (antes de serem cortados nas dimensões do equipamento de medição). Dimensões: Aprox. $3 \mathrm{~mm}$ de diâmetro por aprox. $15 \mathrm{~cm}$ de comprimento.

Para produzir os corpos de prova, foi utilizada uma extrusora Xplore Micro Compounder MC5, com três zonas de aquecimento T1 (entrada), T2 e T3 (saída), nas seguintes condições:

- Temperaturas: $\mathrm{T} 1230^{\circ} \mathrm{C}$; $\mathrm{T} 2210^{\circ} \mathrm{C}$; $\mathrm{T} 3200^{\circ} \mathrm{C}$ 
- Velocidade: 160 RPM

- Força Máxima: $700 \mathrm{~N}$

- Rotação: 30 RPM/min

Também houveram tentativas de produzir filamentos para uso direto em manufatura aditiva, porém limitações da extrusora não permitiram que se chegasse a um diâmetro adequado. Além disso, o controle do diâmetro e da regularidade da seção do filamento, com o equipamento disponível, era bastante impreciso e acarretou em grandes perdas de material.

Desta forma, optou-se por focar nas propriedades das misturas obtidas e desenvolver o material antes de novas tentativas de produzir filamentos. Opções de utilização dos pellets como matéria prima direta para impressão 3D também estão sendo analisadas e apresentam grande potencial e vantagens em relação à utilização e produção de filamentos.

\section{2 \\ Métodos Experimentais}

\subsection{1}

\section{Ensaio de Infravermelho (FTIR)}

O ensaio de FTIR teve como objetivo investigar o processo de degradação sofrido pela matriz durante as diferentes etapas do processamento. As informações geradas pelo FTIR foram utilizadas como base para a definição dos parâmetros de extrusão.

Inicialmente, amostras de ABS puro, processados na extrusora em diferentes temperaturas $\left(180\right.$ e $\left.220^{\circ} \mathrm{C}\right)$ foram investigadas. Essas amostras tiveram por objetivo determinar a degradação sofrida pelo polímero durante o processamento à temperatura.

Posteriormente, pellets de todas as misturas foram ensaiados, a fim de caracterizar possíveis alterações no material com a introdução das fibras de carbono. As análises foram realizadas em um espectrofotômetro de absorção na região do infravermelho médio, modelo Perkin Elmer 100 FT-IR, com dados coletados na região de 4000 a $450 \mathrm{~cm}^{-1}$ e amostragem feita em acessório ATR, à temperatura 
ambiente. Todas as análises foram feitas no Laboratório de Biocombustíveis (LABIO), no Departamento de Química da PUC-Rio.

\subsection{2}

\section{Reologia}

Ensaios para a caracterização das propriedades reológicas do ABS puro e de suas misturas foram feitos utilizando um reômetro capilar (Göttfert Rheograph 25). O objetivo foi determinar a influência da adição de fibras de carbono e óleo de semente de uva na viscosidade do material.

Inicialmente foram testadas 4 temperaturas para o ABS puro: 200, 220, 240 e $260^{\circ} \mathrm{C}$ para verificar o comportamento do material durante o ensaio no reômetro. Para temperaturas muito altas, como foi o caso de $260^{\circ} \mathrm{C}$, a degradação do material não permitiu leituras precisas. A partir dos resultados, a temperatura escolhida para servir de referência para os ensaios das misturas foi a de $240^{\circ} \mathrm{C}$ graus. Esta é a temperatura mais próxima das condições de trabalho determinadas pelo fabricante em que o ensaio ocorreu sem algum tipo de problema. Todos os testes foram realizados com taxa de cisalhamento variando de 12 a $1000 \mathrm{~s}^{-1}$, utilizando um capilar 30/2 (30 mm de comprimento / 2 mm de diâmetro - seção constante) e os dados foram processados através do software Lab Rheo 2.1.6.

Os ensaios foram realizados no TECPOL (IPRJ/UERJ).

\subsection{3}

\section{Análise Termogravimétrica (TGA)}

A análise termogravimétrica foi feita com o objetivo principal de determinar a fração real de fibras de carbono presente nas misturas produzidas através da extrusora dupla rosca.

Também buscou-se analisar a estabilidade térmica do óleo de semente de uva utilizado para melhorar o processo de alimentação do material na extrusora. Através desta análise é possível saber se o óleo permanece na mistura durante o seu processamento, o que pode afetar as características finais do material gerado.

As análises foram realizadas a uma taxa de aquecimento constante de $10^{\circ} \mathrm{C} / \mathrm{min}$, da temperatura ambiente até aproximadamente $900^{\circ} \mathrm{C}$. Todos os ensaios 
foram realizados sob uma atmosfera inerte de Nitrogênio no equipamento Perkin Elmer Pyris1 TGA. Os ensaios foram realizados no LABIO (PUC-Rio), no Laboratório de Microcaracterização de Materiais (PUC-Rio) e no Laboratório de Termoanálises e de Reologia (LABTeR - EQ/UFRJ).

\subsubsection{1}

\section{Cinética de Decomposição via TGA}

Para a análise da cinética de decomposição via TGA, foram obtidos termogramas para cada mistura, com as curvas de cada taxa de aquecimento dispostas no mesmo gráfico. Utilizou-se taxas de 10,20 e $30^{\circ} \mathrm{C} / \mathrm{min}$, em corridas de $50^{\circ} \mathrm{C}$ a $750^{\circ} \mathrm{C}$ em atmosfera inerte (Nitrogênio).

Em seguida, para cada mistura, um gráfico relacionando a taxa de aquecimento e a temperatura de degradação nos níveis analisados, foi plotado. A partir destes gráficos, os coeficientes angulares foram obtidos através de regressão linear, para cada um dos níveis de decomposição. Os níveis de decomposição analisados foram $0,5 \% ; 1,0 \% ; 2,5 \% ; 5,0 \% ; 10,0 \%$ e $20,0 \%$.

Para cada nível em cada mistura, a energia de ativação foi calculada utilizando a Equação de Flynn-Wall (Equação 1), vista na revisão bibliográfica, com a tabela apresentada em Doyle [57] para o processo iterativo.

\subsection{4}

\section{Ensaios Mecânicos}

O objetivo dos ensaios mecânicos foi verificar as propriedades de resistência à tração e módulo de elasticidade de cada mistura produzida. Todos os ensaios foram realizados sob as mesmas condições de $20,9^{\circ} \mathrm{C}$ e $50 \%$ de umidade, no Laboratório de Microcaracterização de Materiais da PUC-Rio.

O equipamento utilizado foi:

- Máquina de ensaios universais Oswaldo Filizola, modelo AME-2kN

- Velocidade de ensaio: $50 \mathrm{~mm} / \mathrm{min}$

- Comprimento útil do corpo de prova: $25 \mathrm{~mm}$

- Secção transversal do corpo de prova: Circular 
O diâmetro de cada corpo de prova foi medido utilizando um paquímetro calibrado, com precisão de 0,01 mm. É importante notar que os corpos de prova utilizados neste projeto não são normalizados. Isto significa que, por não seguirem uma norma internacionalmente reconhecida, os resultados apresentados são para uso comparativo entre si e não para a determinação de valores absolutos.

Como não foi feito o uso de um extensômetro durante o ensaio, a determinação do módulo de elasticidade, foi feita a partir da seguinte equação, que leva em conta a rigidez do equipamento utilizado no ensaio:

$$
\frac{1}{K_{S}}=\frac{1}{K_{m}}+\frac{1}{E} \cdot \frac{L_{0}}{A_{0}}
$$

onde $E$ é o módulo de elasticidade do material ensaiado, $L_{0}$ é o comprimento útil e $A_{0}$ a área de seção transversal do corpo de prova. $K_{m}$ é a rigidez da máquina de ensaio, determinada por Novoa [45], como sendo 546,4 MPa.

$K_{S}$ está relacionado ao módulo de elasticidade não corrigido do material. Este valor é obtido a partir de um par de coordenadas carga x deformação $(P \times \Delta l)$ na parte aproximadamente linear da curva de ensaio [45].

\subsection{5}

\section{Análise Microestrutural}

A superfície da seção transversal dos pellets obtidos após a etapa de extrusão e a superfície de fratura dos corpos de prova ensaiados à tração foram analisadas em um microscópio eletrônico de varredura (MEV). Foi empregado um microscópio JEOL JSM-6510LV SEM, com uma tensão de $20 \mathrm{kV}$ e alto vácuo. As amostras foram previamente metalizadas empregando a técnica de sputtering, utilizando ouro, com o equipamento Balzers SCD 050 Sputter Coater.

Para cada amostra, foram utilizados aumentos de 100, 250 e 500 vezes como padrão. Além destes, outros aumentos foram utilizados quando necessário e estão indicados nas respectivas imagens. Essas análises foram feitas no Laboratório de Microscopia Eletrônica da PUC-Rio. A Figura 15 mostra as amostras analisadas no porta-amostras do equipamento. 


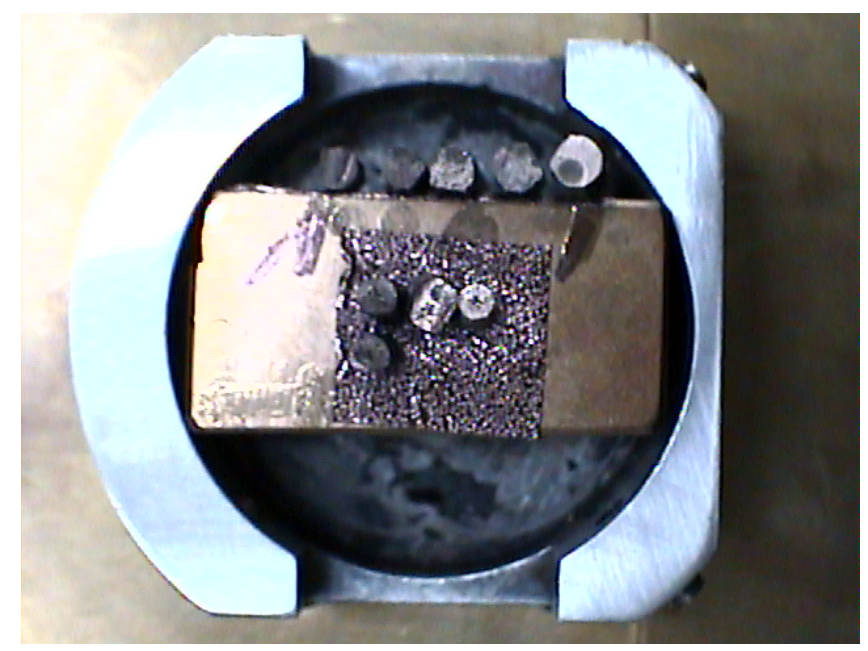

Figura 15: Amostras metalizadas posicionadas no porta-amostras do MEV.

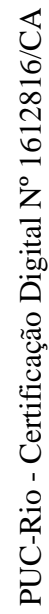




\section{4 \\ Resultados e Discussão}

4.1

\section{Degradação da Matriz Polimérica}

Buscando entender melhor se há degradação do polímero durante o processamento, foram realizados ensaios de espectrometria de infravermelho com transformada de Fourrier (FTIR). O FTIR teve como objetivo verificar a presença de grupos químicos na estrutura polimérica que indiquem algum tipo de degradação.

A Figura 16 mostra o gráfico que relaciona o número de onda (eixo x) com a transmitância (eixo y) para uma amostra de ABS puro. Nela, pode-se observar diversos picos que representam diferentes grupos químicos que compõem a amostra.

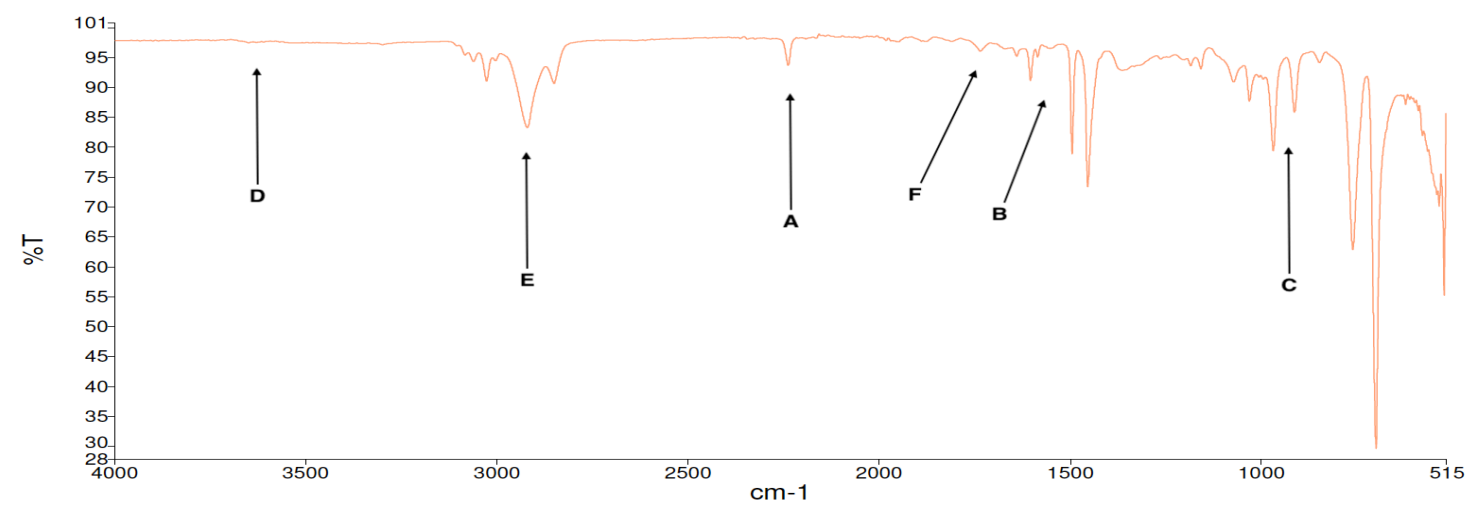

Figura 16: Gráfico resultante do FTIR, gerado pelo software Spectrum (Perkin Elmer), para ABS puro.

Os picos $\mathrm{A}, \mathrm{B}$ e $\mathrm{C}$ representam a presença de grupos químicos, tipicamente encontradas em polímeros do tipo ABS: acrilonitrila, estireno e butadieno, respectivamente. As regiões indicadas por D e F são de especial interesse, pois representam, respectivamente, a presença de umidade e oxidação. Os números de onda entre $3500 \mathrm{~cm}^{-1}$ e $4000 \mathrm{~cm}^{-1}$ (região D) estão geralmente associados a vibrações de alongamento (stretching) de grupos $\mathrm{OH}$ [45], que indicam a presença de umidade no polímero. Já os números de onda entre $1690 \mathrm{~cm}^{-1}$ e $1800 \mathrm{~cm}^{-1}$ (Região F), estão associados a vibrações de alongamento (stretching) dos grupos $\mathrm{C}=\mathrm{O}$, também conhecidos como carbonilas [45]. Como visto na Figura 8, a estrutura do ABS não apresenta nenhum tipo de carbonila. Logo, a presença da 
banda na região $\mathrm{F}$ indica a ocorrência de oxidação das cadeias poliméricas quando expostos à temperatura em uma atmosfera com oxigênio presente, como ocorre no interior da extrusora. A região E representa a presença de hidrocarbonetos (ligações $\mathrm{C}-\mathrm{H})$.

Observando a Figura 17, pode-se identificar o aumento do pico localizado na região $\mathrm{F}$, indicando um aumento da presença de carbonilas em função da temperatura de processamento e, consequentemente, indicando degradação sofrida pelo polímero durante o processamento.

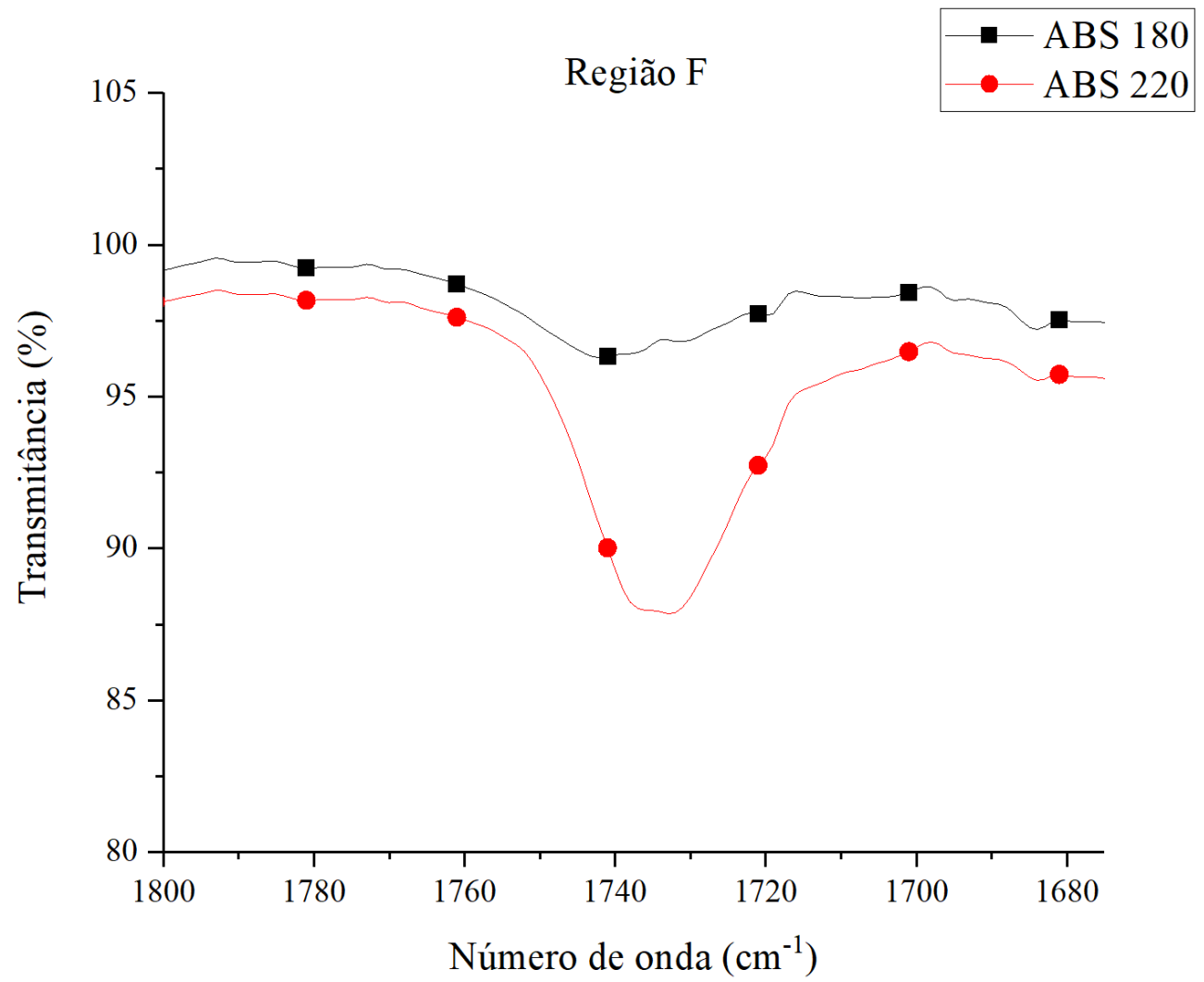

Figura 17: Comparação da região indicativa de oxidação do ABS processado em diferentes temperaturas.

Uma vez identificado que pode ocorrer oxidação durante o processamento, foi possível identificar uma janela de processamento que permitisse obter uma viscosidade adequada do ABS para que ocorra a mistura com o reforço de fibras de carbono sem que houvesse uma degradação excessiva do polímero. Um 
compromisso foi encontrado em $200^{\circ} \mathrm{C}$ entre a processabilidade do material e a possível perda de propriedades mecânicas causadas pela degradação térmica.

Logo, todas as misturas caracterizadas e ensaiadas foram processadas à $200^{\circ} \mathrm{C}$, variando apenas na \% wt CF e presença de óleo de semente de uva. Como pode ser observado na Figura 18, em nenhuma das misturas processadas a $200^{\circ} \mathrm{C}$ nota-se um pico significativo na região indicativa de oxidação.

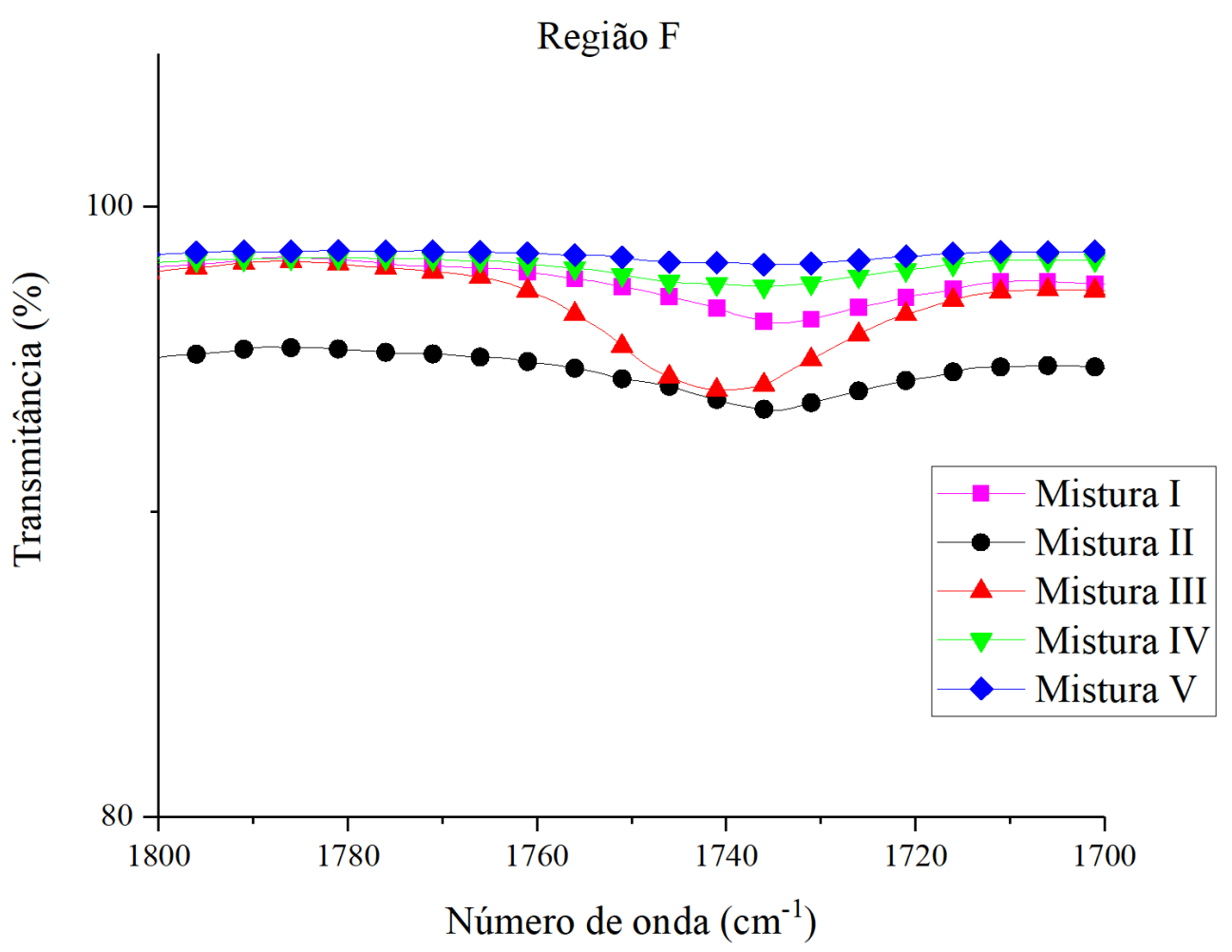

Figura 18: Comparação da Região F para as 5 misturas processadas.

Gráficos detalhados para cada região do espectro das misturas podem ser vistos nas Figuras 19, 20, 21, 22 e 23. Em todas elas, é possível observar que as fibras não influenciam significativamente nenhuma região do espectro. 


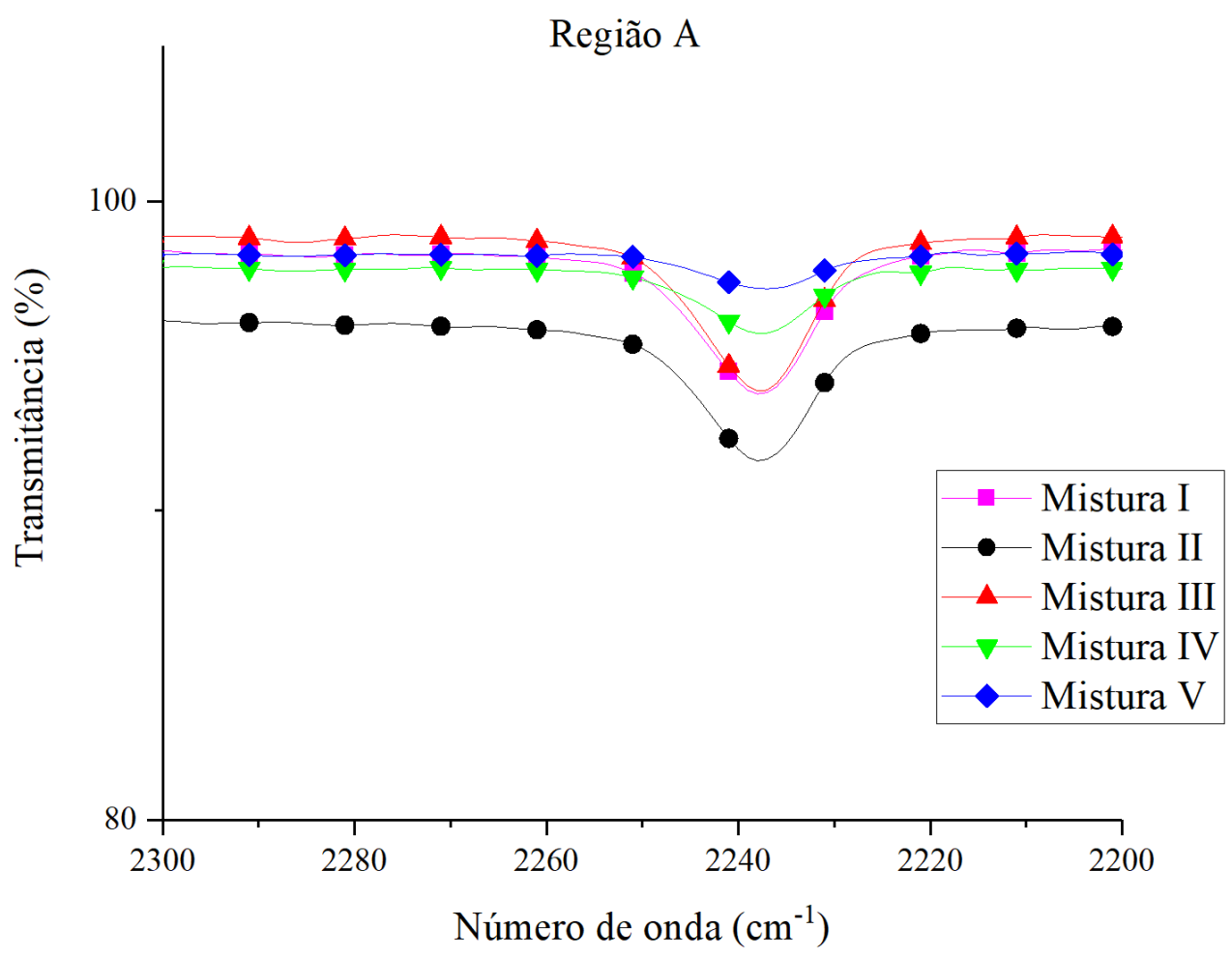

Figura 19: Espectro de FTIR destacado para a região A.

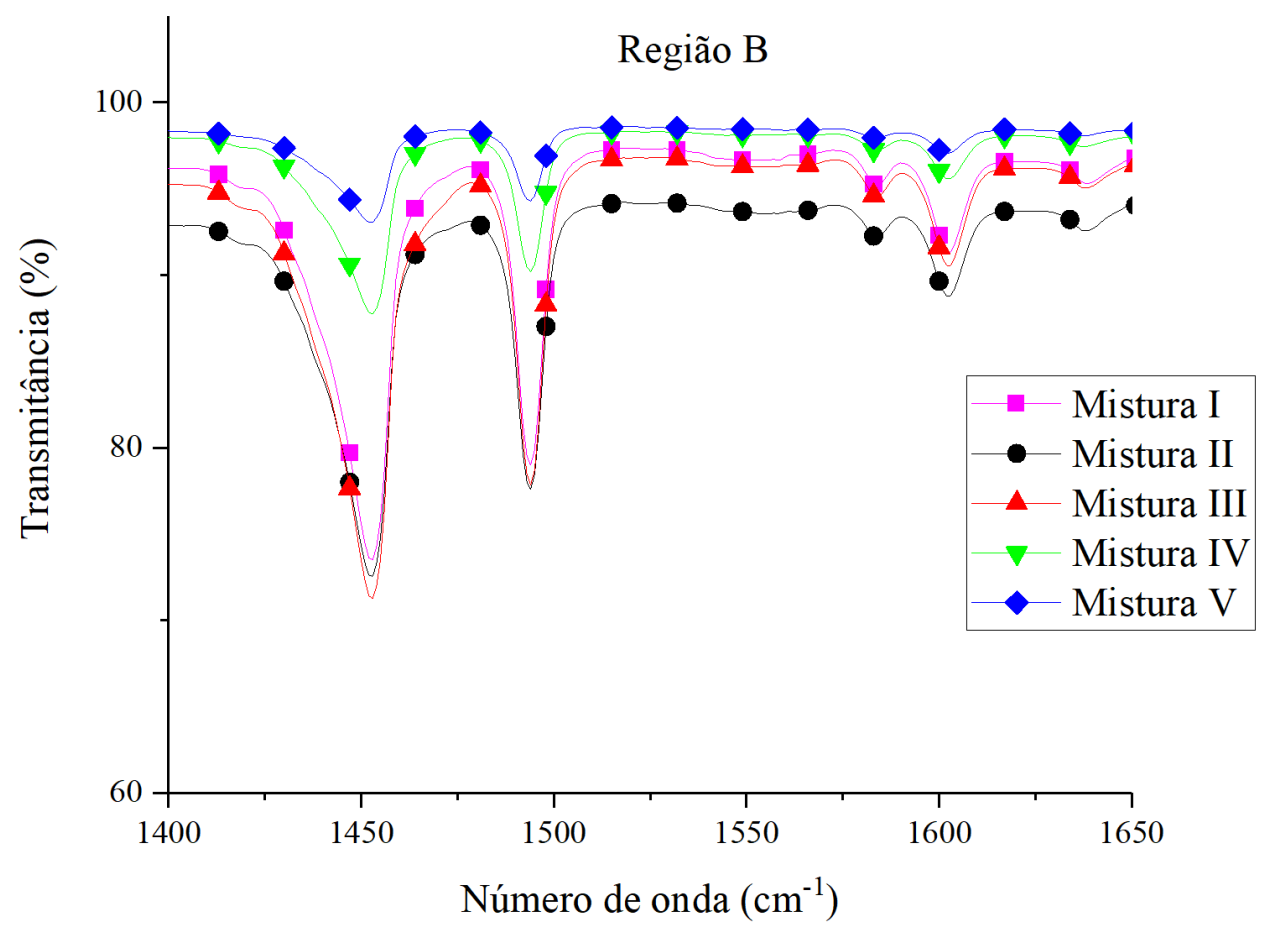

Figura 20: Espectro de FTIR destacado para a região B 


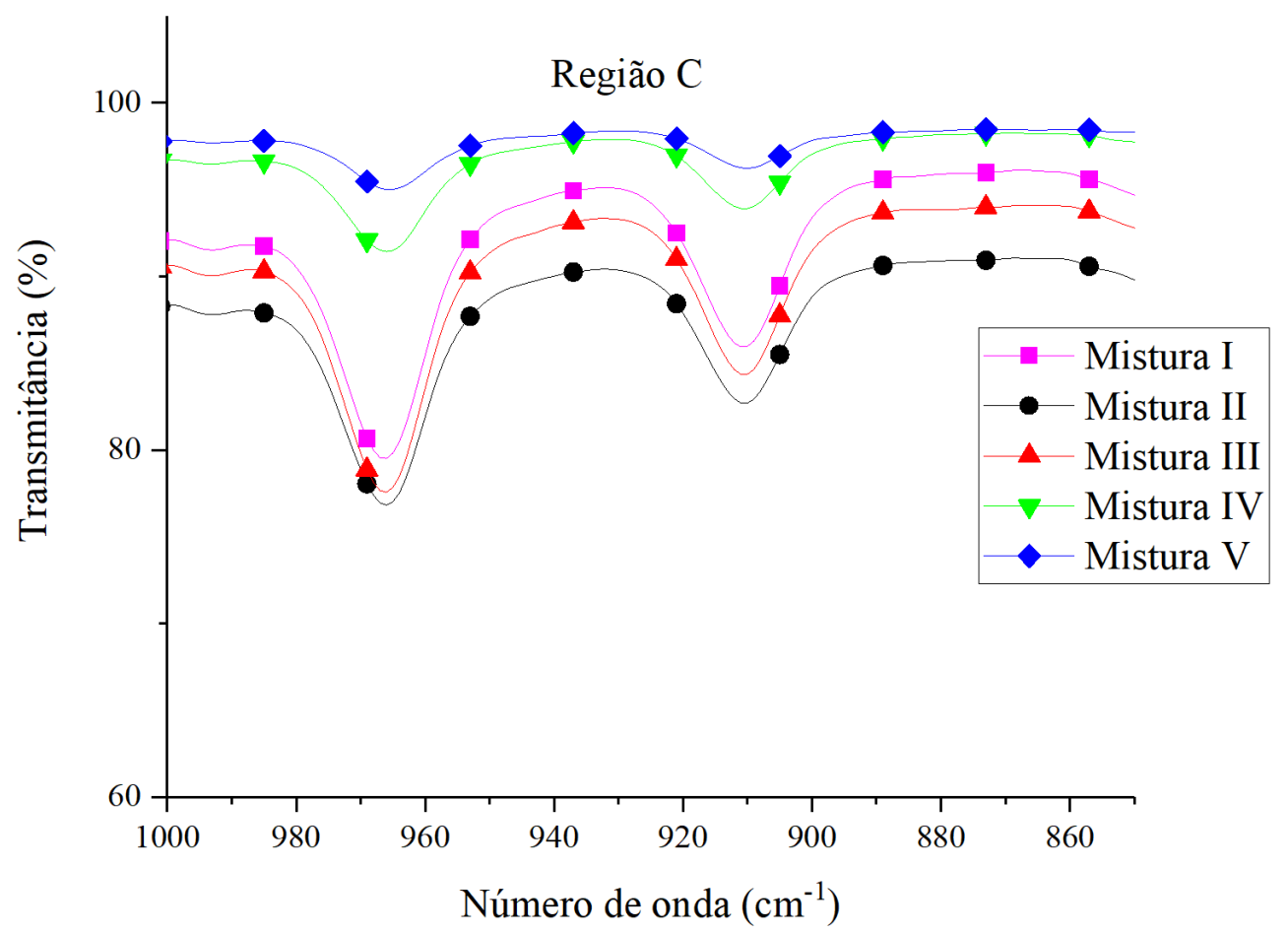

Figura 21: Espectro de FTIR destacado para a região C

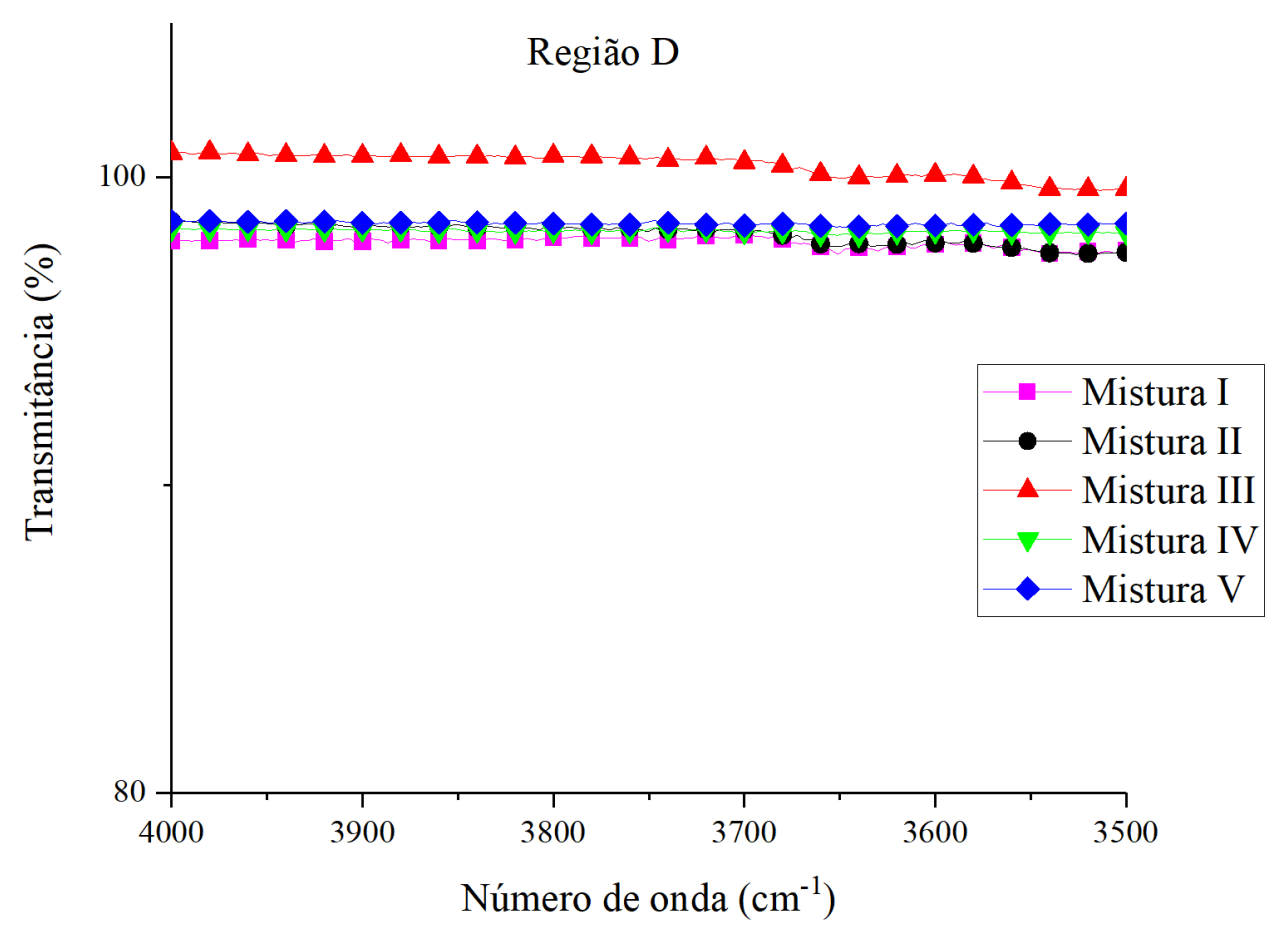

Figura 22: Espectro de FTIR destacado para a região D 


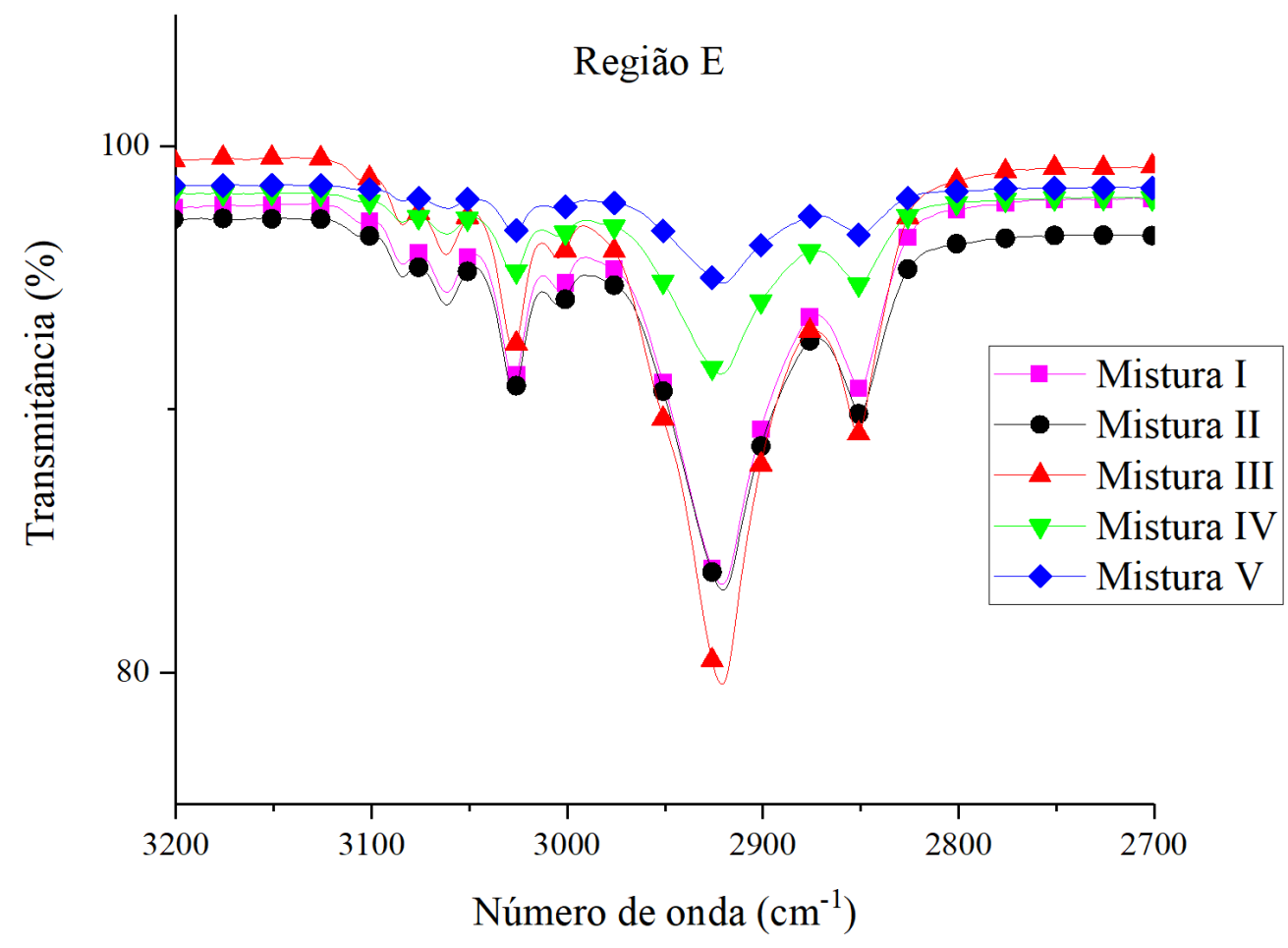

Figura 23: Espectro de FTIR destacado para a região E

\section{2}

\section{Análise Termogravimétrica}

Corridas de TGA foram feitas a três taxas de aquecimento distintas. As taxas utilizadas foram de 10,20 e $30^{\circ} \mathrm{C} / \mathrm{min}$. Os resultados para as análises realizadas com cada taxa estão listados nas tabelas 3,4 e 5 .

Tabela 3: Resultados do TGA para uma taxa de aquecimento de $10^{\circ} \mathrm{C} / \mathrm{min}$.

\begin{tabular}{cccccc}
\hline Mistura & $\begin{array}{c}\text { Peso da amostra } \\
(\mathbf{m g})\end{array}$ & $\begin{array}{c}\text { Onset X } \\
\left({ }^{\circ} \mathrm{C}\right)\end{array}$ & $\begin{array}{c}\text { Onset Y } \\
(\%)\end{array}$ & $\begin{array}{c}\text { Temperatura no ponto } \\
\text { de inflexão }\left({ }^{\circ} \mathrm{C}\right)\end{array}$ & $\begin{array}{c}\text { Taxa no ponto de } \\
\text { inflexão (\%/min) }\end{array}$ \\
\hline I & 22,313 & 419,36 & 97,6672 & 469,98 & $-15,5786$ \\
II & 20,773 & 426,15 & 97,0366 & 476,17 & $-14,9419$ \\
III & 12,632 & 419,37 & 96,1493 & 450,95 & $-14,1667$ \\
IV & 17,874 & 420,94 & 97,9978 & 459,2 & $-13,1275$ \\
V & 13,801 & 428,98 & 96,4327 & 474,85 & $-15,6269$ \\
Óleo & 2,18 & 399,86 & 81,722 & 428,42 & $-15,426$ \\
\hline
\end{tabular}


Tabela 4: Resultados do TGA para uma taxa de aquecimento de $20^{\circ} \mathrm{C} / \mathrm{min}$.

\begin{tabular}{cccccc}
\hline Mistura & $\begin{array}{c}\text { Peso da amostra } \\
(\mathrm{mg})\end{array}$ & $\begin{array}{c}\text { Onset X } \\
\left({ }^{\circ} \mathrm{C}\right)\end{array}$ & $\begin{array}{c}\text { Onset Y } \\
(\%)\end{array}$ & $\begin{array}{c}\text { Temperatura no ponto } \\
\text { de inflexão }\left({ }^{\circ} \mathrm{C}\right)\end{array}$ & $\begin{array}{c}\text { Taxa no ponto de } \\
\text { inflexão }(\% / m i n)\end{array}$ \\
\hline I & 26,156 & 444,36 & 98,1849 & 490,95 & $-28,8991$ \\
II & 6,146 & 452,15 & 96,1697 & 496,69 & $-34,2712$ \\
III & 13,229 & 445,09 & 96,6423 & 489,19 & $-28,9978$ \\
IV & 12,102 & 449,4 & 96,6036 & 495,7 & $-25,3261$ \\
V & 11,374 & 448,83 & 97,1441 & 496,61 & $-23,7656$ \\
\hline
\end{tabular}

Tabela 5: Resultados do TGA para uma taxa de aquecimento de $30^{\circ} \mathrm{C} / \mathrm{min}$.

\begin{tabular}{cccccc}
\hline Mistura & $\begin{array}{c}\text { Peso da amostra } \\
(\mathrm{mg})\end{array}$ & $\begin{array}{c}\text { Onset X } \\
\left({ }^{\circ} \mathrm{C}\right)\end{array}$ & $\begin{array}{c}\text { Onset Y } \\
(\%)\end{array}$ & $\begin{array}{c}\text { Temperatura no ponto } \\
\text { de inflexão }\left({ }^{\circ} \mathrm{C}\right)\end{array}$ & $\begin{array}{c}\text { Taxa no ponto de } \\
\text { inflexão (\%/min) }\end{array}$ \\
\hline I & 26,729 & 457,91 & 96,1504 & 521,93 & $-42,9866$ \\
II & 8,493 & 455,37 & 96,9451 & 503,96 & $-43,1024$ \\
III & 12,183 & 457,17 & 95,7671 & 510,06 & $-42,5434$ \\
IV & 12,087 & 453,99 & 96,91 & 504,43 & $-36,6201$ \\
V & 10,181 & 456,61 & 96,5823 & 503,02 & $-34,9622$ \\
\hline
\end{tabular}

\subsection{1}

\section{Influência das Fibras na Estabilidade Térmica}

A partir dos termogramas obtidos nas três taxas de aquecimento diferentes, é possível observar as variações da temperatura de degradação para cada taxa de aquecimento (Figura 24).

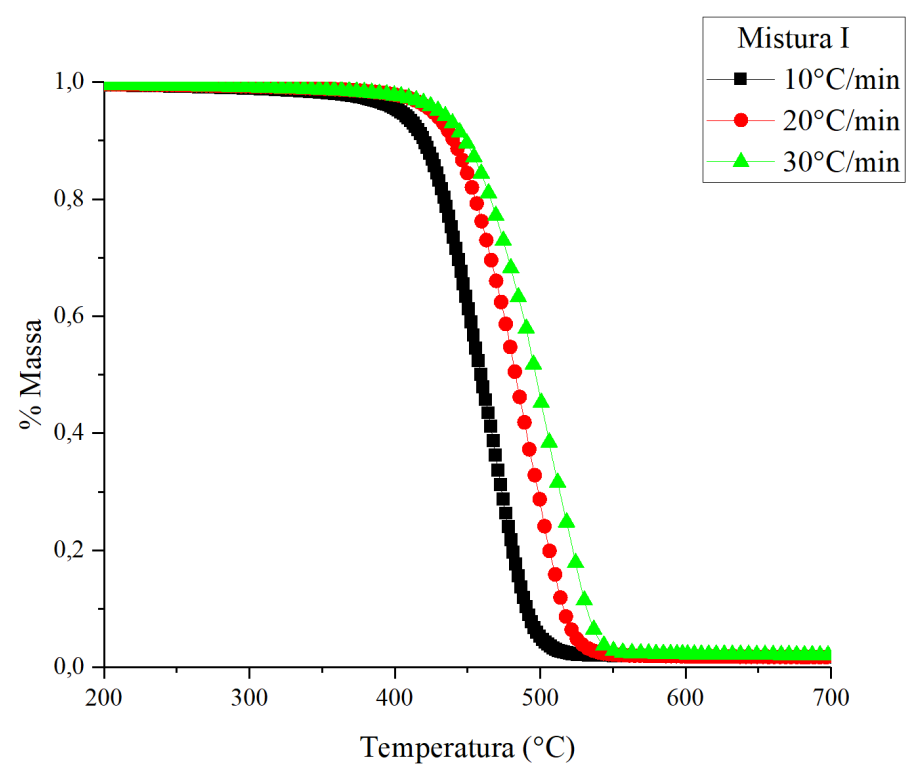

Figura 24: Termograma em função da \% de perda de massa para as três taxas de aquecimento utilizadas. Exemplo para a Mistura I. 
Como exemplo, a Tabela 6 relaciona as temperaturas nas quais cada nível de degradação ocorre para a Mistura II. Já a Figura 25 mostra os gráficos para cada nível de degradação em função da taxa de aquecimento e da temperatura de degradação, ambos em escala logarítmica. É possível observar retas paralelas para níveis mais altos, enquanto nos pontos para níveis mais baixos, há maior dispersão. Segundo Yao et al. [53], o paralelismo das retas indica um mecanismo único de reação durante a degradação do material. Assim, para níveis mais baixos, a ausência (ou presença em menor grau) do paralelismo entre as retas indica a presença de mecanismos complexos. Uma hipótese para a diferença é a possível evaporação de voláteis e umidade durante os estágios iniciais de aquecimento. Por este motivo, apenas taxas de degradação maiores que 2,5\% foram utilizadas para o cálculo das energias de ativação.

Tabela 6: Temperaturas de degradação para a Mistura II.

Temperaturas de degradação para a Mistura II $\left({ }^{\circ} \mathrm{C}\right)$

\begin{tabular}{cccc}
\hline Nível de & \multicolumn{3}{c}{ Taxa de } \\
Degradação & 10 & 20 & 30 \\
\hline 0,5 & 216,1 & 213,3 & 211,5 \\
1,0 & 300,9 & 289,6 & 311,2 \\
2,5 & 381,3 & 378,2 & 396,1 \\
5,0 & 408,7 & 418,7 & 427,4 \\
10,0 & 424,4 & 439,6 & 447,8 \\
20,0 & 438,8 & 456,0 & 464,7 \\
\hline
\end{tabular}

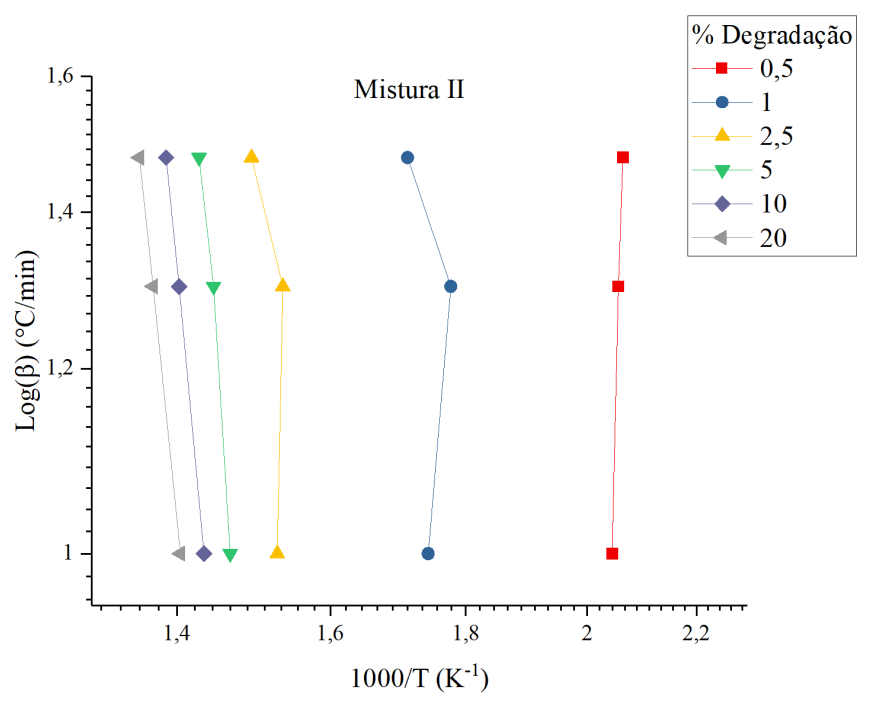

Figura 25: Gráfico dos níveis de degradação em função da taxa de aquecimento e temperatura. 
A tabela 7 relaciona os valores obtidos para as energias de ativação de cada amostra, em cada nível de degradação. Em média, os valores encontrados estão um pouco abaixo dos verificados em Yang [54], porém na mesma ordem de grandeza. Foram utilizados somente os níveis de 5,0\% e 10,0\% de degradação, pois são aqueles cujos pontos estão bem alinhados para todas as misturas, permitindo assim uma aferição dos valores de energia com um erro reduzido.

Tabela 7: Energia de ativação em função do nível de degradação e mistura.

Energia de Ativação $E(\mathrm{kcal} / \mathrm{mol})$

\begin{tabular}{cccccc}
\hline & \multicolumn{5}{c}{ Misturas } \\
Nível de degradação (\%) & I & II & III & IV & V \\
\hline 5,0 & 33,1 & 53,4 & 25,7 & 37,5 & 34,8 \\
10,0 & 33,4 & 44,0 & 29,6 & 35,0 & 33,7 \\
\hline
\end{tabular}

A Figura 26 mostra os valores de energia de ativação em função de cada mistura. É possível observar um pico mais pronunciado para a mistura II em todos os níveis de degradação, que indicam a perda de massa do material à temperatura, enquanto outro pico também pode ser observado para a mistura IV para todos os níveis.

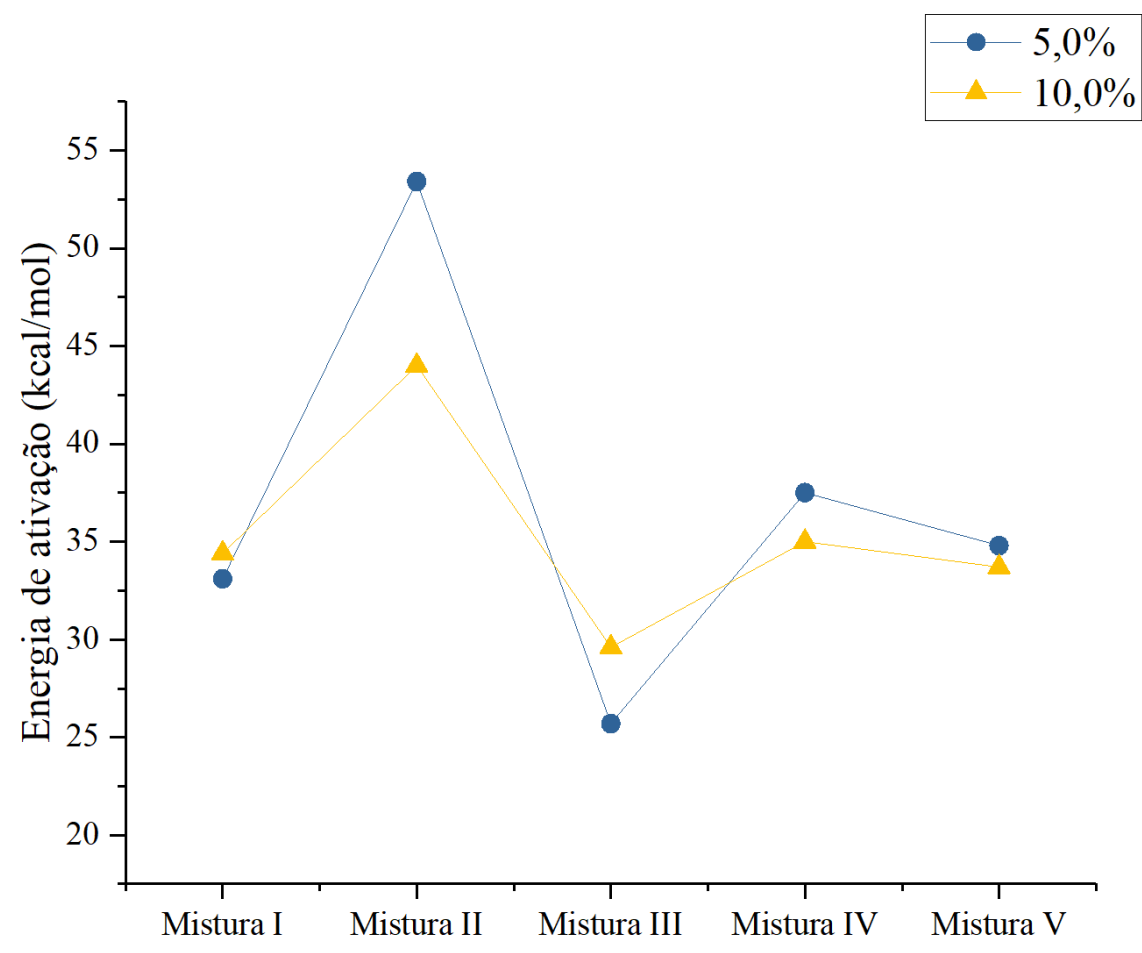

Figura 26: Gráfico das energias de ativação em função das misturas. 
Entre as misturas II e III, cujas \% wt CF são nominalmente iguais, a única diferença foi a utilização de óleo de semente de uva durante o processamento. As misturas IV e $\mathrm{V}$ também foram processadas com o óleo, porém a \% wt CF nestas misturas é significativamente maior. Portanto, uma hipótese para a variação observada nas energias de ativação é que, ao mesmo tempo em que as fibras de carbono aumentam a estabilidade térmica do compósito, ou seja, aumentam a energia de ativação, a presença do óleo de semente de uva a diminui.

O óleo de semente de uva também foi analisado através do TGA, como pode ser observado na Figura 27 e na Tabela 3. Os resultados mostram quem o óleo é estável a temperaturas superiores às temperaturas de processo, logo, ele também faz parte da composição do compósito final, reforçando a hipótese de que a sua presença influencia na estabilidade térmica.

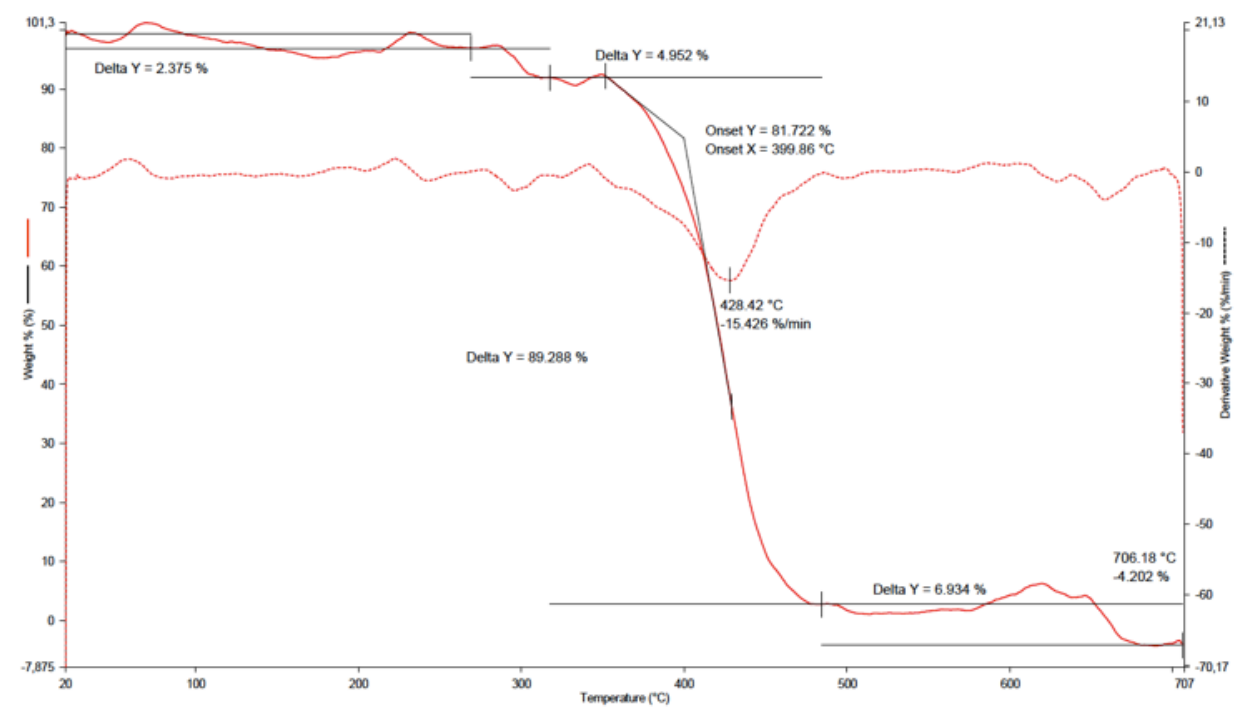

Figura 27: Gráfico resultante do TGA para o óleo de semente de uva.

A tendência de variação da energia de ativação em função da composição das misturas também pode ser observada fixando-se um nível de degradação e observando em maiores detalhes as temperaturas nas quais ele ocorre (Figura 28). Um valor de $5 \%$ de perda de massa foi definido e a temperatura a qual cada mistura chegou a este valor foi medida. No gráfico, é possível observar que a mistura III apresentou a temperatura mais baixa $\left(394,4^{\circ} \mathrm{C}\right)$, enquanto a mistura II, registrou a temperatura mais alta $\left(408,7^{\circ} \mathrm{C}\right)$. A tendência novamente é confirmada com os 
valores da mistura IV e V $\left(407,7^{\circ} \mathrm{C}\right.$ e $405,6^{\circ} \mathrm{C}$, respectivamente) um pouco acima da temperatura da mistura $\mathrm{I}\left(403,7^{\circ} \mathrm{C}\right)$.

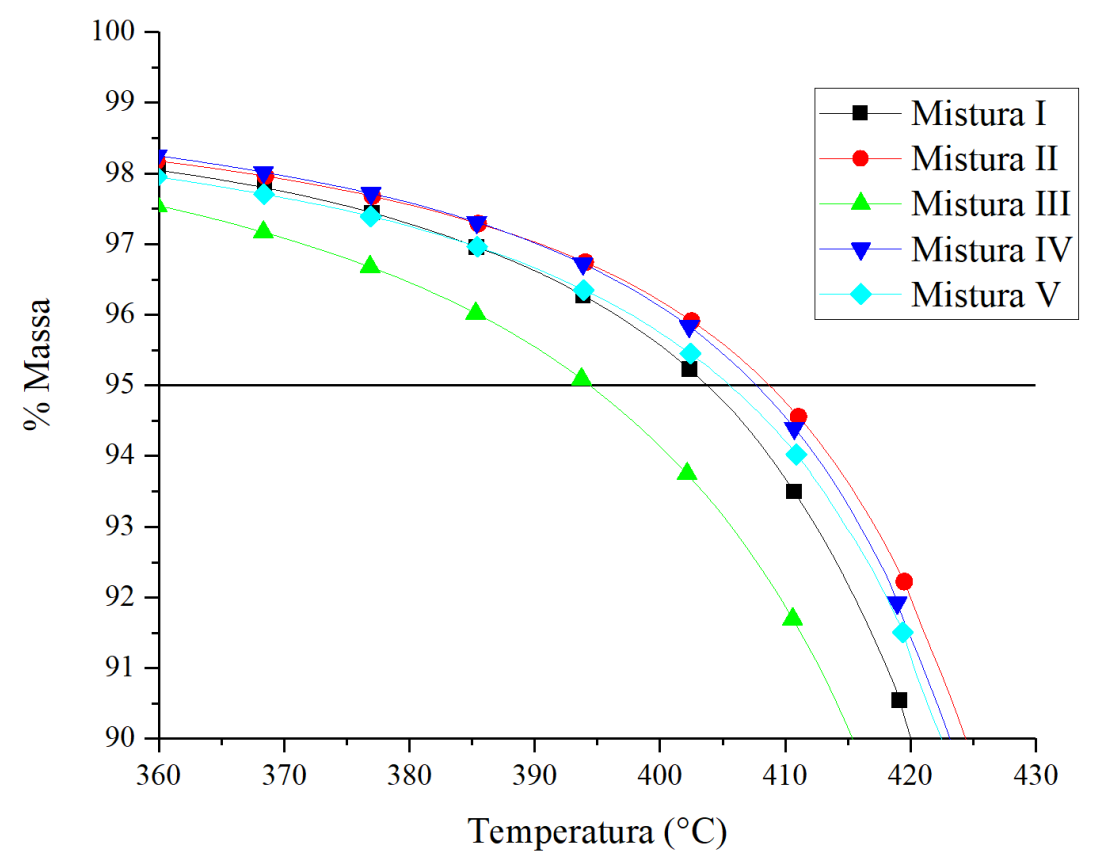

Figura 28: Comparativo das temperaturas de cada mistura à 5\% de perda de massa.

\subsection{2}

\section{Fração Real de Fibras nas Misturas}

Como visto em Hull et al. [52], a quantidade final de fibras pode ser menor do que a inicialmente calculada devido a perdas que ocorrem ao longo do processo. Através da análise termogravimétrica foi possível determinar a quantidade real de fibras de carbono presente nas misturas preparadas na extrusora dupla rosca. A Figura 29 mostra o resultado para o ABS puro, onde observa-se que a massa residual é aproximadamente zero. Consequentemente, na Figura 30, a massa residual a $700^{\circ} \mathrm{C}$ na mistura II foi considerada como sendo apenas devido às fibras de carbono. 


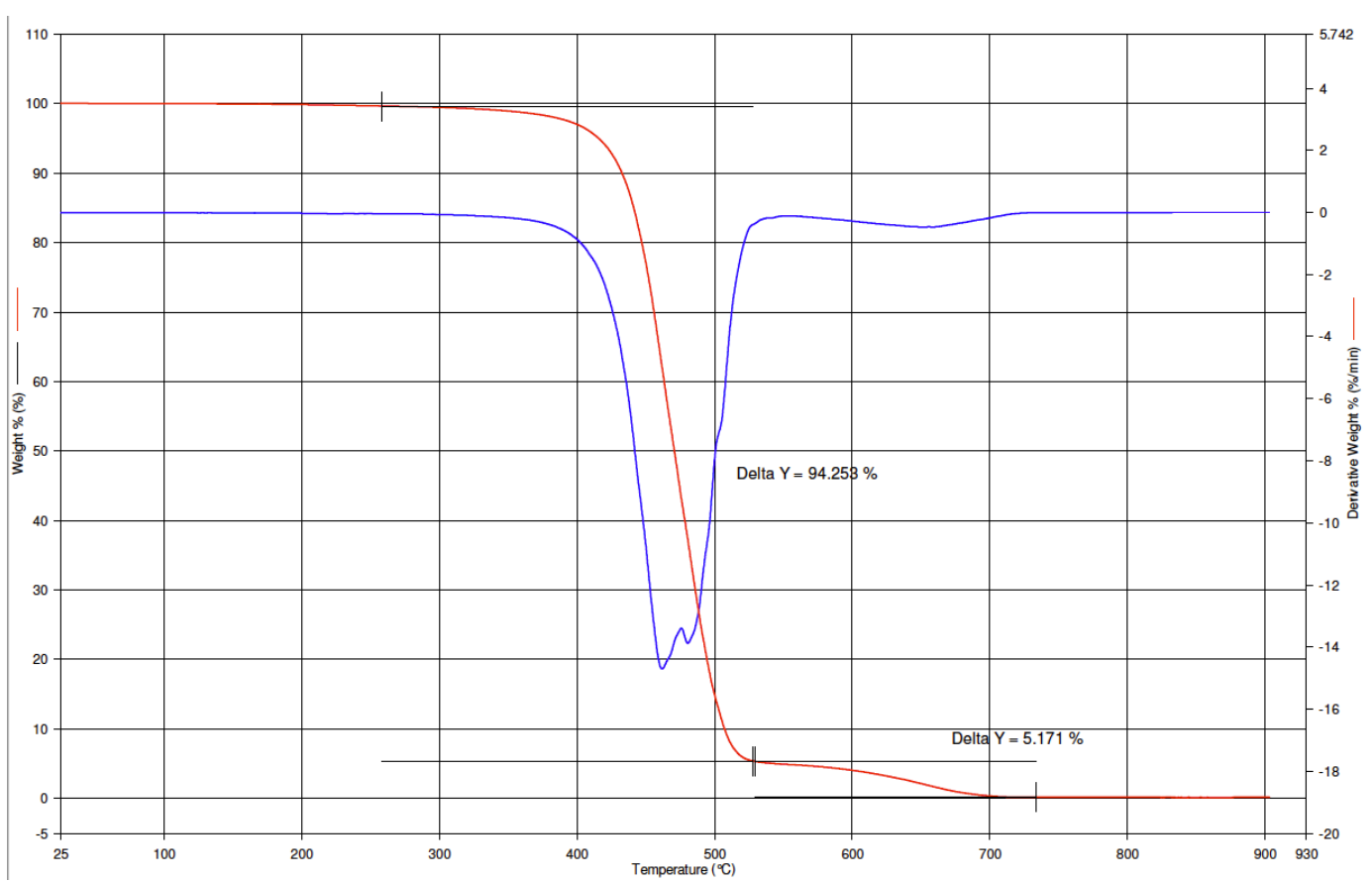

Figura 29: Gráfico resultante do TGA para o ABS puro (Mistura I).

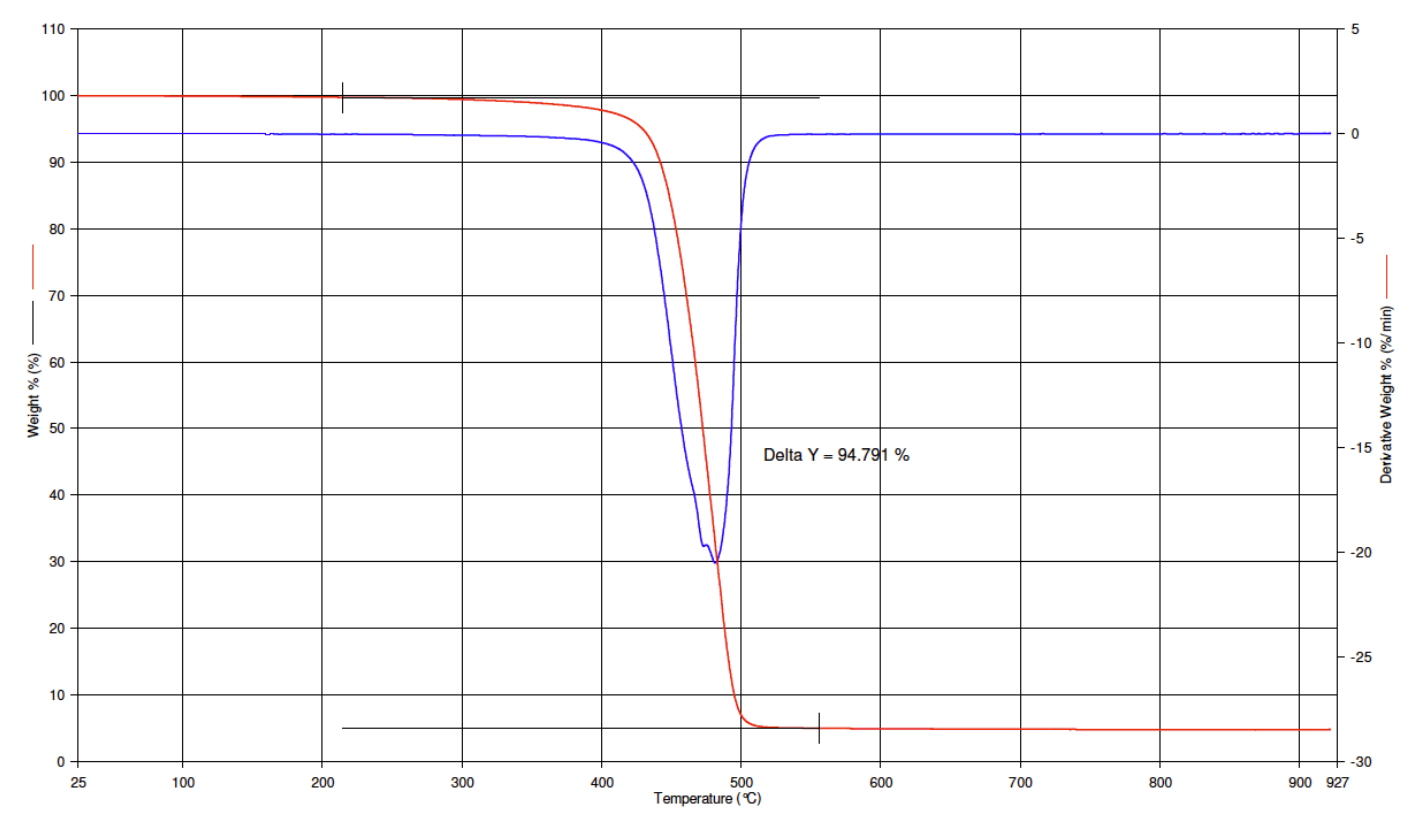

Figura 30: Gráfico resultante do TGA para a mistura III.

Especificamente na extrusora, estas perdas foram mais evidenciadas na etapa de alimentação do material no equipamento. Nesta extrusora, a alimentação ocorre através de um misturador mecânico que empurra a mistura por meio de um tubo utilizando um fuso. Pôde-se notar uma grande quantidade de fibras ficando presas nas paredes do misturador e retidas na saída do fuso. 
É possível observar na Tabela 8 que para as misturas II e III, com 5\% wt CF calculados, a \% wt real aumentou ao adicionar-se o óleo de semente de uva. Estas misturas foram apenas testes para verificar, primeiramente, a viabilidade da mistura na extrusora entre ABS e CF e também a eficácia do óleo como um lubrificante para melhorar o aproveitamento do processo.

Tabela 8: Quadro comparativo das \% wt real e calculada

\begin{tabular}{ccccc}
\hline Mistura & $\begin{array}{c}\text { Óleo de uva } \\
(\% \mathrm{wt})\end{array}$ & $\begin{array}{c}\text { Tipo de CF } \\
(\mathrm{mm})\end{array}$ & $\begin{array}{c}\% \mathrm{wt} \\
\text { calculada }\end{array}$ & $\begin{array}{c}\% \mathrm{wt} \\
\text { real }\end{array}$ \\
\hline I & - & - & 0 & 0 \\
II & - & 3 & 5 & 3,1 \\
III & 1 & 3 & 5 & 5,2 \\
IV & 1 & 3 & 16,7 & 13,2 \\
V & 1 & 6 & 16,7 & 16,5 \\
\hline
\end{tabular}

Com o óleo, não só uma menor quantidade de fibras ficou retida na alimentação da extrusora, como algumas fibras que estavam presas ao longo do tubo foram soltas e entraram na mistura, o que provavelmente explica a quantidade acima do calculado para a fração de fíbras.

Já nas misturas com $16,7 \%$ de CF, onde ambas foram produzidas utilizando óleo de semente de uva, pode-se verificar que o comprimento das fibras foi o fator determinante para a diferença entre \% wt calculada e real. A verificação do comprimento final das fibras nos corpos de prova através de tomografia computadorizada e processamento digital de imagens é sugerida para uma futura confirmação desta hipótese, como feito por Tekinalp et al [17].

\section{3}

\section{Influência das Fibras na Viscosidade}

Através dos ensaios de reologia realizados, foi possível plotar um gráfico relacionando as misturas e a viscosidade, em função da taxa de cisalhamento (Figura 31). 


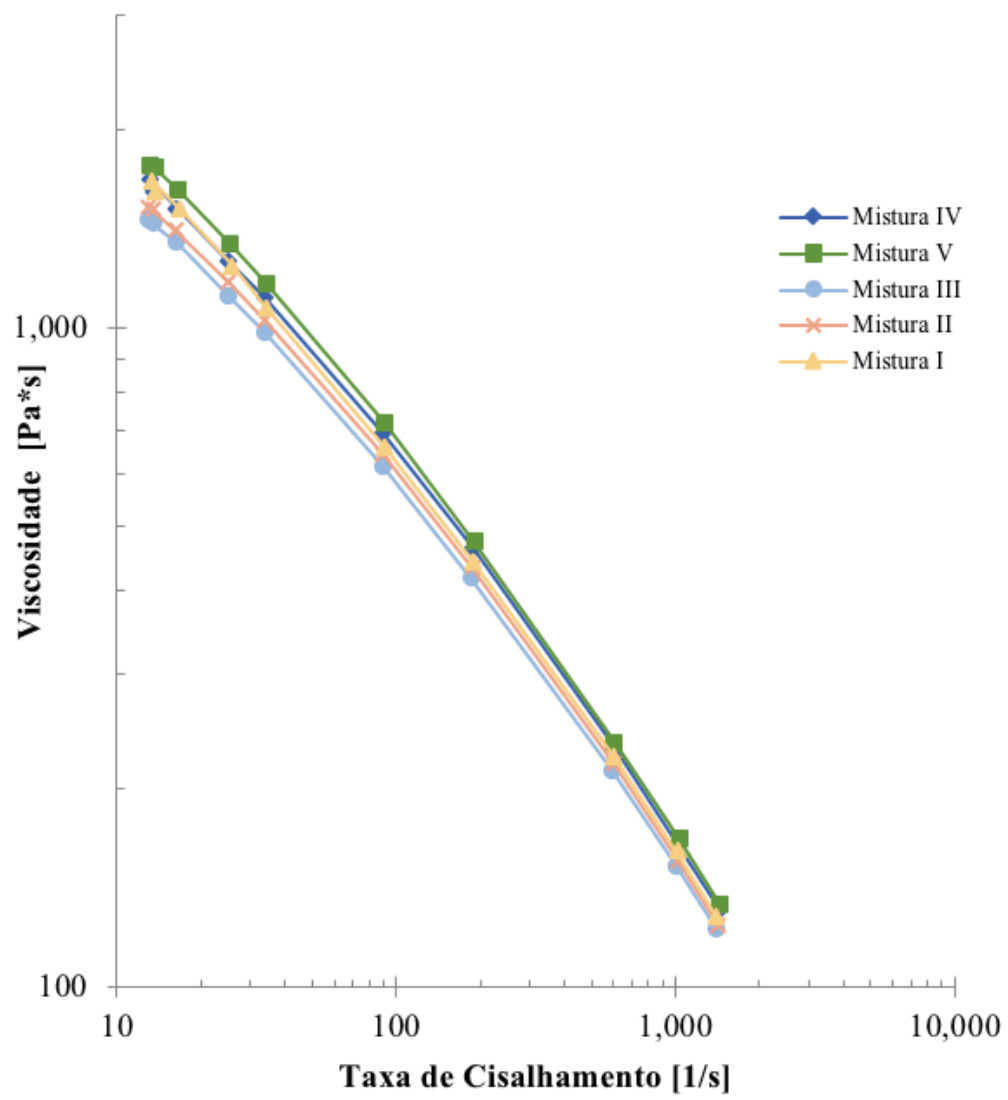

Figura 31: Gráfico Viscosidade x Taxa de Cisalhamento para as 5 misturas analisadas.

No gráfico da Figura 31, é possível observar que a viscosidade pouco variou com a introdução das fibras de carbono. As misturas II e III apresentaram uma leve diminuição da viscosidade, enquanto as misturas IV e $\mathrm{V}$ apresentaram um leve aumento em relação à mistura $\mathrm{I}$, que era esperado, como visto em Ajinjeru et al. [50], devido a maior fração de fibras de carbono adicionadas. Os valores máximos ficaram entre 1780 e $1460 \mathrm{~Pa}^{*}$ s.

\section{4}

Variação das Propriedades em Função da Fração e do Comprimento Inicial de Fibras

\subsection{1}

\section{Resistência à Tração}

A partir dos ensaios mecânicos, foi possível determinar a variação da resistência à tração em função da fração de fibras do material. A Figura 32 relaciona os valores obtidos para cada mistura. 
Em cada Box Plot, a linha de cima e de baixo da caixa representam o $3^{\circ} \mathrm{e}$ $1^{\circ}$ quartis, respectivamente, e a linha ao centro representa a mediana. Os traços representam os máximos e mínimos dentro de uma margem de 1,5 intervalos interquartis, enquanto as barras com x representam os valores máximos e mínimos gerais obtidos. O quadrado dentro das caixas representa a média dos valores para cada mistura especificamente.

De acordo com o datasheet do material [58], o valor para resistência à tração do ABS puro, segundo a norma ASTM D 638, é de 44,9 MPa. Portanto, apesar de apenas comparativo, os valores obtidos experimentalmente estão próximos ao descrito pelo fabricante. Em relação ao ABS puro, mistura I, é possível observar um aumento de $14 \%$ no valor médio da resistência à tração ao se adicionar uma quantidade baixa de fibras de carbono, da ordem de $3 \%$ (mistura II).

Na mistura III, pode-se observar o decréscimo da resistência à tração, em relação à mistura II. O valor decresceu 9,4\% em relação à mistura II, ficando na casa de 43,0 MPa. Este valor aproxima-se do encontrado para a mistura I, ou seja, do ABS puro. Estatisticamente, a diferença da resistência à tração da mistura I e da mistura III é insignificante, assumindo um teste $\mathrm{t}$ de Student com índice de confiabilidade de $95 \%$.

A mistura IV apresentou o maior valor médio, de 50,0 MPa, cerca de 16\% maior que a mistura I e III e cerca de 5\% maior que a mistura II. Porém, também apresentou o maior desvio padrão de todas as misturas ensaiadas.

A mistura $\mathrm{V}$, assim com a mistura III, apresentou um decréscimo da resistência à tração. Não há diferença estatisticamente significativa entre os valores das misturas I, III e V.

Os valores encontrados estão de acordo com o visto em Ning et al. [59, 60]. Em Tekinalp et al. [17], Duty et al. [39] e Love et al. [18], valores mais altos são observados, chegando a valores próximos de $70 \mathrm{MPa}$, porém para \% wt CF mais altas.

Na figura 33 é possível observar o comportamento à tração de uma amostra de cada mistura. Pode-se observar variações nos valores de tensão máxima e na ductilidade, à medida que se aumenta $\mathrm{a} \% \mathrm{wt} \mathrm{CF}$. 


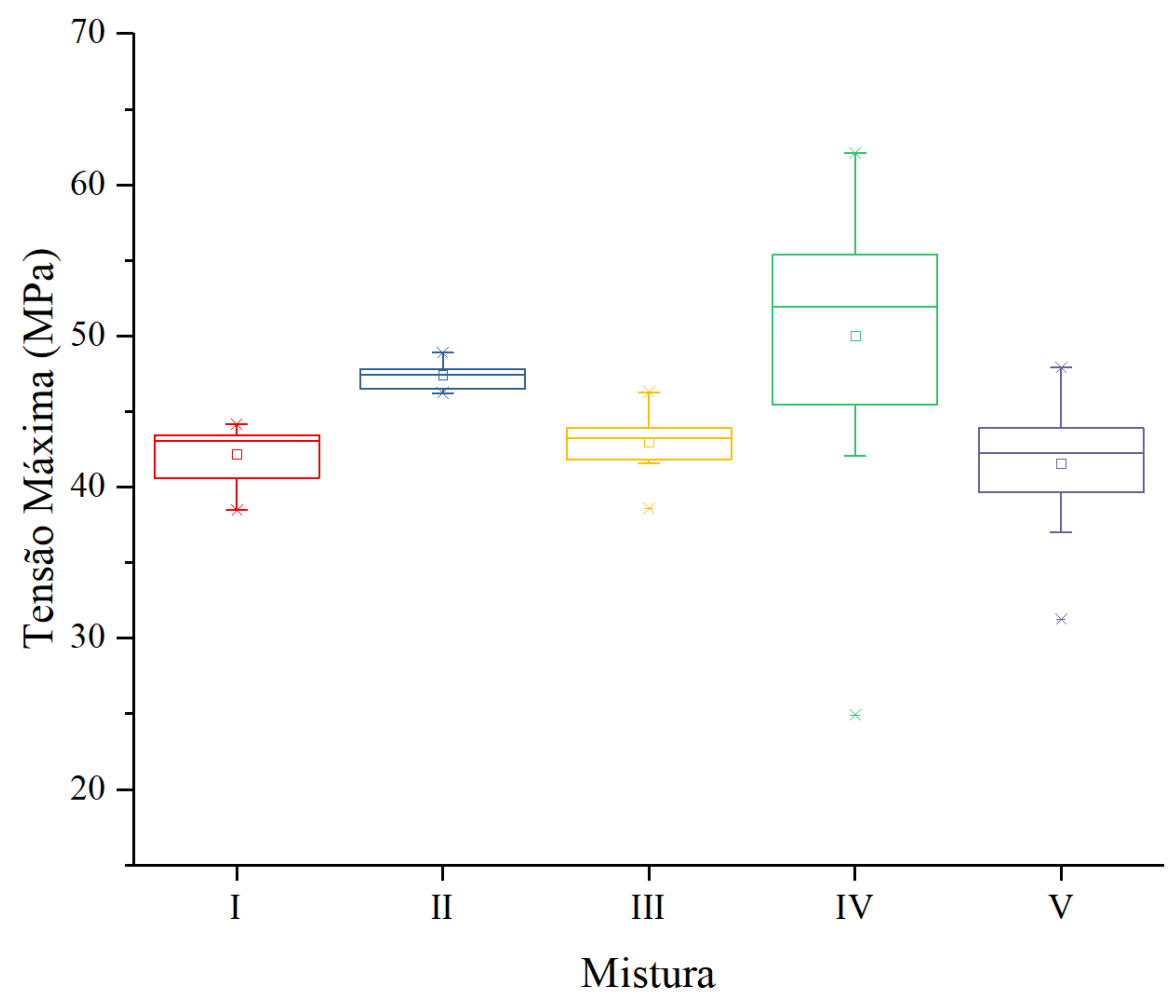

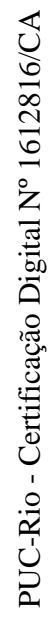

Figura 32: Comparação da resistência à tração entre as misturas.

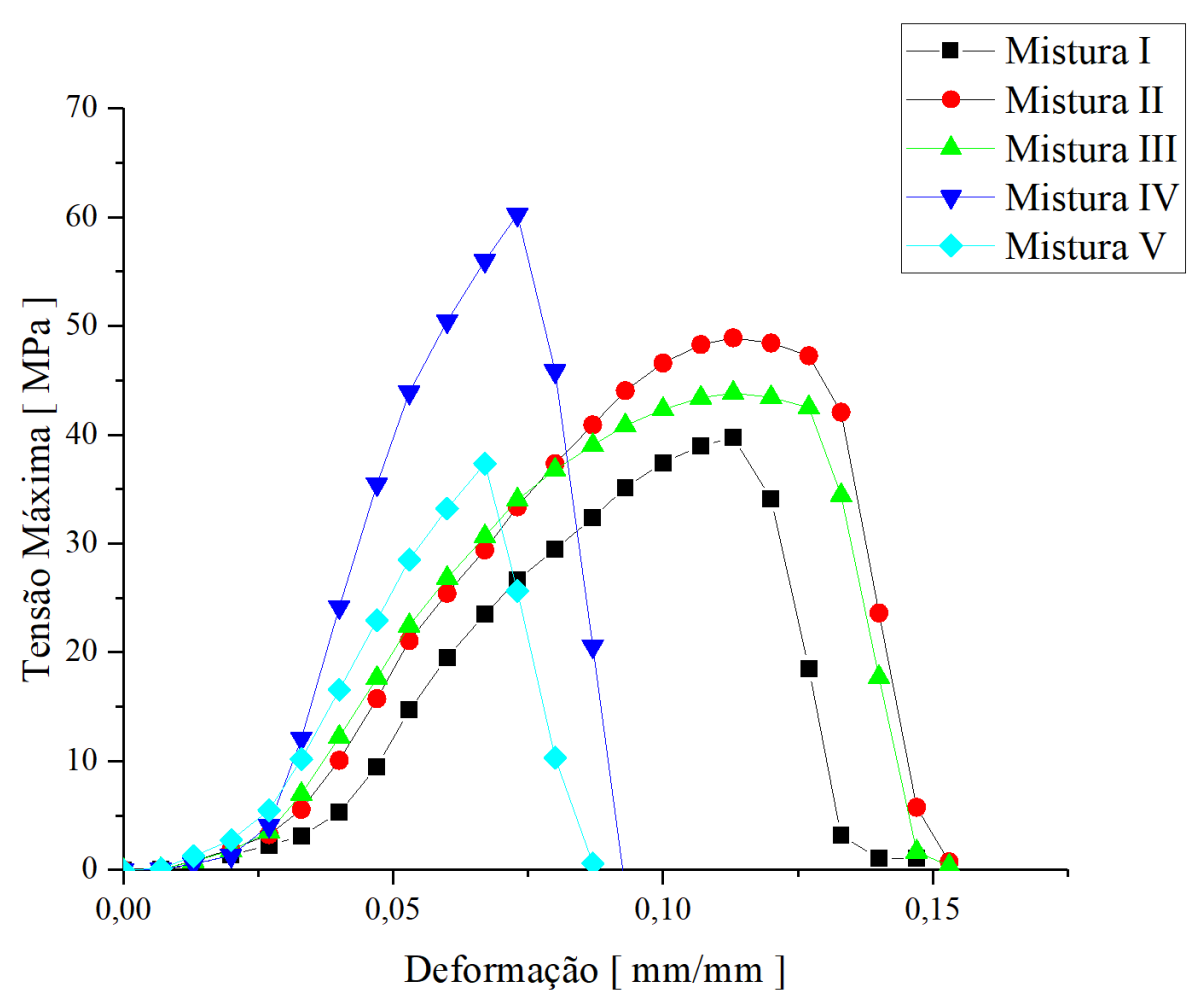

Figura 33: Comparação do gráfico Tensão x Deformação para um corpo de prova de cada mistura. 


\subsection{2 \\ Ductilidade}

A ductilidade das misturas foi medida através dos valores de alongamento apresentados pelos corpos de prova durante os ensaios. Os valores obtidos podem ser observados na Figura 34.

Entre a mistura I e II, não foram observadas diferenças estatisticamente significativas nas medidas de alongamento. Já a mistura III, apresentou uma diminuição da ordem de $20 \%$ em relação às misturas anteriores. O valor do alongamento na fratura decresceu de aproximadamente $12 \%$ para cerca de $10 \%$.

Na mistura IV, foi observado um decréscimo dos valores de alongamento, em relação à mistura III. Porém, estatisticamente, esta diferença não foi significativa, dado o nível de confiança utilizado de 95\%, em um teste t de Student. Em relação ao ABS puro (mistura I), o decréscimo observado foi de $25 \%$.

A mistura $\mathrm{V}$, no entanto, apresentou um decréscimo de aproximadamente $20 \%$ em relação à mistura III e de $30 \%$ em relação à mistura I. A diferença para a mistura IV não foi estatisticamente significativa.

A diminuição dos valores encontrados para o alongamento na fratura era esperada, conforme visto em Ning et al. [59], devido a introdução de um material de alta rigidez como a fibra de carbono na matriz polimérica.

\subsection{3}

\section{Módulo de Elasticidade}

A Figura 35 exibe os valores encontrados para o módulo de elasticidade medidos em cada mistura.

O módulo de elasticidade observado para o ABS puro, na mistura I, foi de 2,1 GPa. O valor informado pelo datasheet do material [58] é de 2,3 GPa, estando assim dentro de uma margem aceitável.

$\mathrm{Na}$ mistura II, pôde-se observar um aumento de $27 \%$ no módulo de elasticidade em relação à mistura I. Na mistura III, observa-se um aumento de $9 \%$ em relação à mistura II - saltando de 2,7 GPa para 2,9 GPa. Os valores encontrados para esta baixa \% wt CF estão de acordo com Ning et al. [59], que em seu estudo encontrou valores na mesma ordem de grandeza, porém usando pó de carbono como reforço ao invés de fibras. 


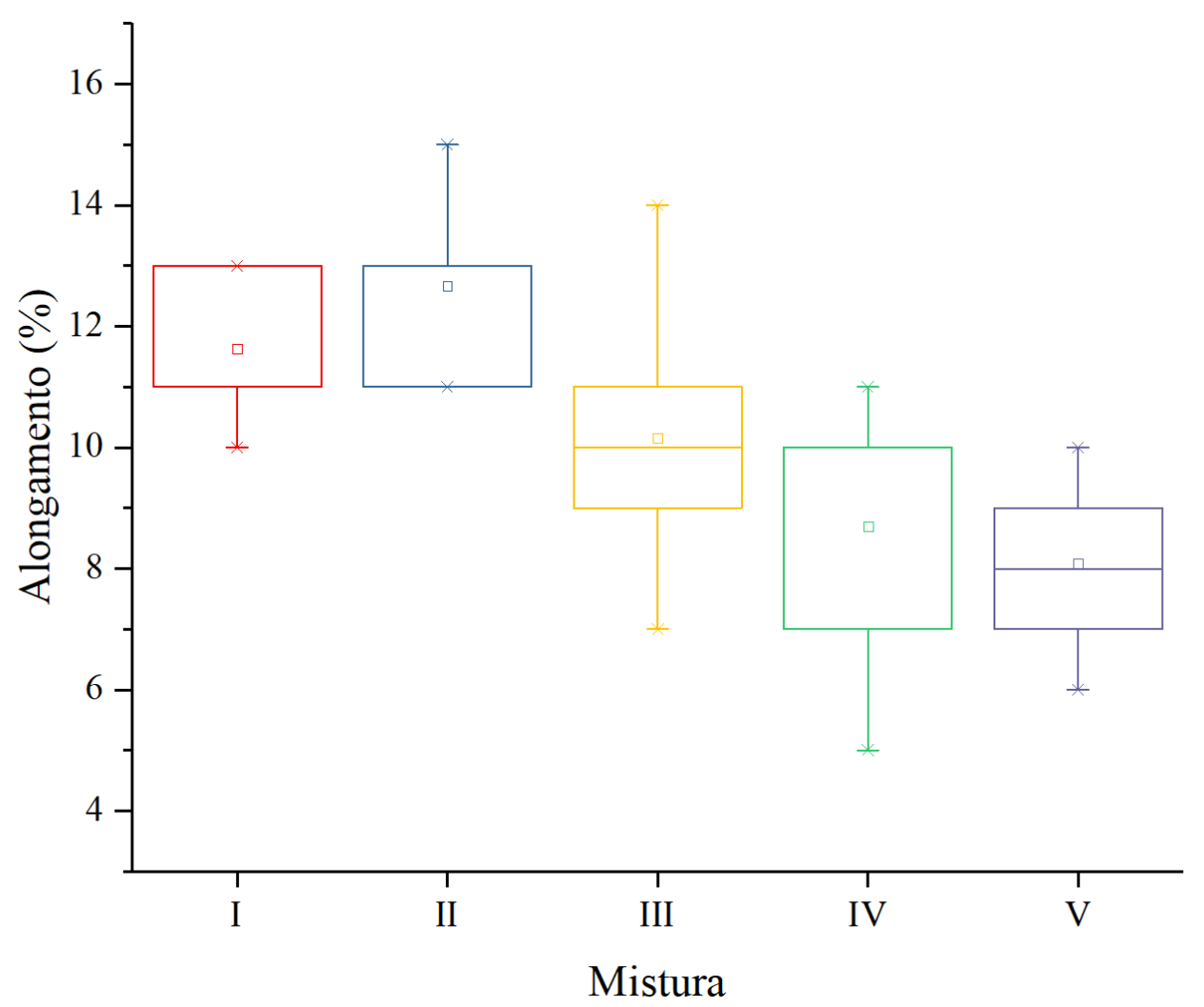

Figura 34: Comparação da ductilidade entre as misturas.

A mistura IV apresentou um aumento de $28 \%$ em relação à mistura III. Isto significa um salto de aproximadamente $78 \%$ em relação ao ABS puro, chegando a 3,7 GPa. Assim como para a resistência à tração, este valor é próximo ao encontrado por Ning et al. [59], porém, abaixo dos valores encontrados por Tekinalp et al. [17], Love et al. [18] e Duty et al. [39], que variam entre 7 e 15 GPa para diferentes \% wt CF.

A mistura $\mathrm{V}$ apresentou um leve decréscimo de menos de $5 \%$ em relação à mistura IV no valor do módulo que, segundo um teste t de Student, com índice de confiabilidade de $95 \%$, é estatisticamente significativo.

\subsection{4}

\section{Influência do Comprimento Inicial das Fibras}

Ao contrário do esperado e visto por Ning et al [59], o comprimento inicial maior de fibras gerou resultados piores (mistura V vs. Mistura IV). Pôde-se notar 
uma diminuição da resistência à tração, módulo de elasticidade e ductilidade dos corpos de prova feitos a partir de fibras inicialmente com $6 \mathrm{~mm}$.

A resistência à tração diminuiu $17 \%$, enquanto o módulo de elasticidade diminuiu aproximadamente 5\%. Apenas a variação da ductilidade não foi estatisticamente significativa.

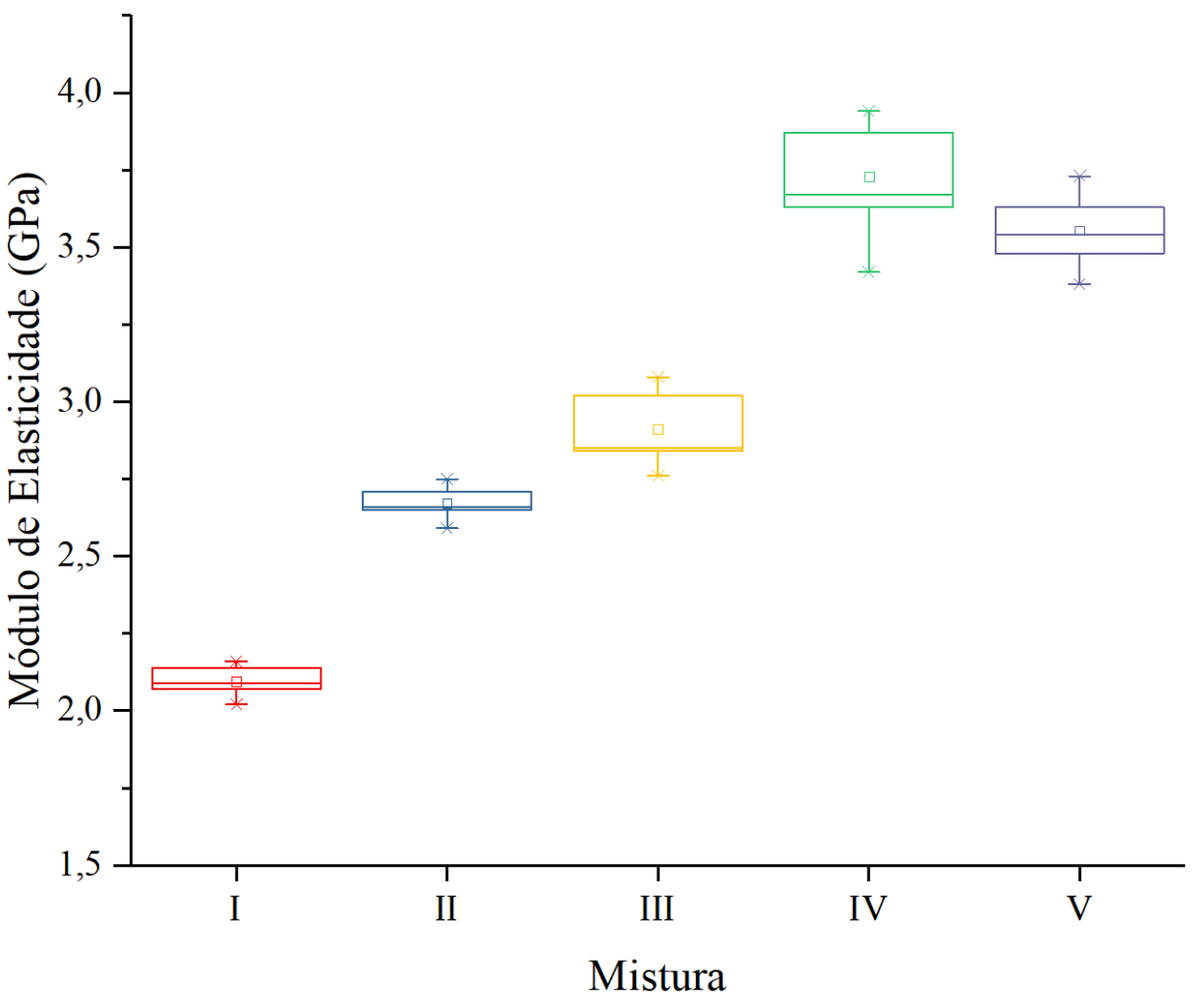

Figura 35: Comparação do módulo de elasticidade entre as misturas.

\section{5}

\section{Microestrutura Resultante}

\subsection{1}

\section{Pellets}

Imagens foram feitas dos pellets produzidos através do processo de extrusão para cada mistura de ABS e fibras de carbono (Misturas II a V).

Na Figura 36, é possível observar a presença de vazios, principalmente na região central dos pellets de todas as misturas. Estes vazios são resultado de bolhas 
de ar que não conseguiram ser eliminadas durante o processamento, possivelmente por gradientes de temperatura durante o resfriamento. Também é possível observar que, à medida em que a \% wt CF aumenta, menores e mais distribuídos são os vazios. Na Figura 37 (a), é possível observar em maior detalhe os vazios presentes na mistura IV.

Nas Figuras 37 (b) e (c) é possível verificar a interação fibra/matriz e a distribuição de fibras ao longo da seção do pellet. A partir da análise das microestruturas é possível notar a presença de pequenos buracos circulares e de espaços vazios ao redor das fibras. Esses aspectos indicam que a interface fibra/matriz é ruim. Isto ocasiona o arrancamento (pull-off) das fibras e uma baixa transferência de carga em matriz e reforço. A distribuição das fibras é razoavelmente uniforme e não há homogeneidade no alinhamento delas em relação a direção de extrusão (perpendicular à superfície do pellet).

Na Figura 37 (d) nota-se a presença de fibras nas regiões de vazios, bem como uma interação entre as próprias fibras. Isto ocorre mais notadamente nas misturas IV e $\mathrm{V}$, devido a maior \% wt $\mathrm{CF}$ e tende a prejudicar as propriedades mecânicas finais do compósito.

A presença de vazios nos pellets está de acordo com o observado em Ning et al. [60]. No trabalho de Ning et al., filamentos para manufatura aditiva foram impressos utilizando um processo semelhante à produção dos pellets deste projeto, com 5\% wt CF. Os filamentos observados por Ning et al. [60] apresentaram uma quantidade e disposição de vazios bastante semelhante ao visto nas Figuras 37 (a) e (b). 


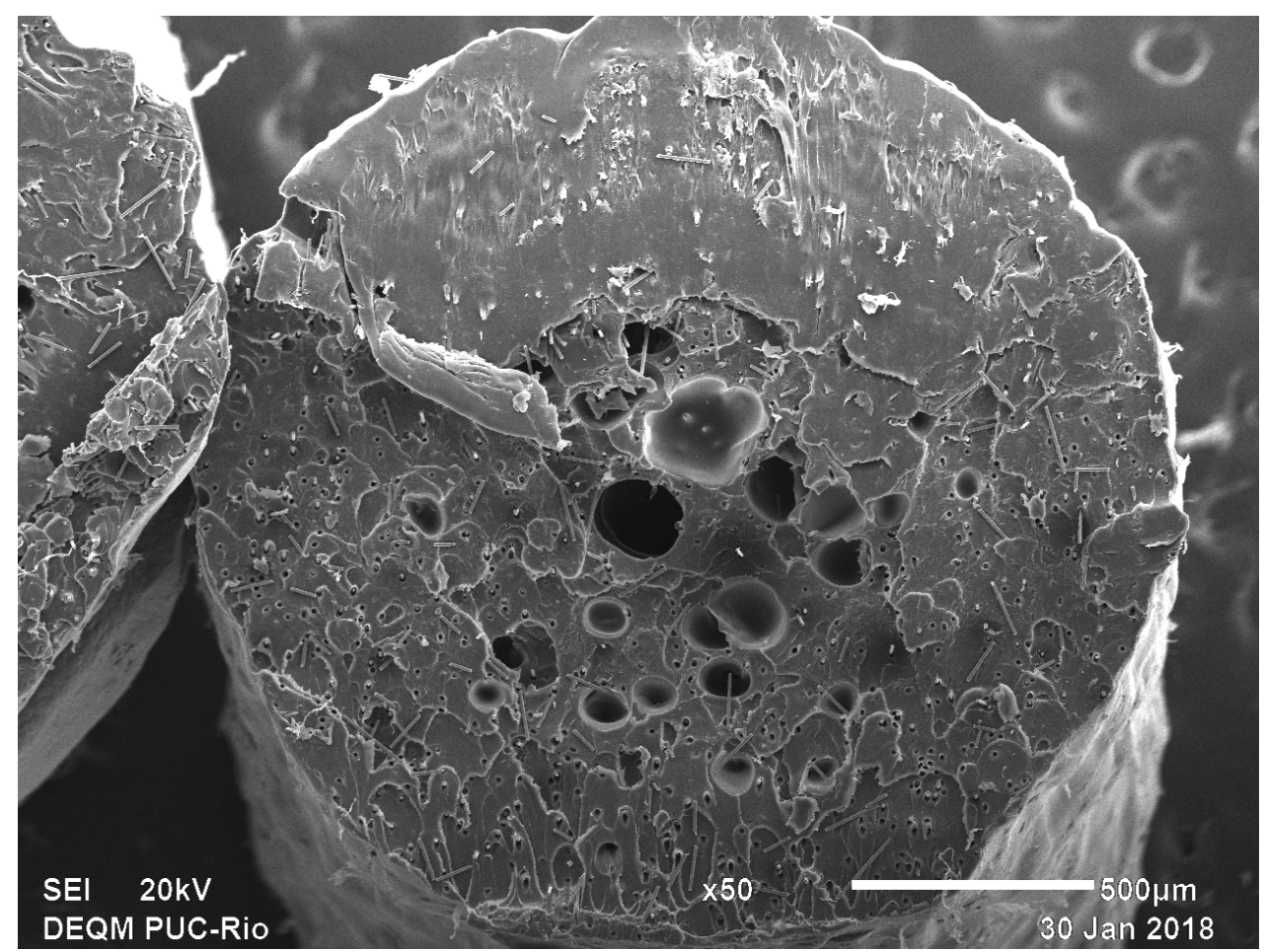

(a)

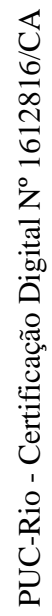

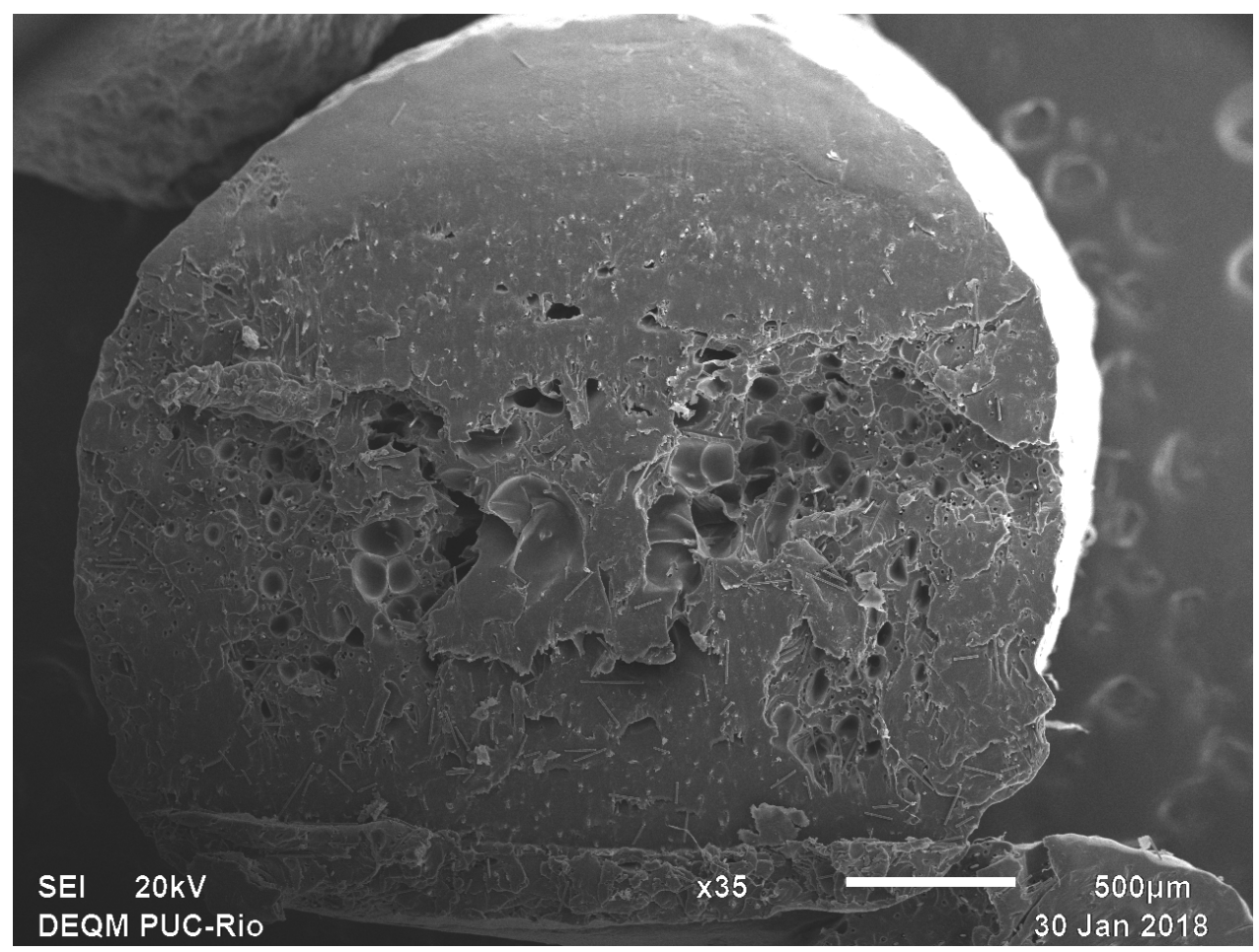

(b) 


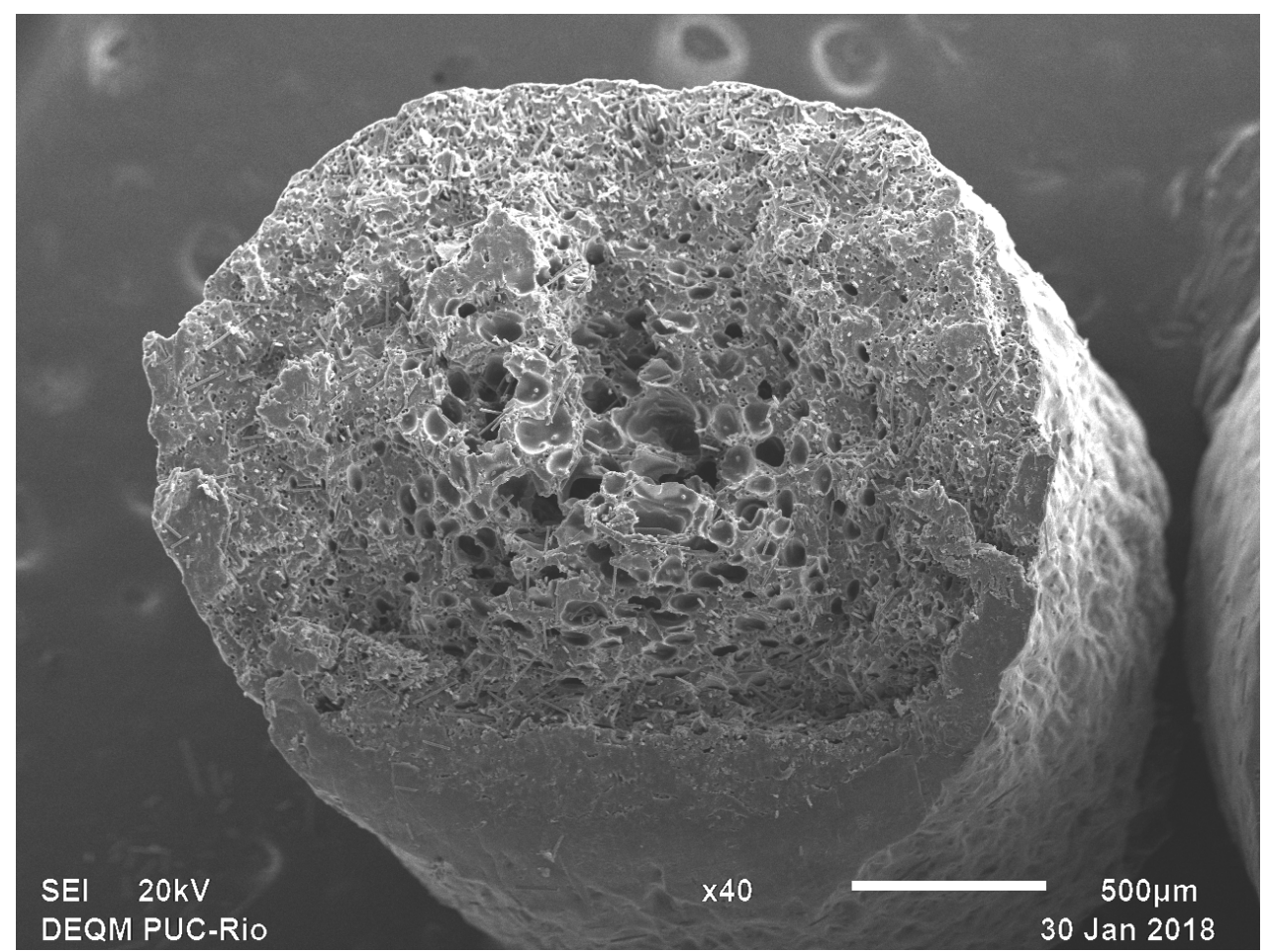

(c)

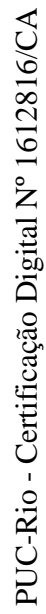

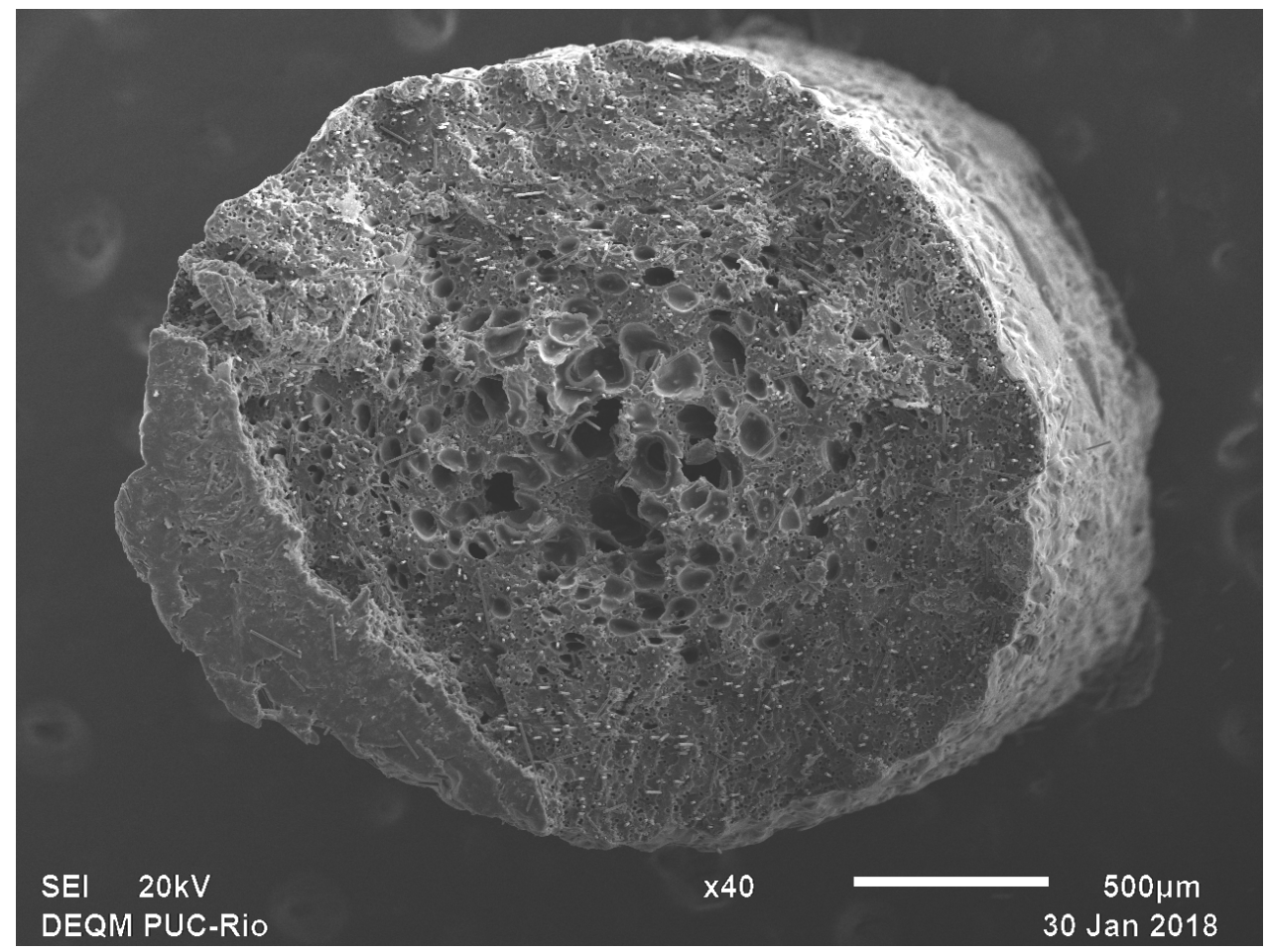

(d)

Figura 36: Visão geral da superfície dos pellets da mistura (a) II; (b) III; (c) IV; (d) V. 


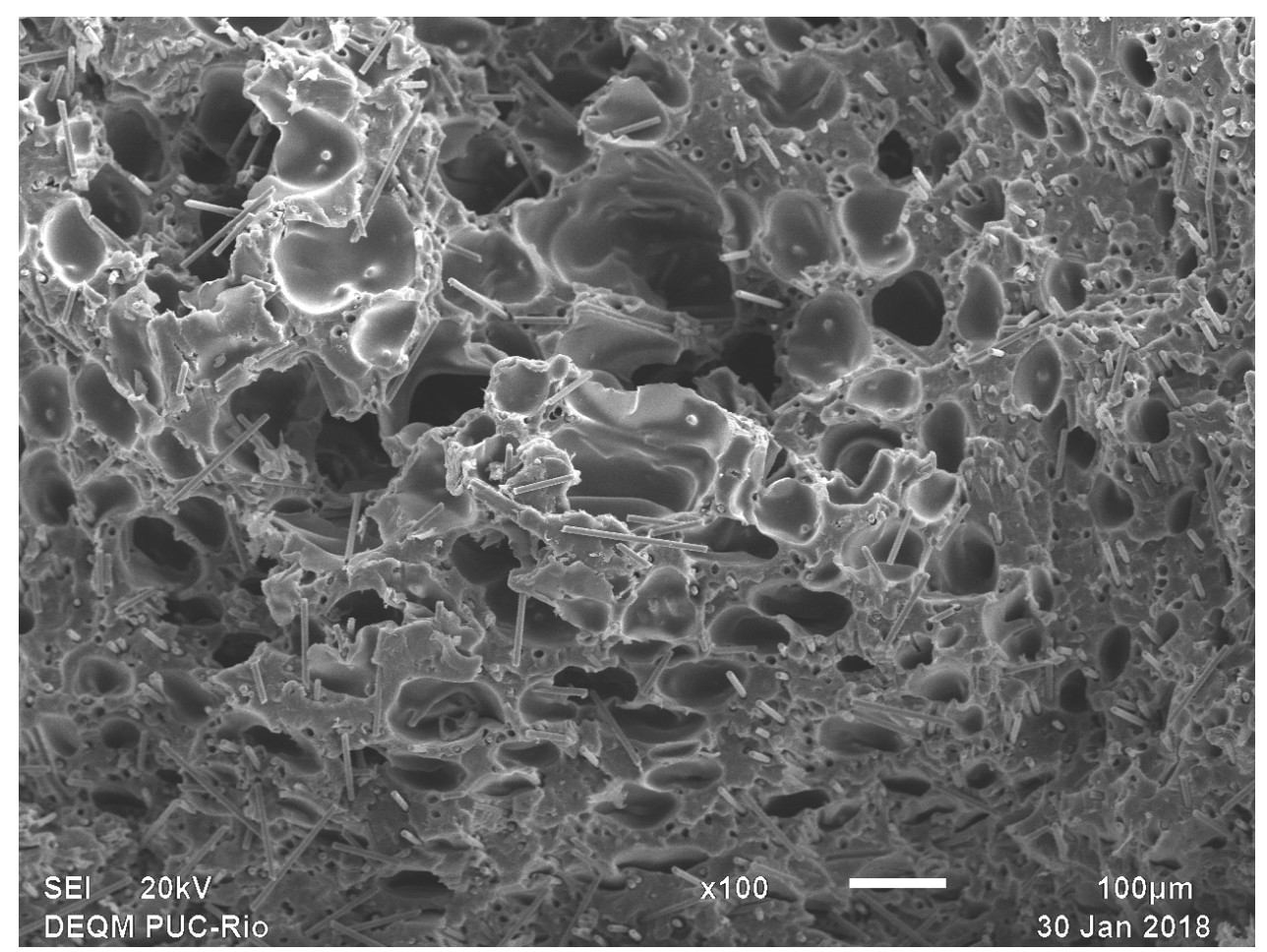

(a)

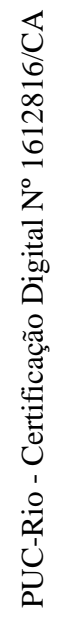

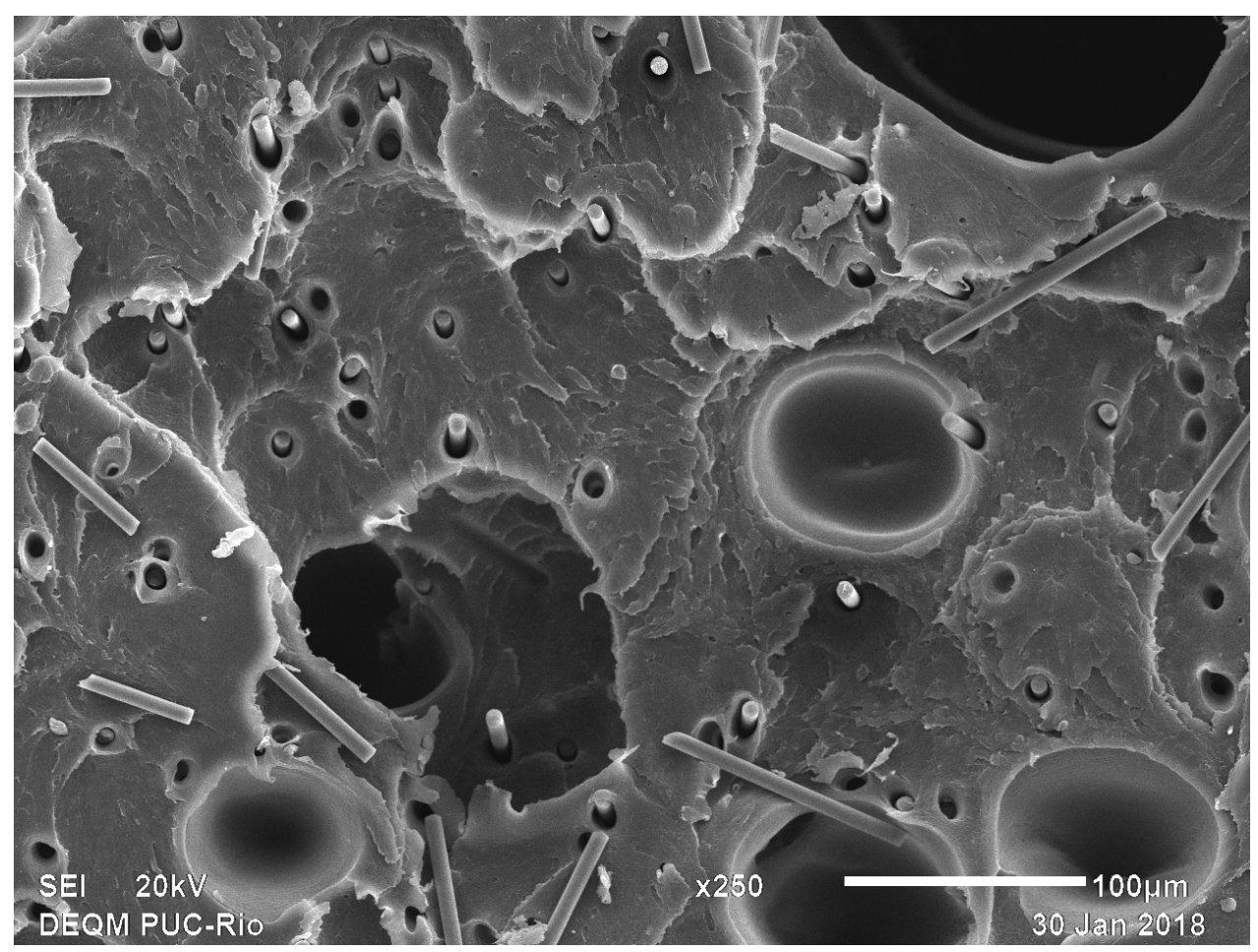

(b) 


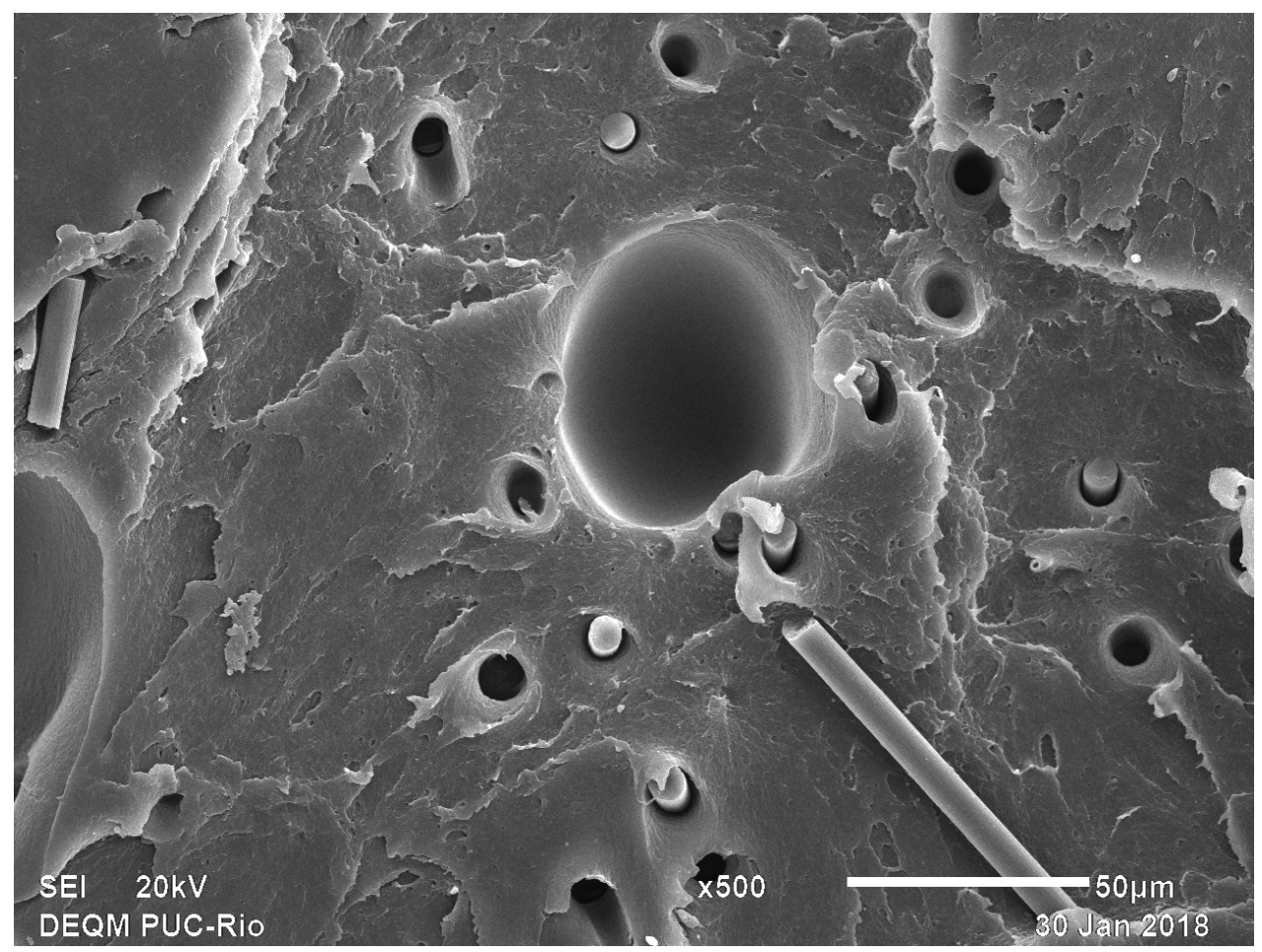

(c)

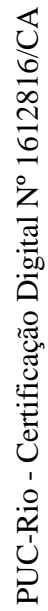

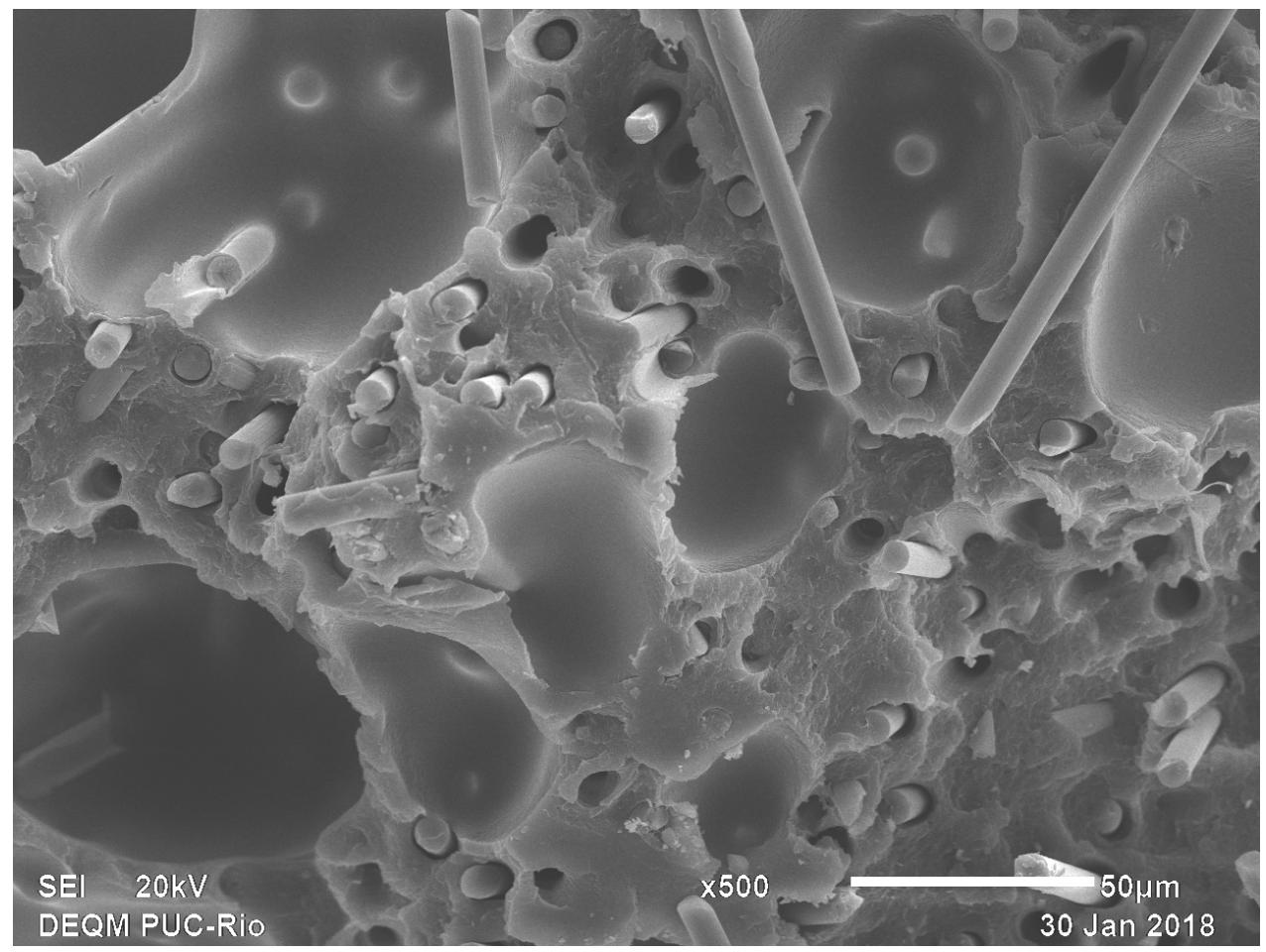

(d)

Figura 37: (a) Vazios na região central da mistura IV; (b) \& (c) Vazios e fibras com fraca interface na mistura II; (d) Fibras dentro de vazios e interação entre fibras na mistura V. 


\subsection{2}

\section{Superfícies de Fratura}

Após os ensaios mecânicos, as misturas de I a V também foram analisadas no MEV. Utilizando baixo aumento (Figura 38), é possível observar que nenhuma das amostras possui os vazios vistos nos pellets. O novo processo de extrusão eliminou qualquer ar retido na estrutura do material, ao contrário do visto em Ning et al. [60], onde os vazios permaneceram na estrutura do material, mesmo após extrudados através do processo de impressão 3D FDM (Fused Deposition Modelling).

Ainda em baixo aumento, pode-se notar que, ao introduzir as fibras de carbono, o processo de fratura do material é alterado. No ABS puro, Figura 38 (a) e 39 (a), pode-se observar uma região bastante evidente de iniciação de fratura $(\rightarrow)$. Nas outras amostras, não é possível observar apenas um sítio de iniciação da fratura, que parece ocorrer de forma menos localizada.

Em aumentos maiores, percebe-se que a fraca interface entre fibra e matriz se mantém, bem como a distribuição razoavelmente aleatória das fibras dentro do compósito. A fraca interface é evidenciada nas Figuras 39 (b) e (c), onde é possível observar que o arrancamento da fibra não ocasionou perda de material polimérico. Ou seja, a adesão entre fibra e matriz é fraca. A distribuição aleatória das fibras é evidenciada na Figura 39 (d).

Para as amostras IV e V, que possuem uma maior \% wt CF, é possível observar o aumento de interações entre fibras, Figura 39 (e). 


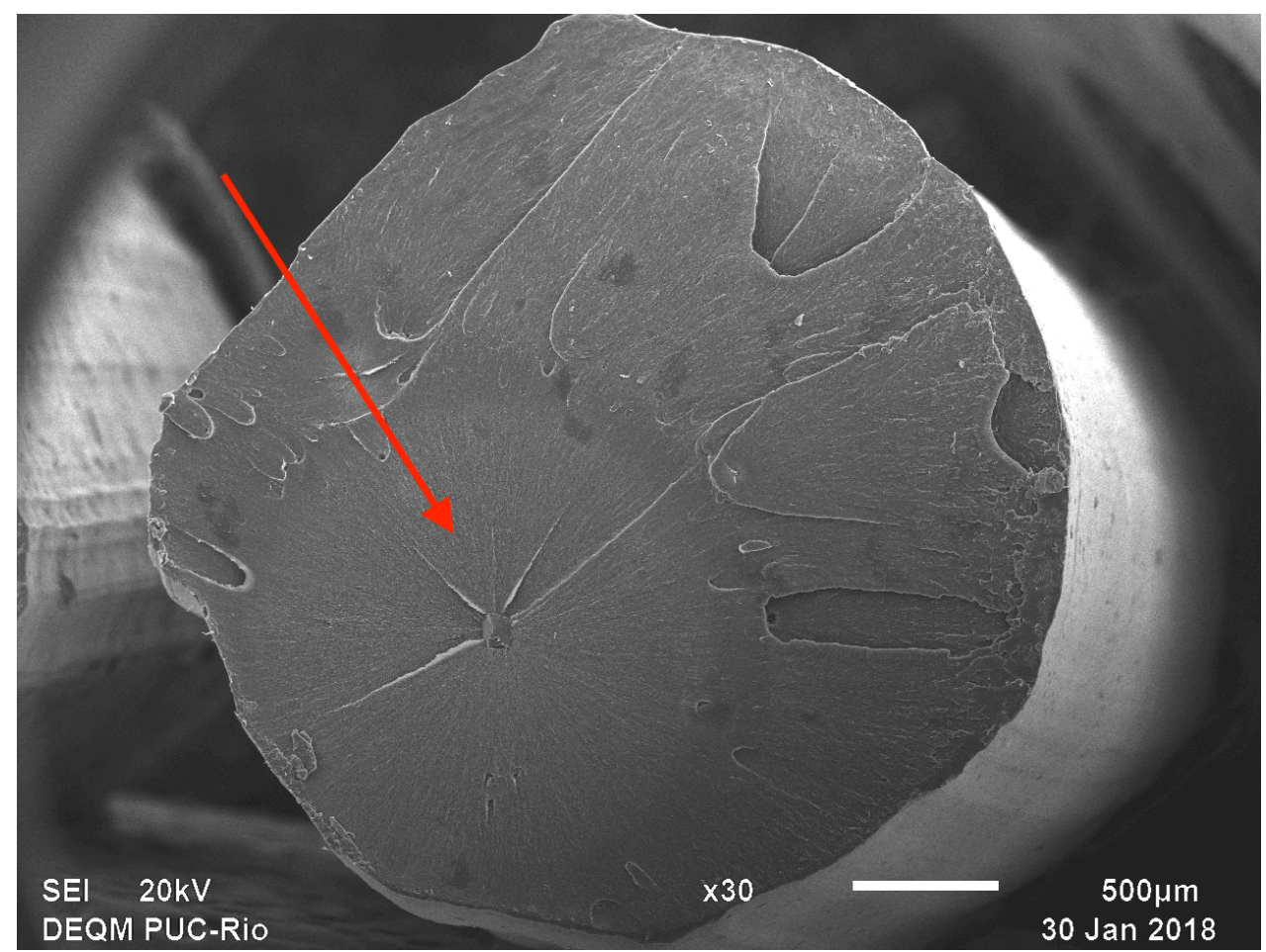

(a)

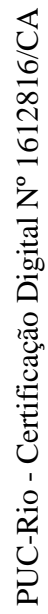

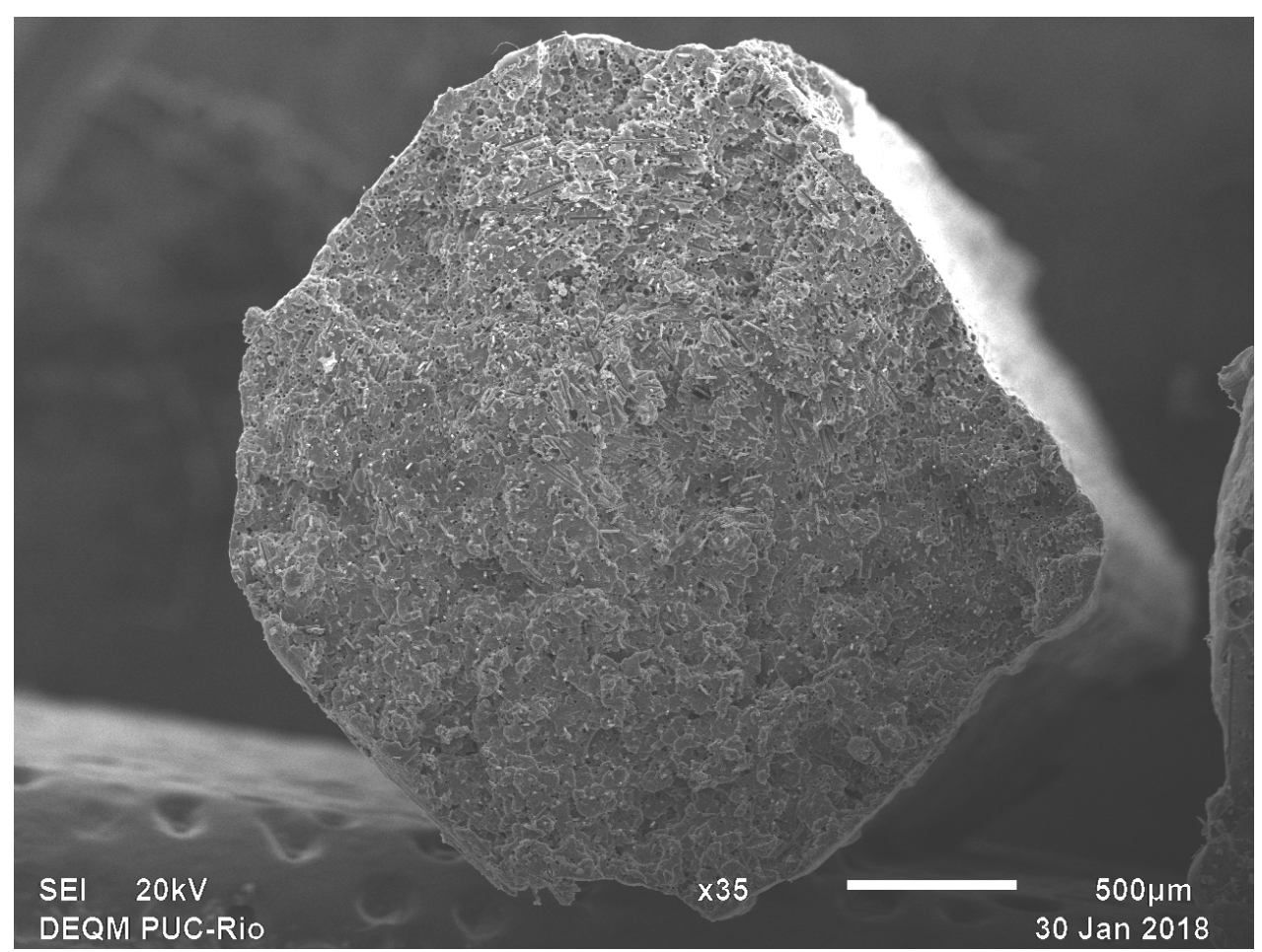

(b) 


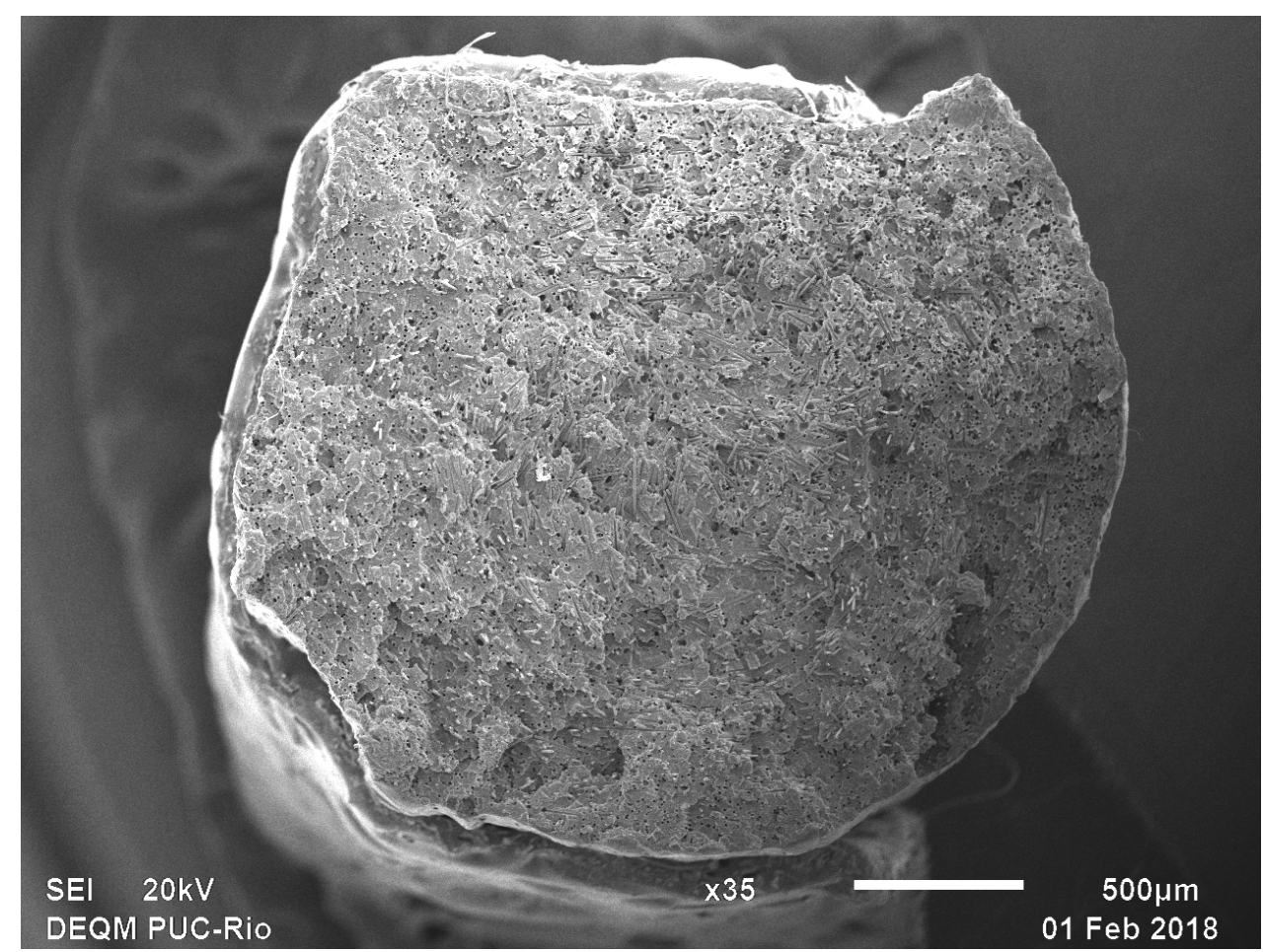

(c)

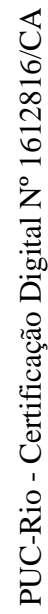

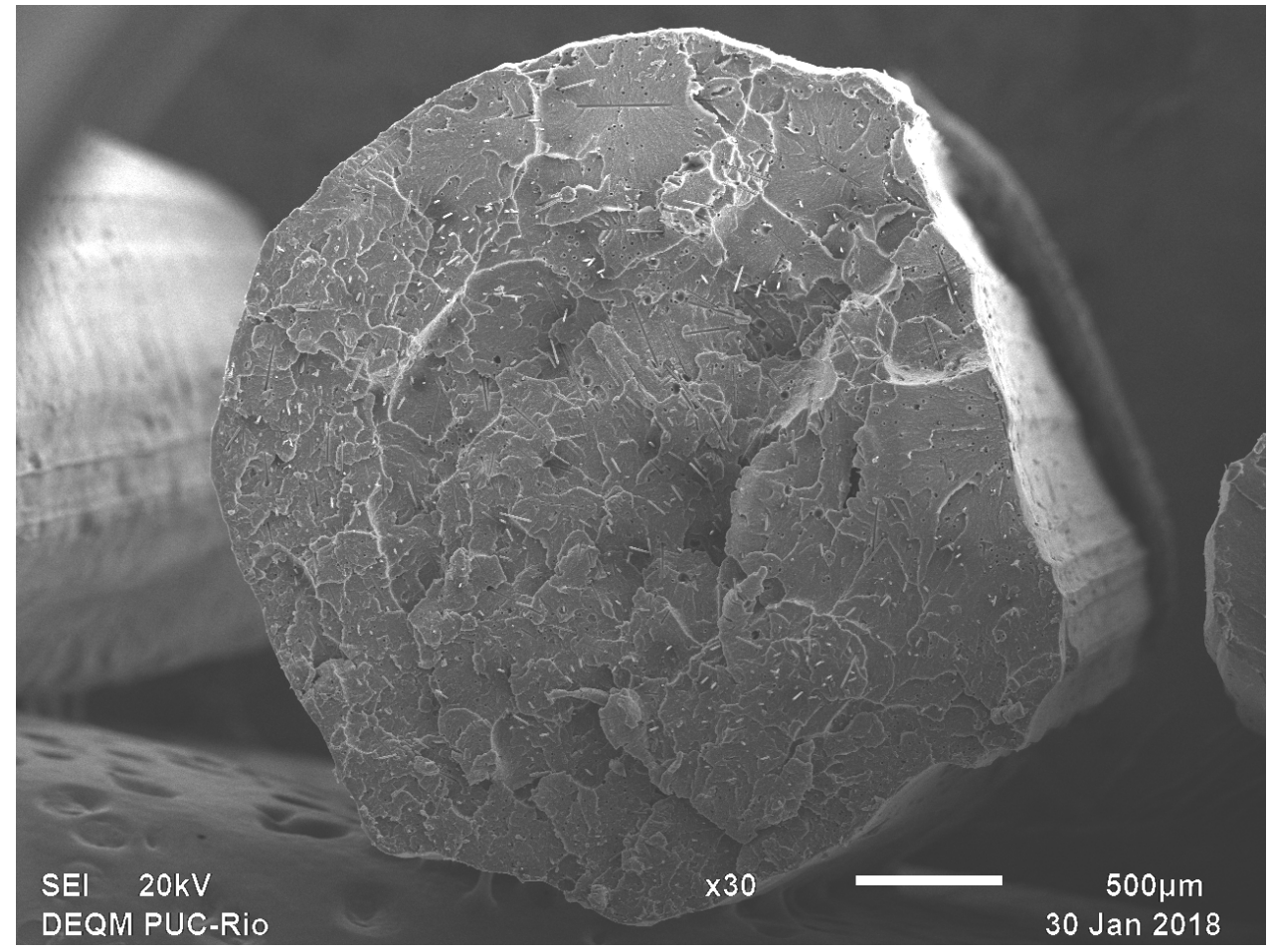

(d) 


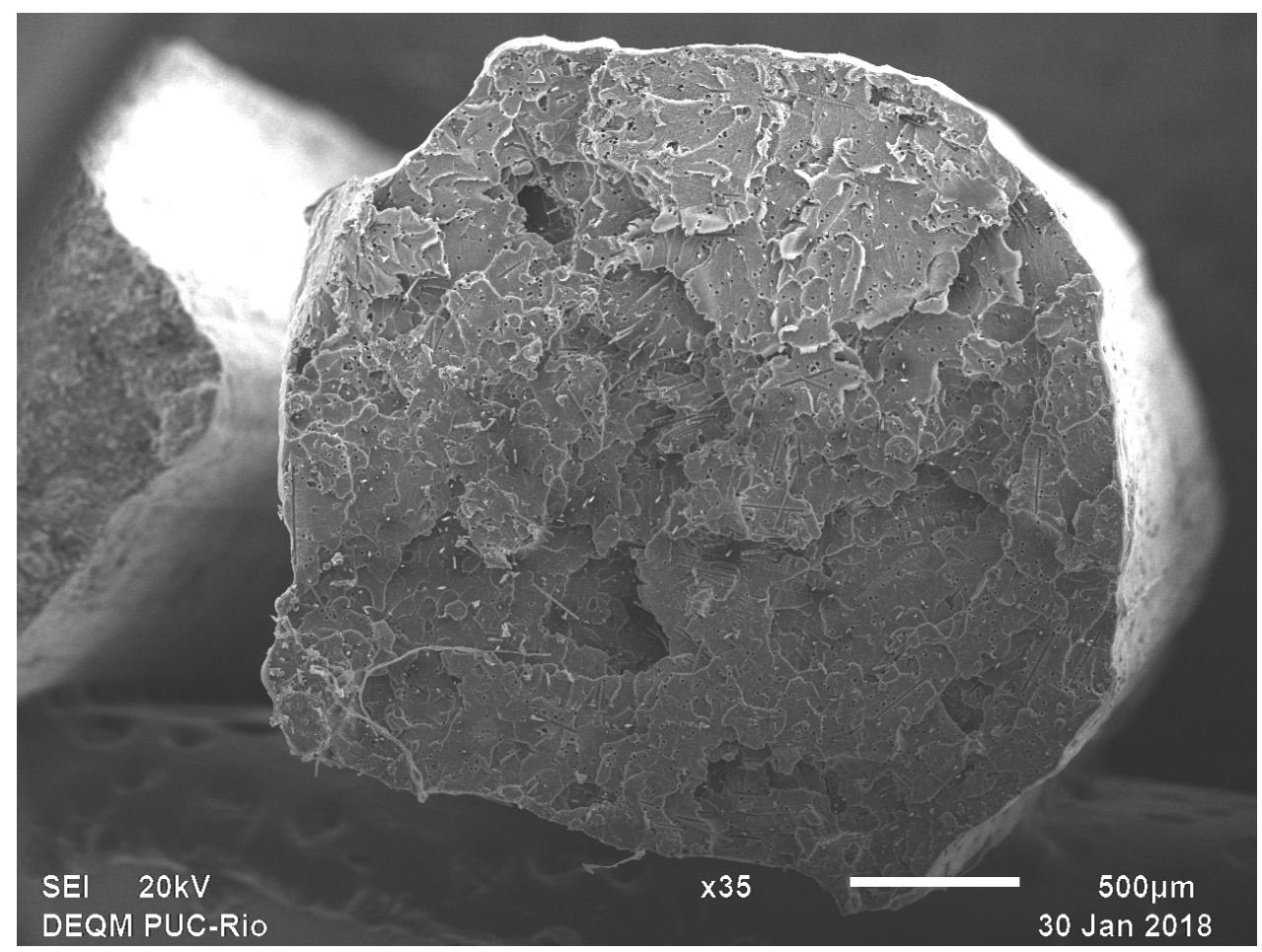

(e)

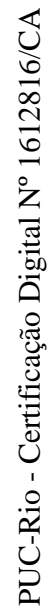

Figura 38: Superfície de fratura das misturas (a) I; (b) II; (c) III; (d) IV; (e)V.



(a) 


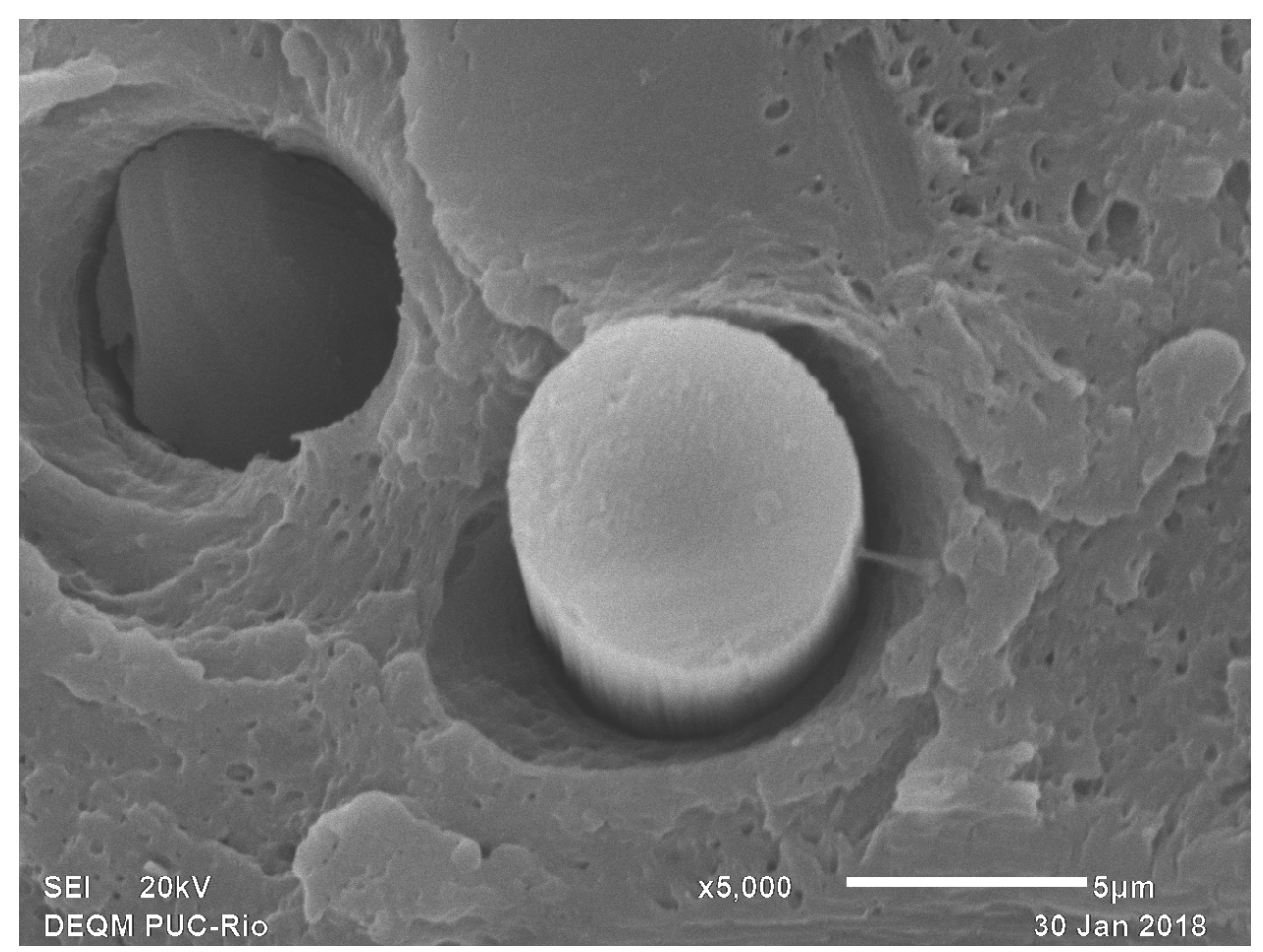

(b)

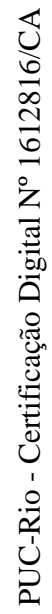

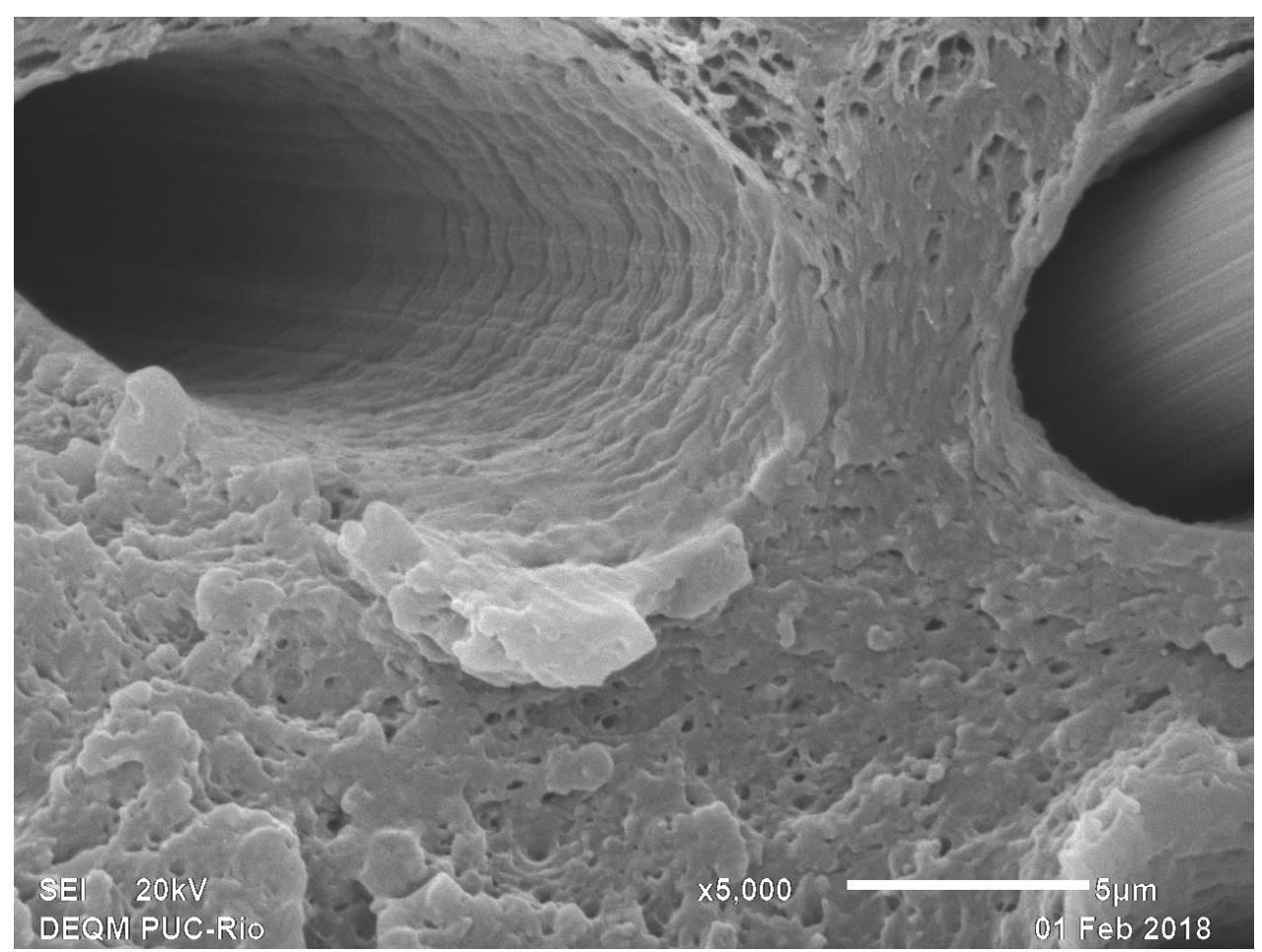

(c) 


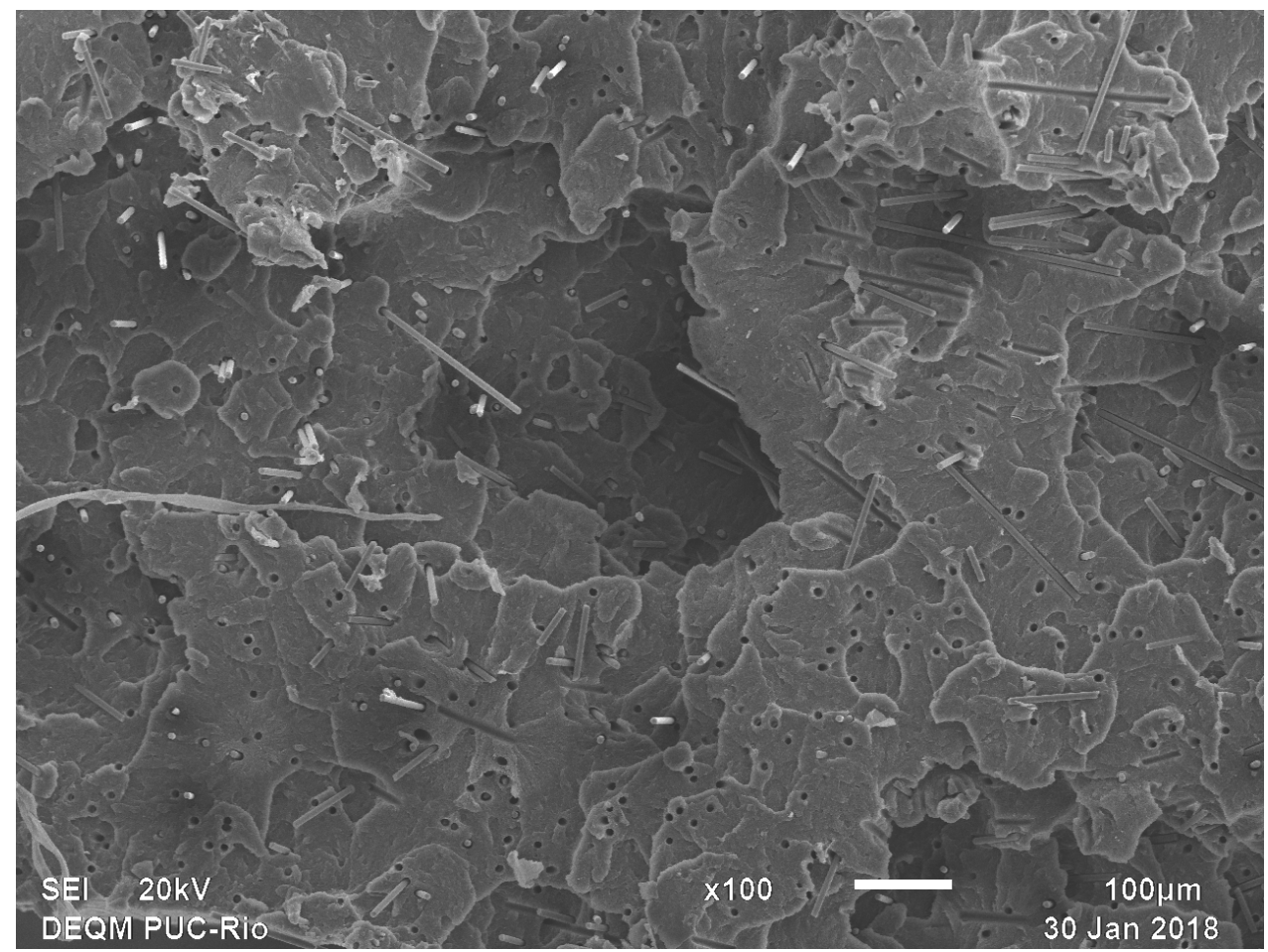

(d)

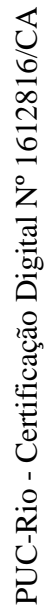

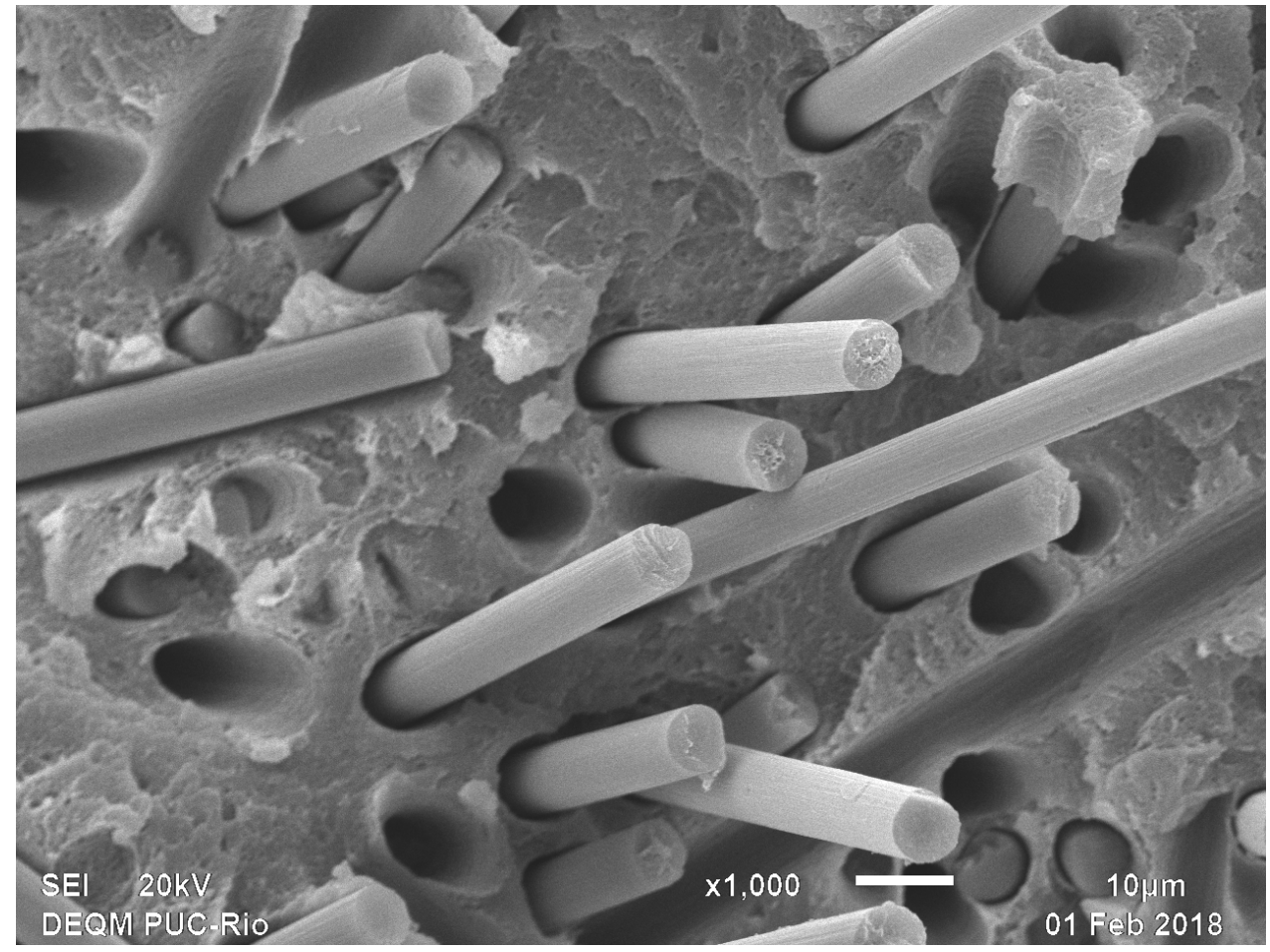

(e)

Figura 39: (a) ponto inicial da fratura - mistura I; (b) fibra arrancada - mistura IV; (c) buraco deixado por fibra arrancada - mistura V; (d) fibras desalinhadas - mistura III; (e) interação entre fibras - mistura V. 


\section{6 \\ Conclusões}

\subsection{1}

\section{Comportamento Mecânico}

I) A adição de fibras de carbono ao ABS, influencia principalmente no módulo de elasticidade e na ductilidade. Os efeitos sobre a resistência à tração podem estar relacionados com a falta de um padrão claro de distribuição e alinhamento das fibras na microestrutura do compósito. Outros fatores que afetam as propriedades mecânicas de um modo geral são a fraca interface entre fibras e matriz, que prejudica a transferência de carga, e a interação entre fibras que causa danos ao reforço do compósito.

II) O comprimento inicial das fibras tem um papel menor do que o esperado nas propriedades mecânicas do compósito, sendo mais influente na diminuição da ductilidade. O comprimento final das fibras, após o processamento, ainda deve ser investigado;

III) Os valores encontrados para o módulo de elasticidade estão em acordo com os valores reportados na literatura para compósitos semelhantes, indicando que o processamento empregado foi adequado.

\subsection{2}

\section{Propriedades do Compósito}

I) A adição de fibras de carbono pouco influencia na viscosidade do compósito, mantendo-se próxima à viscosidade do ABS puro;

II) A presença das fibras não impacta significativamente na degradação da matriz polimérica;

III) As fibras de carbono influenciam na estabilidade térmica do compósito, aumentando a energia de ativação. Porém, a presença do óleo de semente de uva usado no processamento parece também influenciar na estabilidade diminuindo a energia de ativação;

IV) A baixa influência das fibras de carbono nas propriedades reológicas e térmicas do compósito tem relação com a fraca interface entre fibras e matriz verificada nas imagens da MEV. 


\subsection{3}

\section{Processamento do Material}

I) O óleo de semente de uva ajuda no processamento das misturas de pellets e fibras de carbono. Sua influência, porém, nas propriedades mecânicas ainda deve ser determinada;

II) Quanto maior o volume processado, bem como a quantidade de $\% \mathrm{wt}$ de fibras, menores são as perdas de fração de fibras no processamento;

III) Durante o processamento, pode ocorrer um processo de degradação do ABS, mesmo trabalhando dentro das faixas de temperatura estipuladas pelo fabricante.

\subsection{4}

\section{Considerações finais}

O procedimento experimental utilizado neste projeto é baseado em pesquisas em andamento, porém, em grande parte, inédito. Assim como as pesquisas nas quais se baseia, este projeto tem como objetivo maior estabelecer uma base para o desenvolvimento de materiais e processos que permitam a maior utilização de compósitos termoplásticos reforçados na indústria, sobretudo em técnicas de manufatura aditiva (MA).

Nas técnicas de MA que utilizam extrusão e deposição de polímeros, a melhoria das propriedades mecânicas dos materiais utilizados é fundamental para o seu desenvolvimento. O aumento verificado no módulo de elasticidade, que é importante para a integridade estrutural dos componentes produzidos, é um forte indicativo de que a utilização de compósitos é uma alternativa viável para o futuro da MA.

A partir dos dados levantados e desafios descobertos, este é apenas o passo inicial de uma pesquisa que visa aumentar o horizonte de possibilidades dos materiais compósitos de matriz termoplástica e da manufatura aditiva simultaneamente. 


\section{5 \\ Desenvolvimentos Futuros}

Partindo-se dos resultados experimentais deste projeto, é possível identificar algumas áreas de desenvolvimento para este tipo de compósito termoplástico. $\mathrm{O}$ objetivo deste capítulo é propor investigações futuras, bem como áreas de pesquisa e tecnologias do estado da arte, em que este tipo de material apresenta grande potencial.

\section{1}

\section{Melhoria das Propriedades}

Apesar de a introdução de fibras ao ABS ter resultado em aumentos consideráveis na rigidez do material, algumas investigações e desenvolvimentos ainda se fazem necessários, tais como:

- Melhorias na interface entre fibra e matriz;

- Um estudo maior sobre a influência das fibras de carbono na resistência à tração;

- Análise por micro tomografia computadorizada (MicroCT) para verificar o alinhamento, distribuição e comprimento final das fibras no compósito;

- Influência de aditivos de processo, tais como o óleo de semente de uva utilizado neste projeto, nas propriedades finais do compósito;

- Investigação mais detalhada sobre os efeitos dos parâmetros de processamento nas características finais do compósito;

\section{2}

Novos Polímeros como Matriz

A utilização de outros materiais poliméricos como matriz permite desenvolver novos compostos com aplicações mais específicas, tais como:

- Resistência a altas pressões e temperaturas;

- Resistência à abrasão e impacto;

- Propriedades inteligentes como memória de forma, regeneração e cura seletiva [61]. 


\section{3 \\ Reciclagem}

Desde a produção de matéria prima, manufatura, uso e descarte, todas as etapas pelos quais um material passa, consomem energia, que pode ser associada a um custo - seja ele financeiro ou sócio-ambiental (ou ambos). Materiais compósitos, por conta de sua favorável relação entre peso e capacidade estrutural, são uma forma bastante eficaz de reduzir-se o custo energético através da diminuição do peso de estruturas.

Os compósitos termoplásticos representam um grande potencial para a diminuição do consumo de energia ao final do ciclo de vida útil de componentes. Estes compósitos, devido à natureza termoplástica de suas matrizes, são de fácil reprocessabilidade, o que torna os processos de reciclagem menos onerosos quando comparados a metais e compósitos de matriz termorrígida.

Pesquisas que avaliam o consumo de energia durante todo o ciclo de vida de componentes produzidos com compósitos [62] e que avaliam a reciclabilidade de compósitos termoplásticos [38] já estão em andamento. O desenvolvimento destas pesquisas pode tornar este tipo de material mais rentável para a indústria e mais sustentável para o meio ambiente.

\section{4 \\ Manufatura Aditiva em Grande Escala}

A manufatura aditiva (MA) em larga escala representa um enorme potencial para revolucionar a indústria, sobretudo os setores que utilizam materiais compósitos como matéria prima. A MA se apresenta como uma forma muito eficaz de automatizar um processo que, tradicionalmente, ocorre de forma bastante manual - quase artesanal, ao mesmo tempo em que permite, pelas características do processo construtivo da impressão 3D, uma variedade de formas e aplicações nunca antes possível.

O aumento da escala do processo é um passo fundamental para a viabilidade econômica e industrial da manufatura aditiva. Porém, para que a MA em larga escala se torne uma realidade industrial, é necessário que haja um maior desenvolvimento, sobretudo, dos materiais utilizados. Recentemente, este tem sido o foco de muitas pesquisas pioneiras, mais notadamente as do Oak Ridge National 
Laboratory (ORNL) [17, 18, 39, 63-65]. Estes estudos visam entender os efeitos da adição de fibras de carbono em polímeros termoplásticos comumente utilizados em impressão 3D.

Os principais desenvolvimentos, desafios e aplicações da manufatura aditiva e da manufatura aditiva em larga escala estão dispostos no Anexo I. 
6

\section{Referências bibliográficas}

1. M. F. ASHBY, F. R. S. Technology of the 1990's: advanced materials and predictive design. Philosofical Transactions of The Royal Society of London, London, v. 322, n. 1567, p. 393-407, 27 July 1987. ISSN 1471-2962.

2. SCALABRE, $O$. The next manufacturing revolution is here. TED Talks. Paris: [s.n.]. 2016.

3. GIBSON, R. F. Principle of Composite Material Mechanics. 4th. ed. Boca Raton: CRC Press, 2016.

4. FERABOLI, P. et al. Defect and damage analysis of advanced discontinuous carbon/epoxy composite materials. Composites, v. Part A, p. 888-901, July 2010 .

5. FERABOLI, P. et al. Stochastic laminate analogy for simulating the variability in modulus of discontinuous composite materials. Composites, v. Part A, p. 557-570, April 2010.

6. FERABOLI, P. et al. Modulus Measurement for Prepreg-based Discontinuous Carbon Fiber/Epoxy Systems. Journal of Composite Materials, v. 43, n. 19/2009, p. 1947-1965, August 2009.

7. FERABOLI, P. et al. Lamborghini Forged Composite technology for the suspension arms of the Sesto Elemento. ASC Conference. Montreal: American Society for Composites. 2011. p. 1012-1036.

8. FERABOLI, P. et al. Notched behavior of prepreg-based discontinuous carbon fiber/epoxy systems. Composites, v. Part A, n. 40, p. 289-299, March 2009.

9. FERABOLI, P. et al. Characterization of Prepreg-Based Discontinuous Carbon Fiber/Epoxy Systems. Journal of Reinforced Plastics and Composites, v. 28, n. 10/2009, p. 1191-1214, May 2008.

10. BARNES, F. Recycled carbon fiber: Its time has come. CompositesWorld/Columns, 29 June 2016. Disponivel em: $<$ https://www.compositesworld.com/columns/recycled-carbon-fiber-its-timehas-come->. Acesso em: 12 January 2018.

11. BERARDINE, R. C. Advanced Composites Fundamentals Seminar: "From Carbon Fiber to Carbon Fiber Reinforced Thermoplastic". III Congresso SAMPE Brasil. Rio Grande do Sul: SAMPE Brasil. 2015.

12. LIMA, G. Inovação e criatividade no mundo dos compósitos. ALMACO. São Paulo, p. 54. 2017.

13. GOSS, T. M. Panorama e Perspectivas da Indústria Brasileira de Compósitos. Universidade Federal do Rio Grande do Sul. Porto Alegre, p. 38. 2010.

14. BLACK, S. Thermoplastic composites technology: A view from Europe. CompositesWorld, 1 jun. 2016. Disponivel em: $<$ https://www.compositesworld.com/articles/thermoplastic-compositestechnology-a-view-from-europe >. Acesso em: 11 January 2018.

15. THERMOPLASTIC COMPOSITES RESEARCH CENTER. About TPRC. Thermoplastic Composites Research Center Web site, 2018. Disponivel em: <https://tprc.nl/>. Acesso em: 12 January 2018. 
16. THERMOPLASTIC AFFORDABLE PRIMARY AIRCRAFT STRUCTURE CONSORTIUM. About Us. TAPAS Web site, 2018. Disponivel em: $<$ http://www.tapasproject.nl/en/about-us $>$. Acesso em: 12 January 2018.

17. TEKINALP, H. L. et al. Highly oriented carbon fiber-polymer composites via additive manufacturing. Composites Science and Technology, v. 105, p. 144150, 16 Oct 2014.

18. LOVE, L. J. et al. The importance of carbon fiber to polymer additive manufacturing. J. Mater. Res., v. 29, n. 17, 14 Sep 2014.

19. CHAMBON, P. et al. Development of a range-extended electric vehicle powertrain for an integrated energy systems research printed utility vehicle. Applied Energy, 15 January 2017. 99-110.

20. LOVE, L. J. Utility of Big Area Additive Manufacturing (BAAM) for the Rapid Manufacture of Customized Electric Vehicles. Oak Ridge National Laboratory. Oak Ridge, TN, p. 21. 2014. (TM-2014/607).

21. ORNL, LOCAL MOTORS INC. Advanced Manufacturing of Complex Cyber Mechanical Devices through Community Engagement and Micromanufacturing. Oak Ridge National Laboratory. Oak Ridge, TN, p. 4. 2014. (MDF-TC-2014-040).

22. ORNL, TECHMER ENGINEERED SOLUTIONS. Material Development for Tooling Applications Using Big Area Additive Manufacturing (BAAM). Oak Ridge National Laboratory. Oak Ridge, TN, p. 8. 2015. (MDFTC-2014-053).

23. ORNL, TRU-DESIGN LLC. Evaluation of Additive Manufacturing for Composite Part Molds. Oak Ridge National Laboratory. Oak Ridge, TN, p. 5. 2014. (MDF-TC-2014-042).

24. U.S. DEPARTMENT OF ENERGY. Transforming Wind Turbine Blade Mold Manufacturing. [S.1.], p. 8. 2016. (DOE/GO-102016-4870).

25. LOVE, L. J.; DUTY, C. Cincinnati Big Area Additive Manufacturing (BAAM). Oak Ridge National Laboratory. Oak Ridge, TN. 2015.

26. SUBSEA WORLD NEWS. Airborne to Provide FMECA for Libra TCP Riser. Subsea World News Web site, 16 May 2016. Disponivel em: $<$ https://subseaworldnews.com/2016/05/16/airborne-provides-fmeca-forlibra-tcp-riser/>. Acesso em: 12 January 2018.

27. KREMERS, M. A brief history of Thermpolastic Composite Pipe. Linkedin.com/Pulse, 17 March 2017. Disponivel em: $<$ https://www.linkedin.com/pulse/brief-history-thermoplastic-compositepipe-marcus-kremers $>$. Acesso em: 12 January 2018.

28. THE BOEING COMPANY. One For The Record Books. The Boeing Company website, 26 August 2016. Disponivel em: $<$ http://www.boeing.com/features/2016/08/record-books-08-16.page>. Acesso em: 30 November 2016.

29. MALLICK, P. K. Fiber-Reinforced Composites Materials, Manufacturing and Design. 3rd Edition. ed. Dearborn: CRC Press, 2007. ISBN 13:978-08493-4205-9.

30. William D. CALlister, J. Materials Science and Engineering an Introduction. 7th. ed. Salt Lake City: John Wiley \& Sons, Inc., 2007. 
31. SGL GROUP. Thermoplastic composite materials made from carbon and glass fibers. SGL Group SE. [S.1.]. 2017.

32. TOHO TENAX. Produtos: Fibra de Carbono Tenax. Site da Toho Tenax, 2017. Disponivel em: <http://www.tohotenax.com/pt/produtos/fibra-decarbono-tenax\%C2\%AE/>. Acesso em: 25 Março 2017.

33. QUANTUM COMPOSITES. Products: AMC. Quantum Composites Web site, $2017 . \quad$ Disponivel em: $<$ http://www.quantumcomposites.com/images/products/large/AMC8593.jpg>. Acesso em: 26 abr. 2017.

34. LOPES, B. J. Avaliação da Integridade Estrutural de Pultrudados de Fibra de Vidro após Exposição a Incêndios. Universidade do Estado do Rio de Janeiro. Rio de Janeiro, p. 77. 2015.

35. CHANG, I. Y.; LEES, J.. Recent Development in Thermoplastic Composites: A Review of Matrix Systems and Processing Methods. Journal of Thermoplastic Composite Materials, v. 1, n. 3, p. 277-296, 1988.

36. RAYNAL, J. Fast RTM: A evolução de um processo. Institut de Soudure Groupe. São Paulo, p. 48. 2017.

37. FERNÁNDEZ, I.; BLAS, F.; FRÖVEL, M. Autoclave forming of thermoplastic composite parts. Journal of Materials Processing Technology, Madrid, n. 143-144, p. 266-269, December 2003.

38. MCCOOL, R. et al. Thermoforming carbon fibre-reinforced thermoplastic composites. Proceedings of the Institution of Mechanical Engineers, Part L: Journal of Materials: Design and Applications. Belfast: IMechE. 2012. p. 91102.

39. DUTY, C. E. et al. Structure and mechanical behavior of Big Area Additive Manufacturing (BAAM) materials. Rapid Prototyping Journal, v. 23, n. 1, p. 181-189, January 2017. ISSN ISSN 1355-2546.

40. JONES, R. M. Mechanics of Composite Materials. 2nd Edition. ed. Blacksburg: Taylor \& Francis, Inc, 1999.

41. MORTIMER, S.; SMITH, M. J.; OLK, E. Product Development for Out-ofAutoclave (OOA) Manufacture of Aerospace Structures. Hexcel Corporation. Duxford, p. 17. 2010.

42. MOORE, J. D. Acrylonitrile-butadiene-styrene (ABS) - a review. Composites, May 1973.

43. INEOS STYROLUTION. Terluran GP-35 Technical Datasheet. INEOS Styrolution. [S.1.], p. 3. 2016.

44. BASF CORPORATION. Ultramid 8202 HS Polyamide 6 Product Information. BASF Corporation. Wyandotte, MI, p. 3. 2018.

45. ULTIMAKER. Technical data sheet - Ultimaker PLA. Ultimaker. [S.1.], p. 5. 2017.

46. PAOLI, M.-A. D. Degradação e Estabilização de Polímeros. Segunda versão online. ed. São Paulo: Artliber, 2008.

47. THERMO FISHER SCIENTIFIC. FTIR Basics. Thermo Fischer Scientific Web site, 2017. Disponivel em: $<$ http://www.thermofisher.com/br/en/home/industrial/spectroscopyelemental-isotope-analysis/spectroscopy-elemental-isotope-analysis-learning- 
center/molecular-spectroscopy-information/ftir-information/ftir-basics.html>. Acesso em: 13 November 2017.

48. FISCHER, G.; LÜDERWALD, I.; OTTENBREIT, P. Characterization of Acrylonitrile-Butadiene-Styrene Terpolymers by Computer Aided FT-IR Spectroscopy. Die Angewandte Makromolekulare Chemie, Basel, v. 149, n. 2444, p. 179-187, 1987. ISSN 0003-3146/8.

49. NOVOA, D. M. C. Avaliação físico-química do polietileno de alta densidade processado pelo método de impressão 3D por modelagem por fusão e deposição FDM. PUC-Rio. Rio de Janeiro, p. 100. 2014. $(1212416 / \mathrm{CB})$.

50. SANTOS, R. M.; BOTELHO, G.; MACHADO, A. V. Avaliação da fotodegradação de ABS exposto a condições naturais. Ciência \& Tecnologia dos Materiais, Lisboa, v. 22, n. 1-2, p. 87-90, Junho 2010. ISSN ISSN 08708312 .

51. FREIRE, I. D. S. Reologia escoamento e deformação da matéria. Serviço Brasileiro de Respostas Técnicas. [S.1.], p. 23. 2012.

52. WINTER, H. H. Rheometry with Capillary Rheometers. In: EOLSS Encyclopedia of Life Support Systems (EOLSS). 1st Edition. ed. Paris: UNESCO-Publishers Co Ltd, v. I, 2008. p. 11.

53. PEREIRA, R. G.; BENIRSCHKE, A. Análise do Processamento de Polímeros Utilizando Reometria Capilar. Universidade Federal Fluminense. Niterói, RJ, p. 6.

54. AJINJERU, C. et al. The Influence of Rheology on Melt Processing Conditions of Amorphous Thermoplastics for Big Area Additive Manufacturing (BAAM). Proceedings of the 27th Annual International Solid Freeform Fabrication Symposium - An Additive Manufacturing Conference. Austin, TX: [s.n.]. 2016. p. 754-761.

55. RAMACHANDRAN, V. et al. Handbook of thermal analysis of construction materials. Norwich: Noyes Publications, 2002.

56. HULL, E. et al. Effects of Process Variables on Extrusion of Carbon Fiber Reinforced ABS Filament for Additive Manufacturing. ASME 2015 International Manufacturing Science and Engineering Conference. Charlotte, North Carolina: ASME. 2015. p. MSEC2015-9396.

57. YAO, F. et al. Thermal decomposition kinetics of natural fibers: Activation energy with dynamic thermogravimetric analysis. Polymer Degradation and Stability, v. 93, n. 1, p. 90-98, January 2008. ISSN 0141-3910.

58. YANG, M.-H. The thermal degradation of acrylonitrile-butadiene-styrene terpolymer under various gas conditions. Polymer Testing, v. 19, n. 1, p. 105110, February 2000. ISSN 0142-9418.

59. TA INSTRUMENTS. Thermal Analysis Application Brief: Estimation of Polymer Lifetime by TGA Decomposition Kinetics. TA Instruments. [S.1.], p. 4. (TA-125).

60. FLYNN, J. H.; WALL, L.. A quick, direct method for the determination of activation energy from thermogravimetric data. Polymer Letters, v. 4, n. 5, p. 323-328, May 1966.

61. DOYLE, C. D. Kinetic Analysis of Thermogravimetric Data. Journal of Applied Polymer Science, v. V, n. 15, p. 285-292, May/June 1961. 
62. NING, F. et al. Additive Manufacturing of CFRP Composites Using Fused Deposition Modeling: Effects of Carbon Fiber Content and Length. ASME 2015 International Manufacturing Science and Engineering Conference. Charlotte, North Carolina: ASME. 2015. p. MSEC2015-9436.

63. NING, F. et al. Additive manufacturing of thermoplastic matrix composites using fused deposition modeling: A comparison of two reinforcements. Journal of Composite Materials, v. 51, n. 27, p. 3733-3742, 1 November 2017. ISSN 0021-9983.

64. SZEBÉNYI, G. et al. 3D printing-assisted interphase engineering of polymer composites: Concept and feasibility. eXPRESS Polymer Letters, Budapest, 11, n. 7, 2017. 525-530.

65. SONG, Y. S.; YOUN, J. R.; GUTOWSKI, T. G. Life cycle energy analysis of fiber-reinforced composites. Composites: Part A, v. 40, n. 8, p. 1257-1265, May 2009. ISSN 1359-835X.

66. KISHORE, V. et al. Infrared preheating to improve interlayer strength of big area additive manufacturing (BAAM) components. Additive Manufacturing, 2 December 2016. 7-12.

67. BRENKEN, B. et al. Fused Deposition Modeling of Fiber-Reinforced Thermoplastic Polymers: Past Progress and Future Needs. Proceedings of the Thirty-First Technical Conference of the ASC. Williamsburg: American Society for Composites. 2016.

68. DENARDO, N. M. Additive Manufacturing of Carbon Fiber Reinforced Thermoplastic Composites. Purdue University. West Lafayette, Indiana, p. 183. 2016. (ProQuest 10181531). 


\section{Anexo I \\ Manufatura Aditiva}

\section{A.1 Introdução}

Manufatura aditiva (MA) é o nome dado ao processo que produz um objeto tridimensional camada a camada, a partir de um arquivo gerado digitalmente. Este processo, que também é conhecido como impressão 3D, pode ocorrer de diversas formas e utilizar uma gama bastante variada de materiais. Suas inúmeras vantagens, frente a processos construtivos tradicionais, proporcionam grande versatilidade e aplicabilidade. Porém, algumas limitações ainda existem e impedem uma maior difusão da MA na cadeia produtiva.

No começo dos anos 80, a MA surgiu como uma forma completamente inovadora e disruptiva de construir. A partir de um arquivo produzido digitalmente, seja feito do zero em um software de CAD (Computer-aided Design) ou de um objeto escaneado tridimensionalmente, são geradas camadas (ou, do inglês, slices). Estas camadas representam seções do componente ao longo de um eixo e é a partir delas que o material será depositado, uma camada sobre a outra [AI.1, AI.2].

Os diferentes processos de MA variam em função da forma com que o material é depositado e/ou do próprio material em si. Existem processos que utilizam a sinterização de matéria prima em pó através de um feixe de lasers (SLS), processos que utilizam fusão de ligas metálicas por feixe de elétrons em alto vácuo (EBM) e outros que utilizam a deposição de polímeros aquecidos através de uma extrusora (FDM), apenas para citar alguns exemplos. A gama de materiais utilizados compreende muitos dos tipos de materiais utilizados em engenharia: metais, polímeros e cerâmicos.

As principais vantagens da MA, segundo Tekinalp et al. [AI.1], ocorrem pela diferença de abordagem em relação aos processos construtivos tradicionais. Historicamente, a produção de um objeto acontece principalmente de duas formas: ou através da retirada de material de um bloco sólido, como os processos de usinagem em geral, ou através de uma ferramenta que confere ao componente o seu formato final, como fundição, forjamento e moldagens por injeção. A MA se apresenta como uma alternativa a estes processos, pois é muito mais eficiente na forma com que utiliza sua matéria prima e ferramental. 
Por depositar material somente onde é necessário e na quantidade exata, o desperdício é significativamente reduzido. As geometrias alcançáveis pela MA são bastante mais complexas do que aquelas obtidas por processos de fabricação tradicionais. Outra grande vantagem da MA é a capacidade de produzir uma gama infinitamente variável de componentes a partir do mesmo ferramental. Normalmente, para cada geometria ou design de um componente, um ferramental de produção específico é necessário. A versatilidade da MA permite a construção de componentes de formas complexas sem a necessidade de moldes ou, até mesmo, a construção de moldes de forma muito mais rápida, eficiente e mais próximo ao seu local de destino [AI.3]. No caso da produção de moldes, produzi-los através de MA, pode reduzir significativamente os custos associados ao processo de projetar, construir e transportar moldes, que pode ser bastante demorado e oneroso [AI.4].

Porém, problemas como a baixa produtividade e alto custo de matéria prima ainda impedem a maior adoção da MA como uma forma de produção em larga escala [AI.5]. Mesmo os processos mais modernos de impressão 3D ainda produzem volumes muito pequenos e a um custo alto, fazendo com que processos de MA sejam geralmente utilizados para prototipagem rápida e modelos de baixo volume de produção [AI.6]. Segundo um estudo feito por Post et al. [AI.6], onde o custo de produção de uma ferramenta a partir do processo FDM é analisado, o custo de processamento (deposição) e matéria prima representam, respectivamente, 38,3\% e 58,7\% do total, como pode ser observado na Tabela AI.1.

Tabela AI.1: Custos associados ao processo FDM [AI.6]

\begin{tabular}{cccc}
\hline & Tempo/material & Custo & Porcentagem \\
\hline Pré-impressão & $2 \mathrm{~h}$ & US\$ 100,00 & $3,2 \%$ \\
Material & $65 \mathrm{lbs}$ & US\$ $12.018,00$ & $38,3 \%$ \\
Processamento & $460 \mathrm{~h}$ & US\$ $18.400,00$ & $58,7 \%$ \\
\hline Pós processamento & & & $2,7 \%$ \\
\hline Mão de obra & $2 \mathrm{~h}$ & US\$ 100,00 & \\
Máquina & $5 \mathrm{~h}$ & US $\$ 750,00$ & \\
Total & $9 \mathrm{~h}$ & US\$ 31.368,00 & \\
\hline
\end{tabular}

Porém, processos que envolvem deposição de polímeros reforçados por fibras em grandes volumes vêm sendo desenvolvidos a fim de aumentar a competitividade da MA, focando em reduzir justamente custos de material e 
processamento. DeNardo [AI.3], em seu estudo, comparou diretamente o custo da produção de um molde através do processo tradicional e via um processo de MA de larga escala. Foram observadas economias de aproximadamente 50\% utilizando o processo aditivo. Ainda segundo dados de Post et al. [AI.6], novos processos de extrusão de polímeros em larga escala, consomem menos de um décimo da energia necessária para forjamentos, fundição e processos de soldagem, sendo assim bastante eficientes energeticamente.

\section{A. 2 \\ Fused Deposition Modelling (FDM)}

Segundo Tekinalp et al. [AI.1], a fused deposition modelling (FDM) é uma técnica de prototipagem rápida que realiza a construção de um objeto camada a camada, depositando um material extrudado por um bico extrusor, em um padrão composto por linhas paralelas. Historicamente, a FDM é utilizada para a fabricação de protótipos e componentes demonstrativos, pois as propriedades dos materiais utilizados neste processo nem sempre permitem a sua aplicação em componentes funcionais. Porém, recentemente, estudos demonstram que o desenvolvimento de novos materiais permite que a FDM seja usada para a fabricações de componentes de uso final [AI.1, AI.2. AI.7].

Segundo Turner et al. [8], em um processo típico, o material, que se encontra na forma de filamento, é alimentado no equipamento através de um rolo que o pressiona e o empurra adiante. A matéria prima é então aquecida até liquefazer-se, com a parte sólida do filamento atuando como um pistão que a empurra em direção ao bico extrusor. Um atuador movimenta o bico extrusor no eixo $\mathrm{x}-\mathrm{y}$, enquanto o material é depositado em uma superfície que se move ao longo do eixo z. Este processo permite que formas geométricas complexas sejam produzidas à medida que o material depositado se solidifica.

Os materiais mais utilizados em FDM são polímeros termoplásticos amorfos, sendo o ABS o mais utilizado [AI.8]. Plásticos como o ABS e outros comumente utilizados em FDM, dificultam a produção de componentes funcionais por conta de suas propriedades mecânicas insuficientes e empenamento durante o resfriamento, o que impacta nas tolerâncias geométricas finais do produto [AI.2]. Como forma de reduzir o empenamento, alguns sistemas FDM utilizam um ambiente de impressão 
com temperatura controlada, que visa diminuir os gradientes de temperatura durante o processo. Isto, todavia, aumenta o custo de operação e nível de complexidade do equipamento, prejudicando a sua rentabilidade [AI.2, AI.8].

Assim como outras técnicas de MA, a FDM sofre com o seu pequeno volume de construção - 0,03 a $0,3 \mathrm{~m}^{3}$, baixas taxas de deposição - 15 a $85 \mathrm{~cm}^{3} / \mathrm{h}$, e alto custo - 100 a 200 USD/kg [AI.5]. Apesar de, atualmente, a FDM ser capaz de produzir componentes aceitáveis para uso final em casos específicos, ela não se apresenta como uma forma economicamente eficiente de manufatura em larga escala [AI.6].

\section{A.3 FDM utilizando polímeros reforçados por fibras de carbono}

A adição de fibras de carbono ao processo de FDM auxilia no desenvolvimento da MA em três pontos importantes. Primeiro, as propriedades mecânicas melhoram com a introdução do reforço de fibras [AI.1, AI.2, AI.5]. Segundo, em consequência das melhores propriedades do material, a escala do processo pode ser aumentada, aumentando assim, também, a produtividade e a variedade de designs possíveis. Finalmente, os custos de matéria prima reduzem-se drasticamente em relação aos materiais utilizados normalmente para a impressão de componentes estruturais [AI.6].

Conforme já colocado, os materiais mais utilizados para o processo de FDM são polímeros termoplásticos de baixas propriedades mecânicas e temperatura de fusão. Esses polímeros são utilizados devido ao baixo custo, facilidade de processamento e disponibilidade no mercado. Estas características os tornam boas opções para a produção de protótipos, geralmente sem propriedades estruturais [AI.7, AI.8]. O reforço por fibras nestes materiais tem como objetivo a melhoria das propriedades mecânicas, tais como módulo de elasticidade e resistência à tração. Um aumento nestas propriedades é necessário para a manufatura de uma gama maior de componentes capazes de desempenhar funções estruturais [AI.5].

Os gráficos mostrados nas Figuras AI.1 e AI.2 relacionam as propriedades mecânicas de alguns compósitos em função da porcentagem em peso do reforço de fibras e do processo pelo qual foram obtidos os corpos de prova [AI.1-AI.3, AI.9]. Na Figura AI.1 estão representados apenas os dados obtidos experimentalmente por 
de processos de MA. Na Figura AI.2, os dados foram retirados de datasheets disponibilizados por fornecedores.

Na Figura AI.1, cada material está representado da seguinte forma: matriz polimérica/reforço de fibras, porcentagem em peso das fibras $(\% \mathrm{wt})$ e o processo de fabricação entre parêntesis. FDM significa que a matéria prima foi utilizada na forma de filamentos para impressão 3D, enquanto MALE (Manufatura Aditiva em Larga Escala) significa que foram utilizados pellets. Os pontos que possuem * foram obtidos graficamente de seus respectivos artigos, caso contrário foram retirados de tabelas de valores. Na Figura AI.2, todos os dados foram obtidos do mesmo processo de fabricação e seus valores retirados de tabelas.

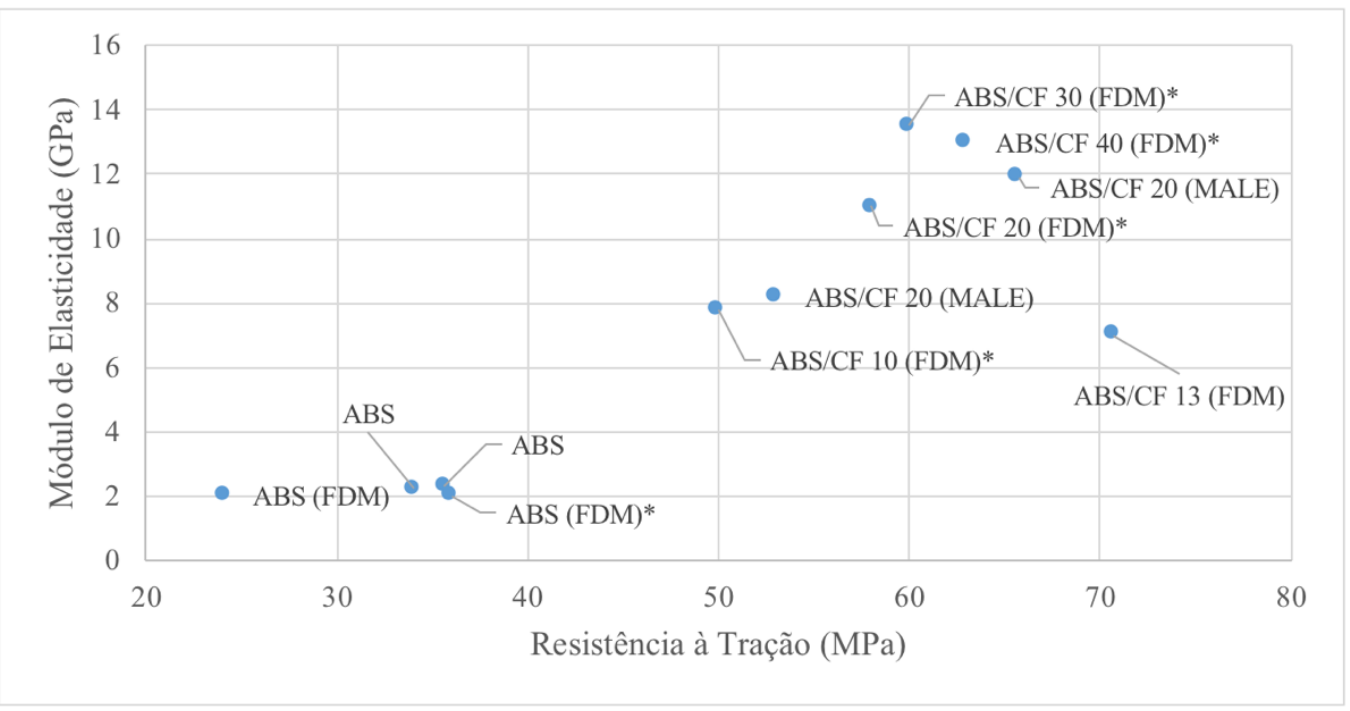

Figura AI.1: Propriedades mecânicas obtidas experimentalmente [AI.1-AI.3, AI.9]. 


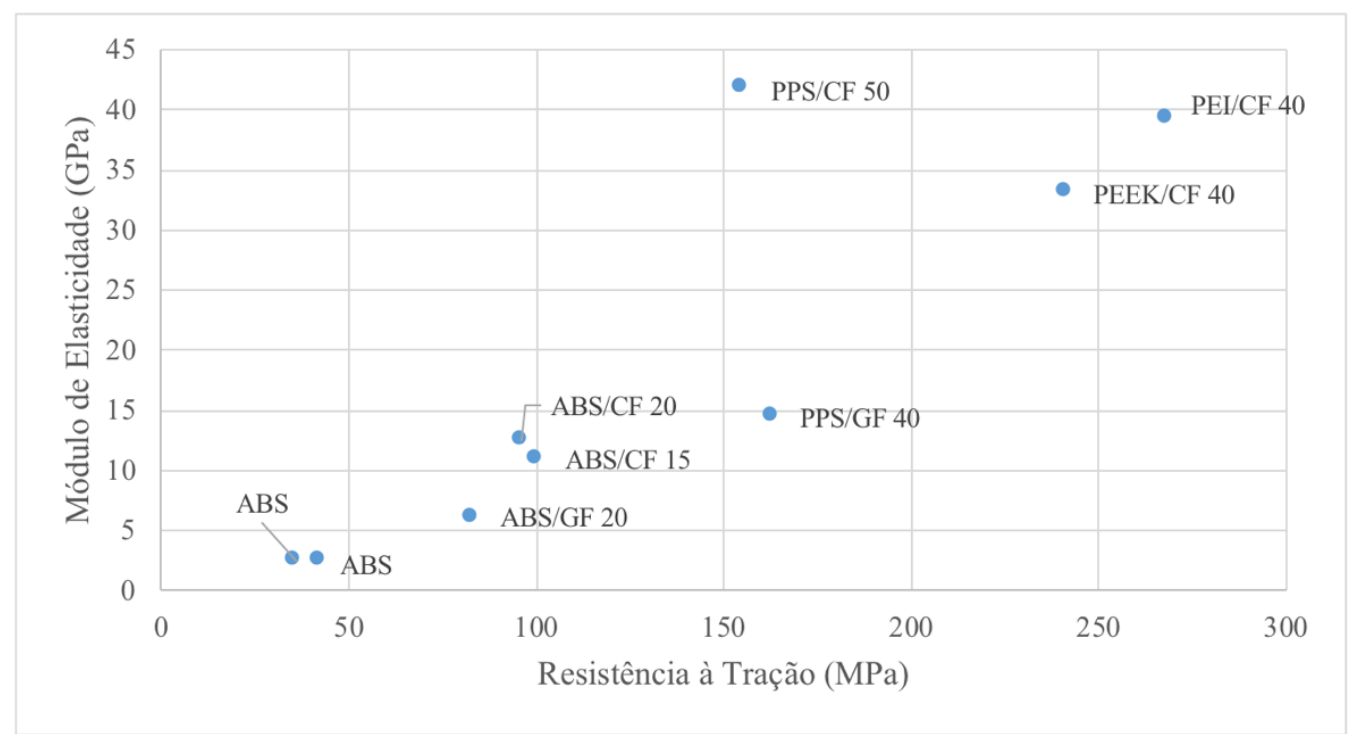

Figura AI.2: Propriedades mecânicas obtidas a partir de datasheets [AI.1-AI.3, AI.9].

É possível observar uma clara tendência ascendente de ambas as propriedades medidas, à medida que se aumenta a porcentagem de fibras. Além disto, o tipo de polímero utilizado na matriz demonstra uma forte influência nas propriedades finais do compósito. Também é possível observar que há uma discrepância entre valores medidos experimentalmente e retirados de datasheets. Isto ocorre porque os valores de datasheet são obtidos através do processamento da matéria prima na forma de pellets utilizando o método de moldagem por compressão. Estes dados são relevantes, pois a utilização de produtos disponíveis no mercado na forma de pellets para moldagem por compressão é uma forma bastante eficaz de reduzir os custos de material da MA [AI.6]. A diferença nas propriedades mecânicas pode ser interpretada como uma forma de medir a influência que o tipo de processamento sofrido pelo material exerce sobre suas características finais.

A introdução da fibra de carbono também altera a condutividade térmica do material depositado, o que melhora significativamente o processo de fabricação da impressão $3 \mathrm{D}$ e reduz o gradiente de temperatura do processo. $\mathrm{O}$ aumento da condutividade térmica faz com que a temperatura se mantenha naturalmente mais estável durante a deposição, o que torna possível imprimir componentes à temperatura ambiente com graus de empenamento extremamente reduzidos [AI.1, AI.2]. Segundo Brenken et al. [AI.7], 95\% da energia total de um processo FDM é consumida para manter a temperatura elevada do ambiente de impressão, ou seja, a 
utilização de polímeros reforçados por fibra de carbono também torna o processo mais energeticamente eficiente.

A impressão à temperatura ambiente diminui as limitações de tamanho de objetos impressos e aumenta a possibilidade de integrar outros componentes ao sistema de impressão. A introdução de um cabeçote de corte, por exemplo, permite que etapas de acabamento sejam realizadas pelo mesmo equipamento [AI.10]. Outro exemplo é a utilização de lâmpadas de emissão infravermelha para um melhor controle da temperatura superficial das camadas impressas [AI.11].

Alterações no processo, como a utilização de matéria prima em pellets, ajudam a reduzir os custos de material e permitem uma maior velocidade de deposição. Polímeros reforçados por fibras na forma de pellets utilizados em moldagem por injeção são mais baratos e disponíveis no mercado do que na forma de filamentos específicos para FDM. Em seu estudo, Brenken et al. [AI.7] compara o custo de matéria prima para a fabricação de ferramentas de PPS com 50\% wt de fibra de carbono e conclui que a utilização de pellets representa uma economia de mais de $90 \%$ (U\$ 8/lbs vs. U\$180/lbs).

Ainda segundo Brenken et al. [AI.7] e Post et al. [AI.6], o tempo de processo é o fator de maior influência no custo da FDM, representando cerca de 58,7\% do total. A utilização de filamentos é um fator limitante da velocidade de processo, visto que a deposição será tão rápida quanto a capacidade de a impressora fundir o material. A utilização de polímeros reforçados por fibras de carbono permite processos em escalas maiores e com maiores taxas de deposição, fazendo com que se alcancem taxas de produção 50 vezes maiores e redução de 17 vezes do custo de MA, como visto na Tabela A1.1, em comparação com a Tabela A1.2.

Tabela AI.2: Custos associados ao processo de MA em larga escala [AI.6]

\begin{tabular}{cccc}
\hline & Tempo/material & Custo & Porcentagem \\
\hline Pré-impressão & $2 \mathrm{~h}$ & US\$ 100,00 & $5,3 \%$ \\
Material & $65 \mathrm{lbs}$ & US\$ 520,00 & $27,8 \%$ \\
Processamento & $2 \mathrm{~h}$ & US\$ 400,00 & $21,4 \%$ \\
& & & \\
\hline Pós processamento & & & $45,5 \%$ \\
\hline Mão de obra & $2 \mathrm{~h}$ & $\mathrm{US} \$ 100,00$ & \\
Máquina & $5 \mathrm{~h}$ & $\mathrm{US} \$ 750,00$ & \\
Total & $9 \mathrm{~h}$ & $\mathrm{US} \$ 1.870,00$ & \\
\hline
\end{tabular}


Comercialmente, este tipo de material compósito ainda é pouco disponível e possui propriedades que variam amplamente em função do polímero utilizado como matriz, bem como da fração volumétrica e das características geométricas (comprimento, orientação, etc.) do reforço de fibras. O emprego desta técnica, porém, torna possível a fabricação totalmente digital de componentes que, em alguns casos, possuem propriedades comparáveis às do alumínio [AI.1].

O material em estudo neste projeto apresenta um grande potencial para aplicações estruturais, pois a utilização de fibras avançadas como reforço pode fazer com que valores de resistência e módulo aumentem até 115\% e 700\%, respectivamente, em relação ao ABS puro [AI.1].

O próprio processo de extrusão para a fabricação do filamento, bem como a passagem pelo bico injetor da impressora, faz com que o compósito seja depositado com um alto grau de alinhamento das fibras (Figura AI.3). Isto faz com que este material apresente uma alta ortotropia, que deve ser levada em conta durante o projeto de componentes e também na escolha do caminho de deposição da impressão [AI.1].

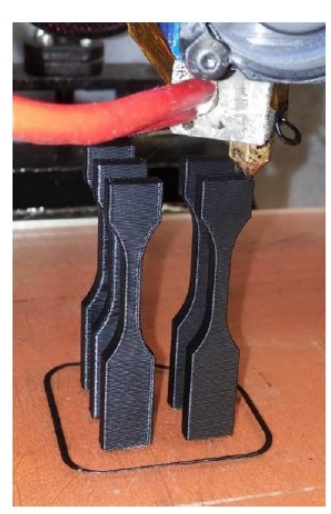

Figura AI.3: Corpos de prova impressos 3D utilizando ABS reforçado por fibras de carbono [AI.2]. 


\section{A.4 \\ Referências bibliográficas}

AI.1. TEKINALP, H. L. et al. Highly oriented carbon fiber-polymer composites via additive manufacturing. Composites Science and Technology, v. 105, p. $144-150,16$ Oct 2014.

AI.2. LOVE, L. J. et al. The importance of carbon fiber to polymer additive manufacturing. J. Mater. Res., v. 29, n. 17, 14 Sep 2014.

AI.3. DENARDO, N. M. Additive Manufacturing of Carbon Fiber Reinforced Thermoplastic Composites. Purdue University. West Lafayette, Indiana, p. 183. 2016. (ProQuest 10181531).

AI.4. U.S. DEPARTMENT OF ENERGY. Transforming Wind Turbine Blade Mold Manufacturing. [S.1.], p. 8. 2016. (DOE/GO-102016-4870).

AI.5. DUTY, C. E. et al. Structure and mechanical behavior of Big Area Additive Manufacturing (BAAM) materials. Rapid Prototyping Journal, v. 23, n. 1, p. 181-189, January 2017. ISSN ISSN 1355-2546.

AI.6. POST, B. K. et al. The Economics of Big Area Additive Manufacturing. Solid Freeform Fabrication 2016: Proceedings of the 27th Annual International Solid Freeform Fabrication Symposium - An Additive Manufacturing Conference. Austin, TX: [s.n.]. 2016. p. 1176-1182.

AI.7. BRENKEN, B. et al. Fused Deposition Modeling of Fiber-Reinforced Thermoplastic Polymers: Past Progress and Future Needs. Proceedings of the Thirty-First Technical Conference of the ASC. Williamsburg: American Society for Composites. 2016.

AI.8. TURNER, B. N.; STRONG, R.; GOLD, S. A. A review of melt extrusion additive manufacturing processes: I. Process design and modeling. Rapid Prototyping Journal, v. 20, n. 3, p. 192-204, March 2014. ISSN ISSN 1335-2546.

AI.9. ORNL, TECHMER ENGINEERED SOLUTIONS. Material Development for Tooling Applications Using Big Area Additive Manufacturing (BAAM). Oak Ridge National Laboratory. Oak Ridge, TN, p. 8. 2015. (MDF-TC-2014-053).

AI.10 ORNL, LOCAL MOTORS INC. Advanced Manufacturing of Complex Cyber Mechanical Devices through Community Engagement and Micro-manufacturing. Oak Ridge National Laboratory. Oak Ridge, TN, p. 4. 2014. (MDF-TC-2014-040).

AI.11. KISHORE, V. et al. Infrared preheating to improve interlayer strength of big area additive manufacturing (BAAM) components. Additive Manufacturing, 2 December 2016. 7-12.

AI.12. William D. CALlister, J. Materials Science and Engineering an Introduction. 7th. ed. Salt Lake City: John Wiley \& Sons, Inc., 2007. 


\section{Anexo II}

\section{All.1}

Espectros de FTIR

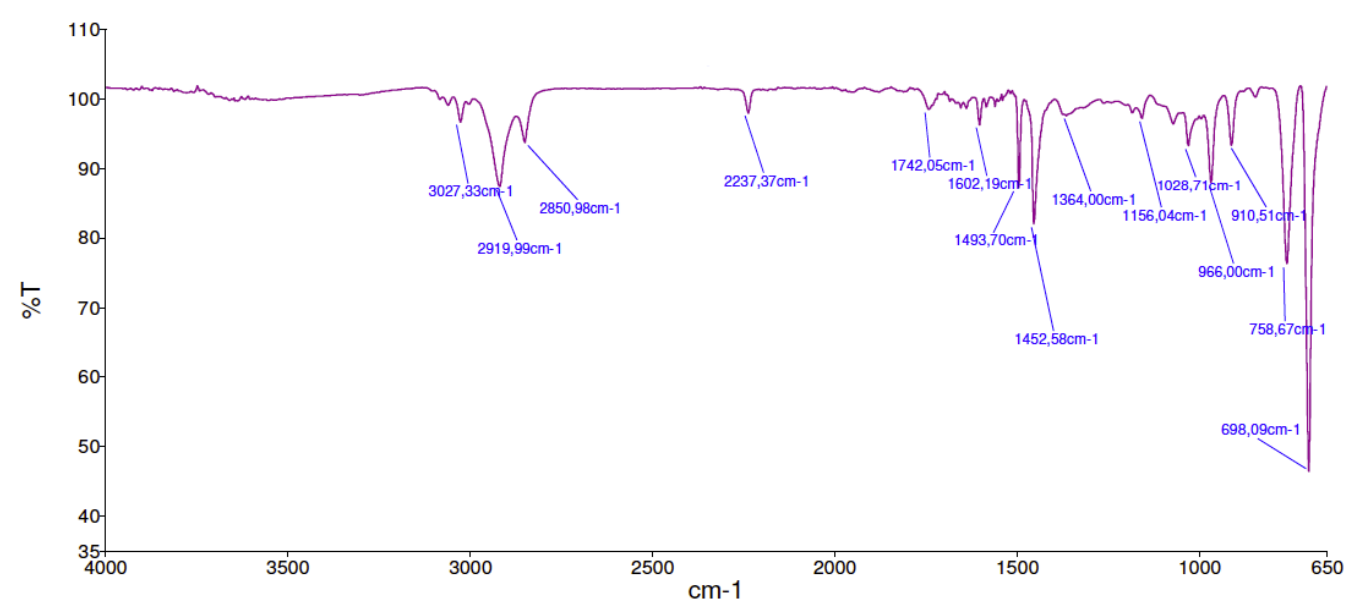

Figura 40: Gráfico do FT-IR, gerado pelo software Spectrum (Perkin Elmer), para amostra processada a $180^{\circ} \mathrm{C}$.

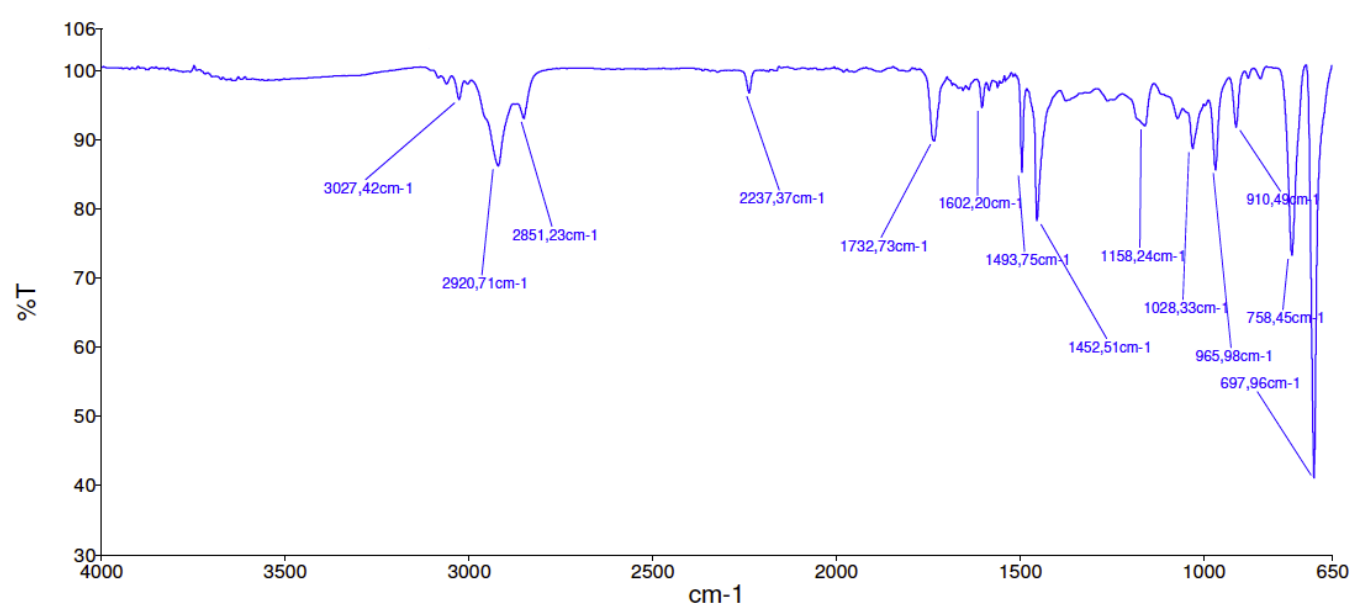

Figura 41: Gráfico do FT-IR, gerado pelo software Spectrum (Perkin Elmer), para amostra processada a $220^{\circ} \mathrm{C}$. 


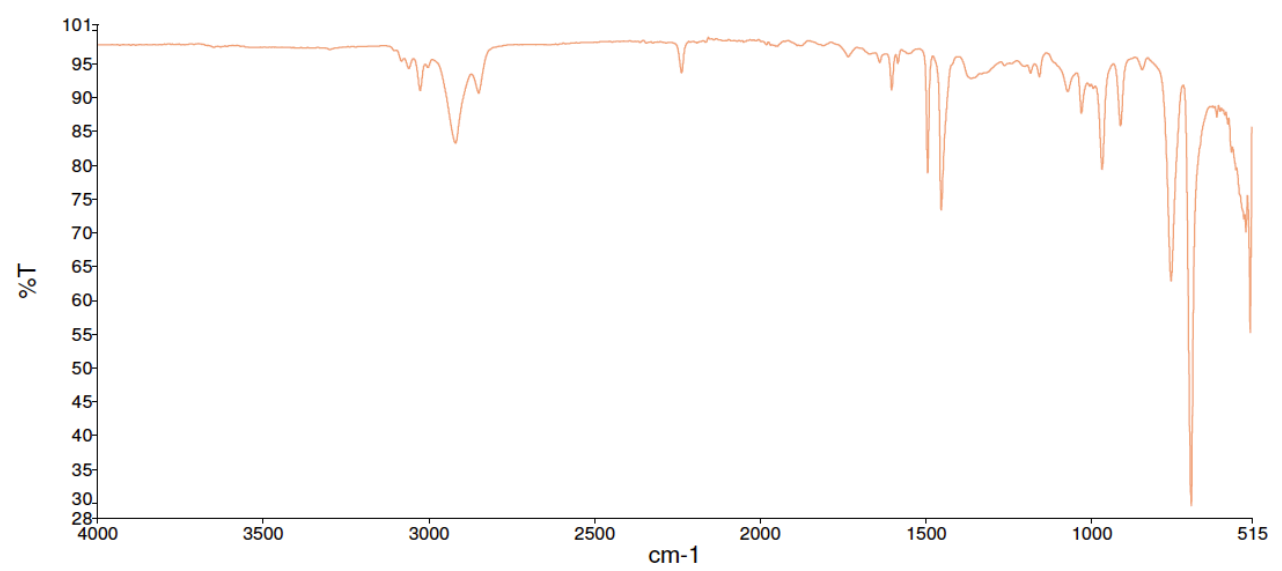

Figura AII.42: Gráfico do FTIR da mistura I.

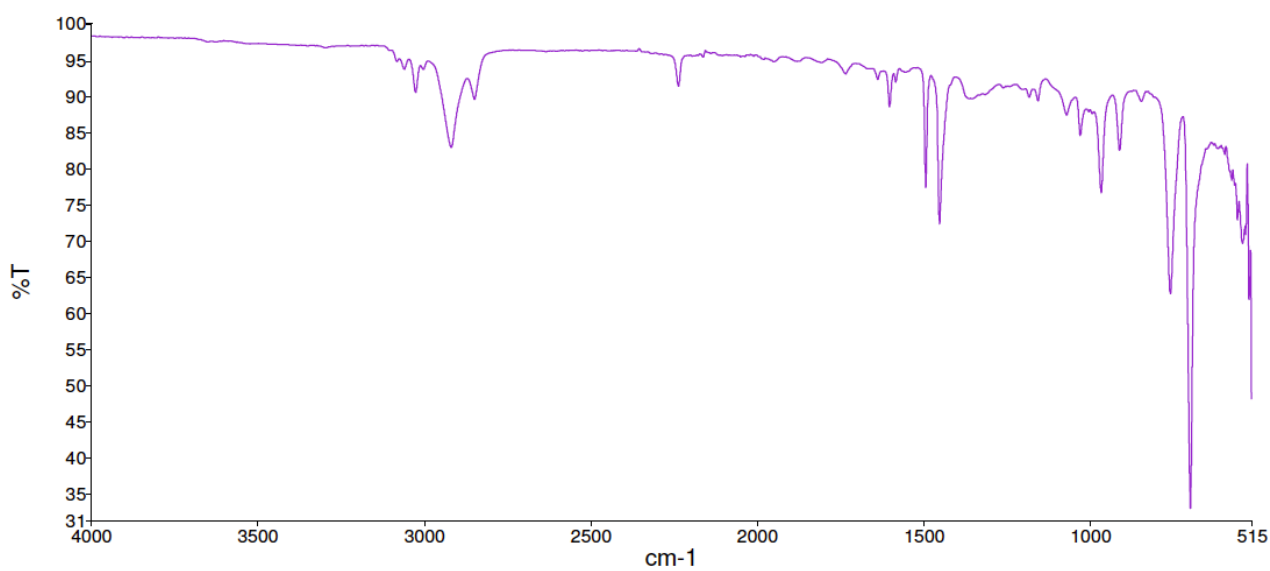

Figura AII.43: Gráfico do FTIR da mistura II.

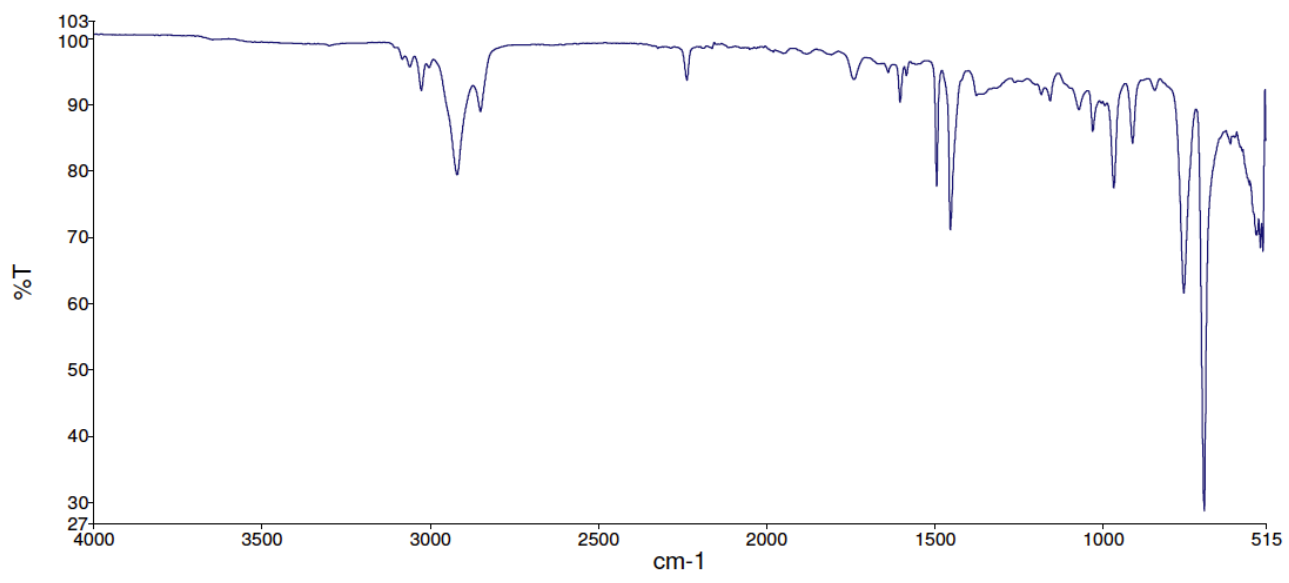

Figura AII.44: Gráfico do FTIR da mistura III. 


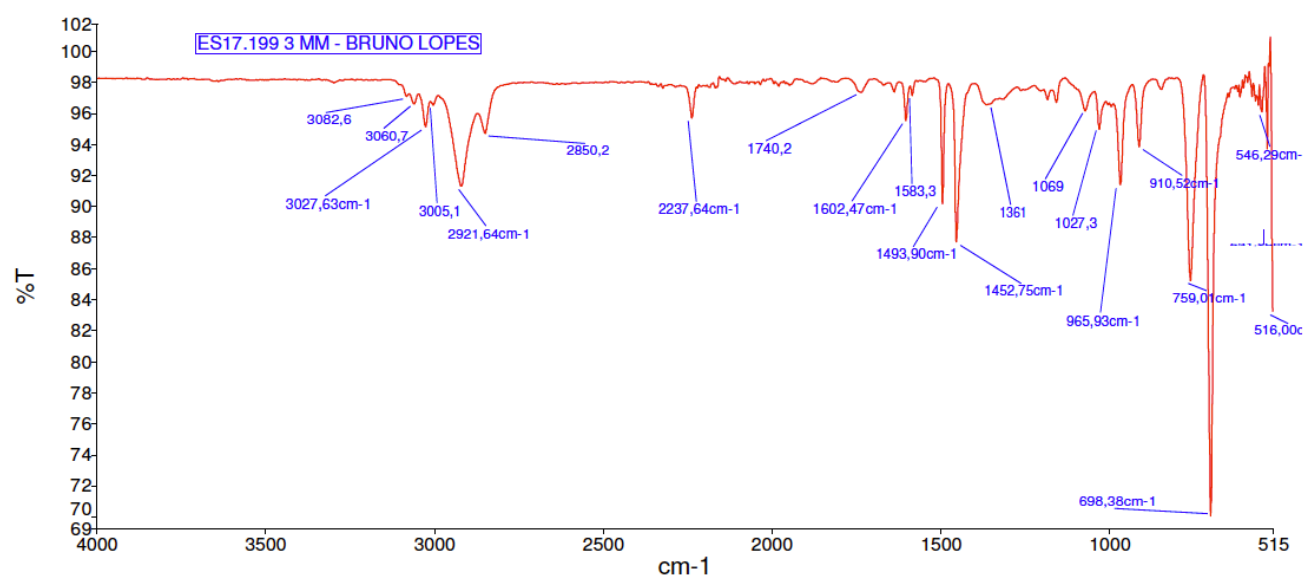

Figura AII. 45: Gráfico do FTIR da mistura IV.

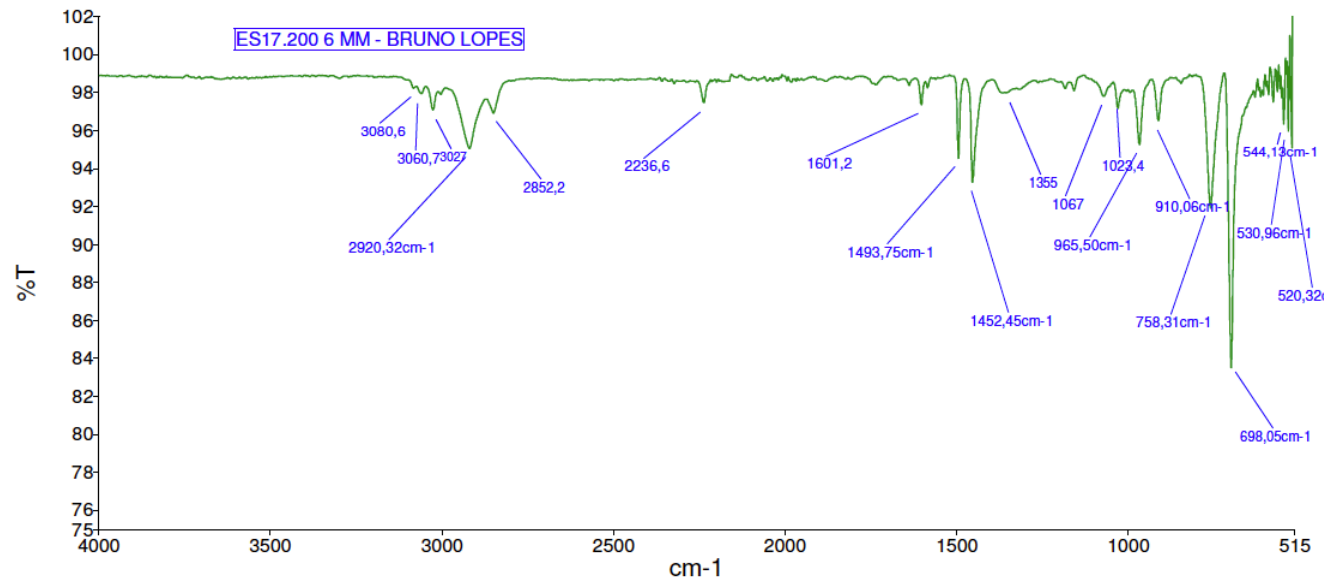

Figura AII.46: Gráfico do FTIR da mistura V. 


\section{All.2}

\section{Termogramas}

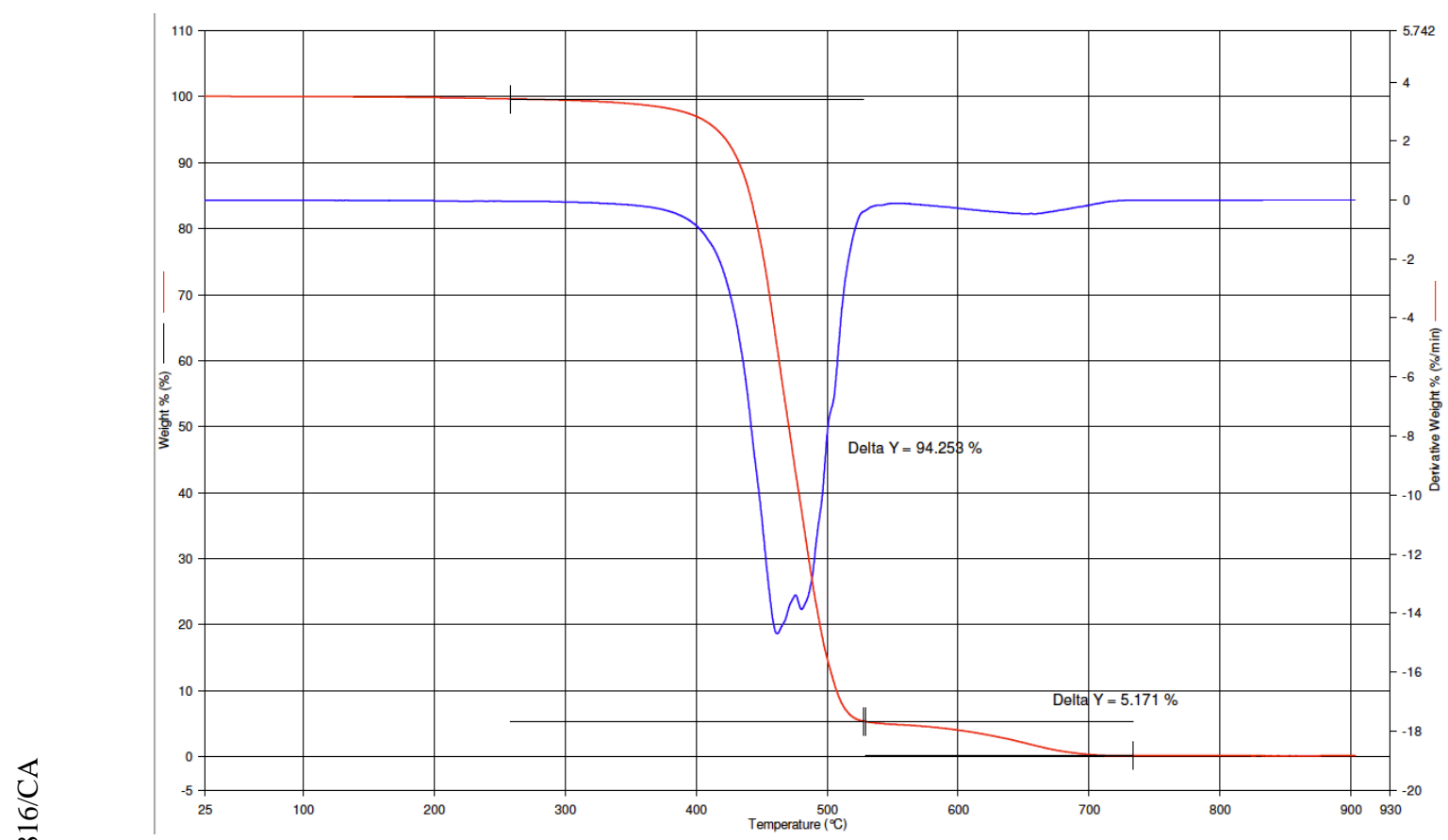

Figura A.47: Gráfico resultante do TGA para a mistura I (ABS puro).

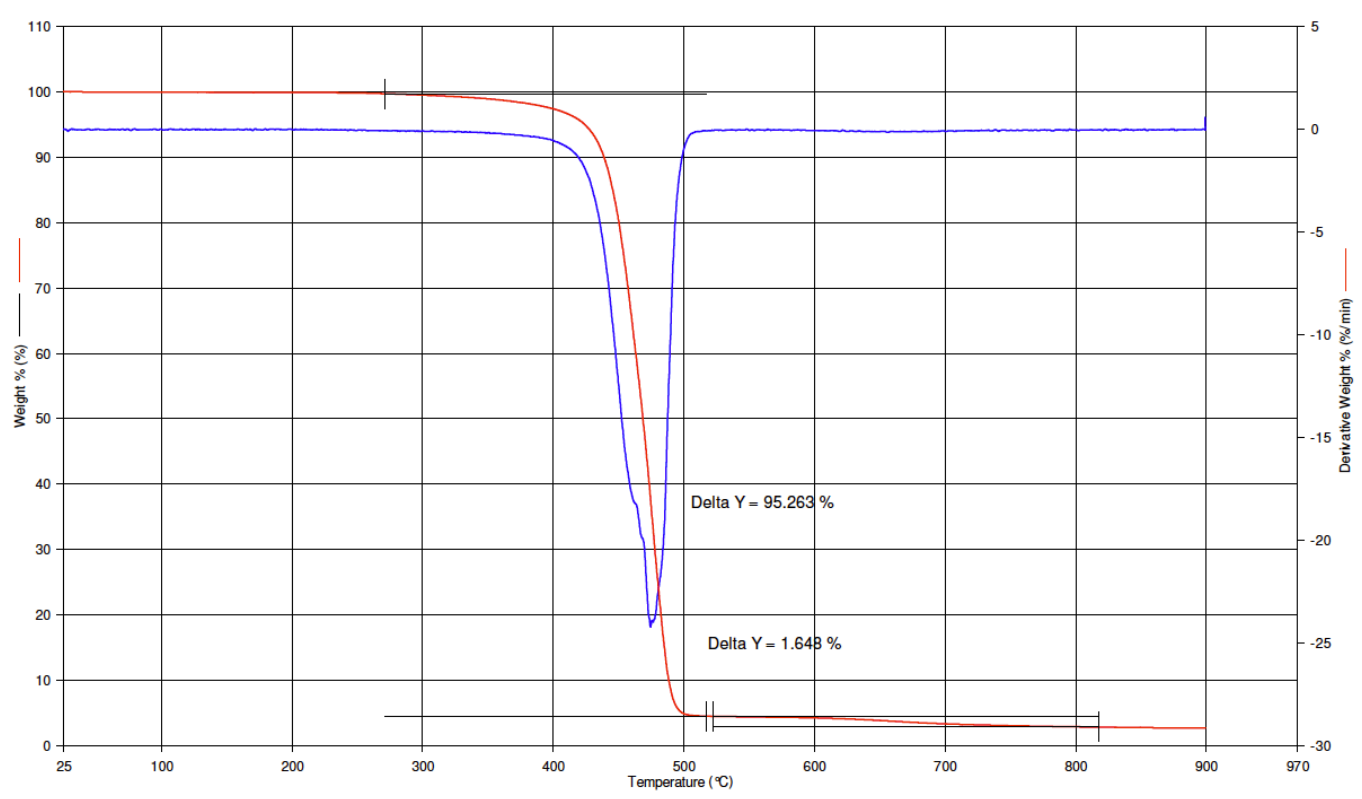

Figura A.48: Gráfico resultante do TGA para a mistura II. 


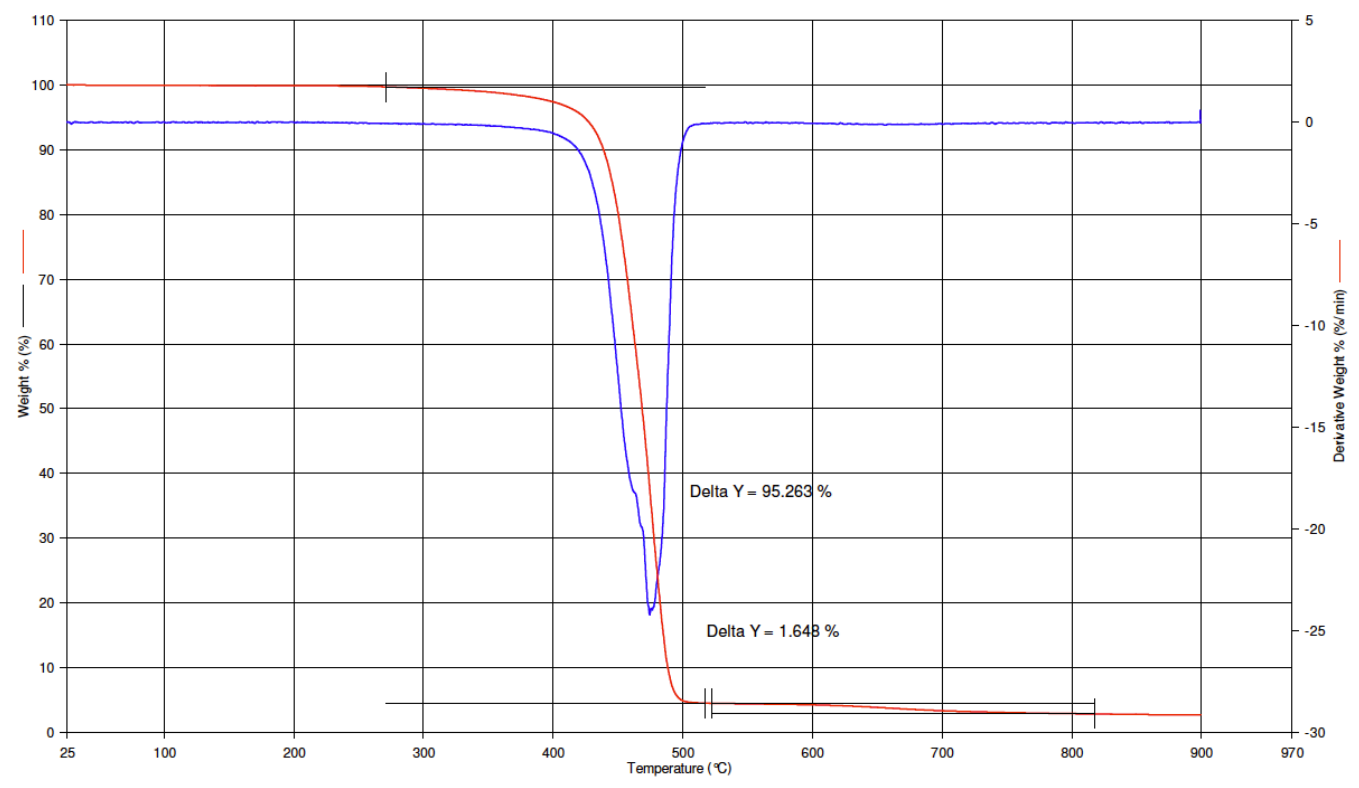

Figura A.49: Gráfico resultante do TGA para a mistura III.

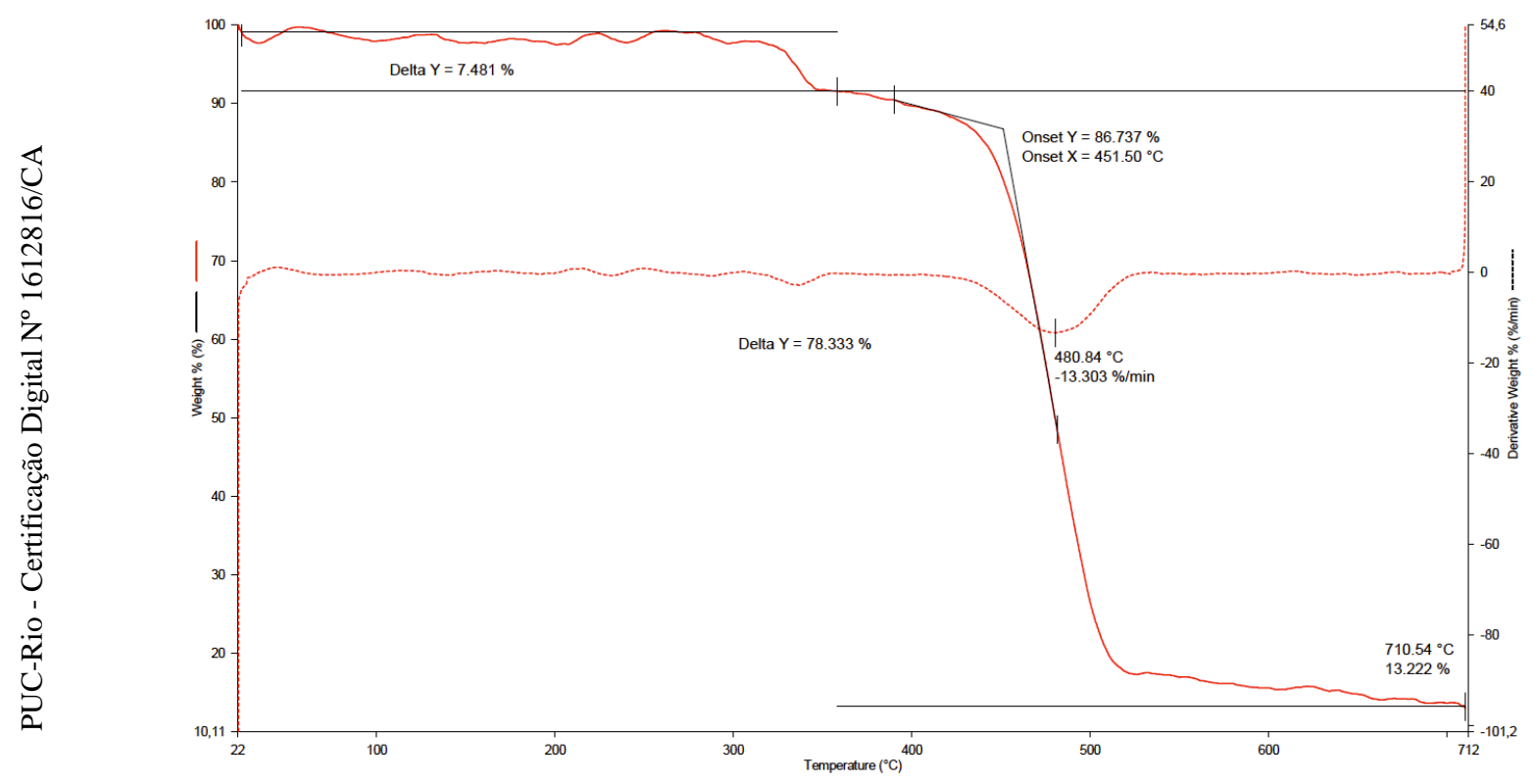

Figura A.50: Gráfico resultante do TGA para a mistura IV. 


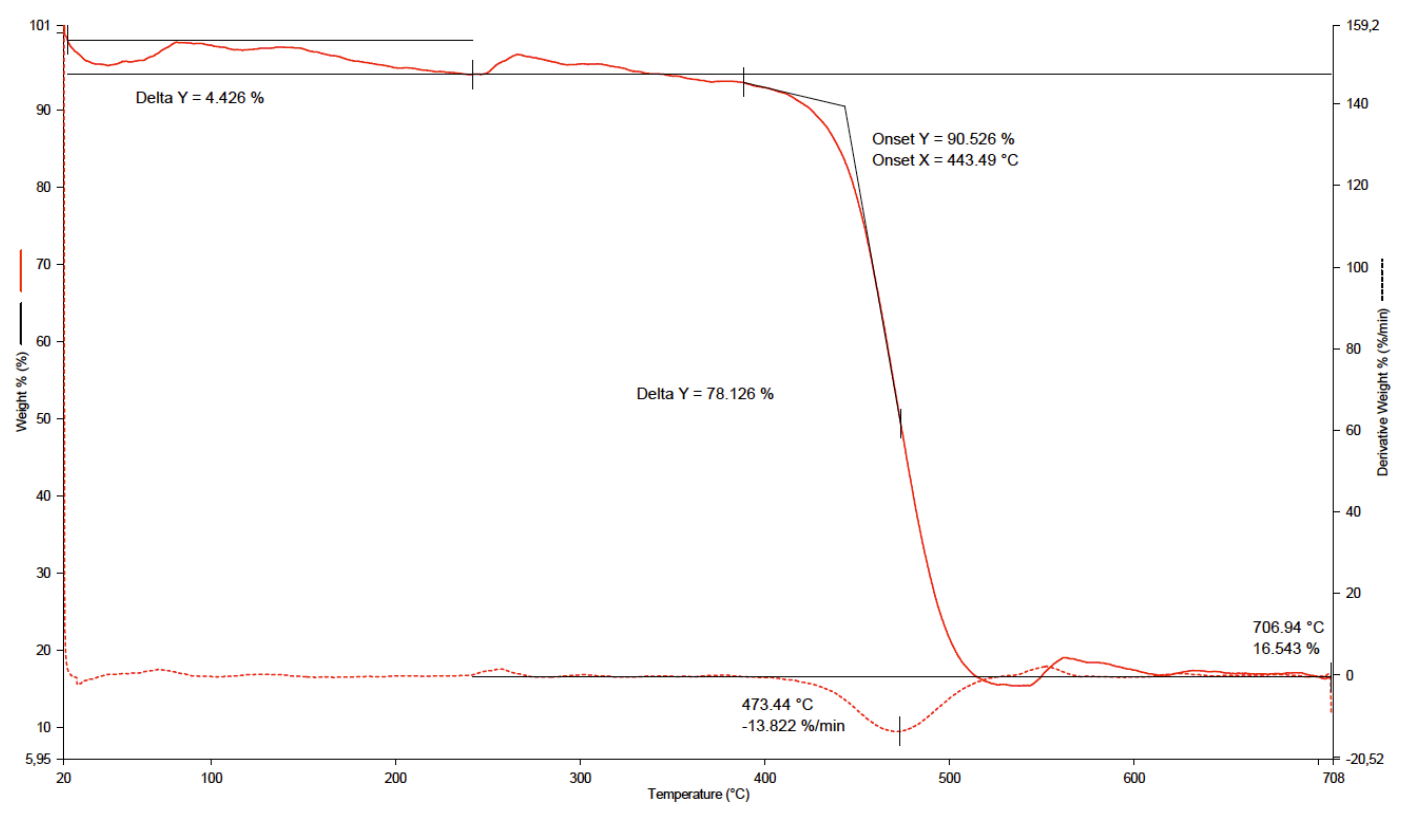

Figura A.51: Gráfico resultante do TGA para a mistura V.

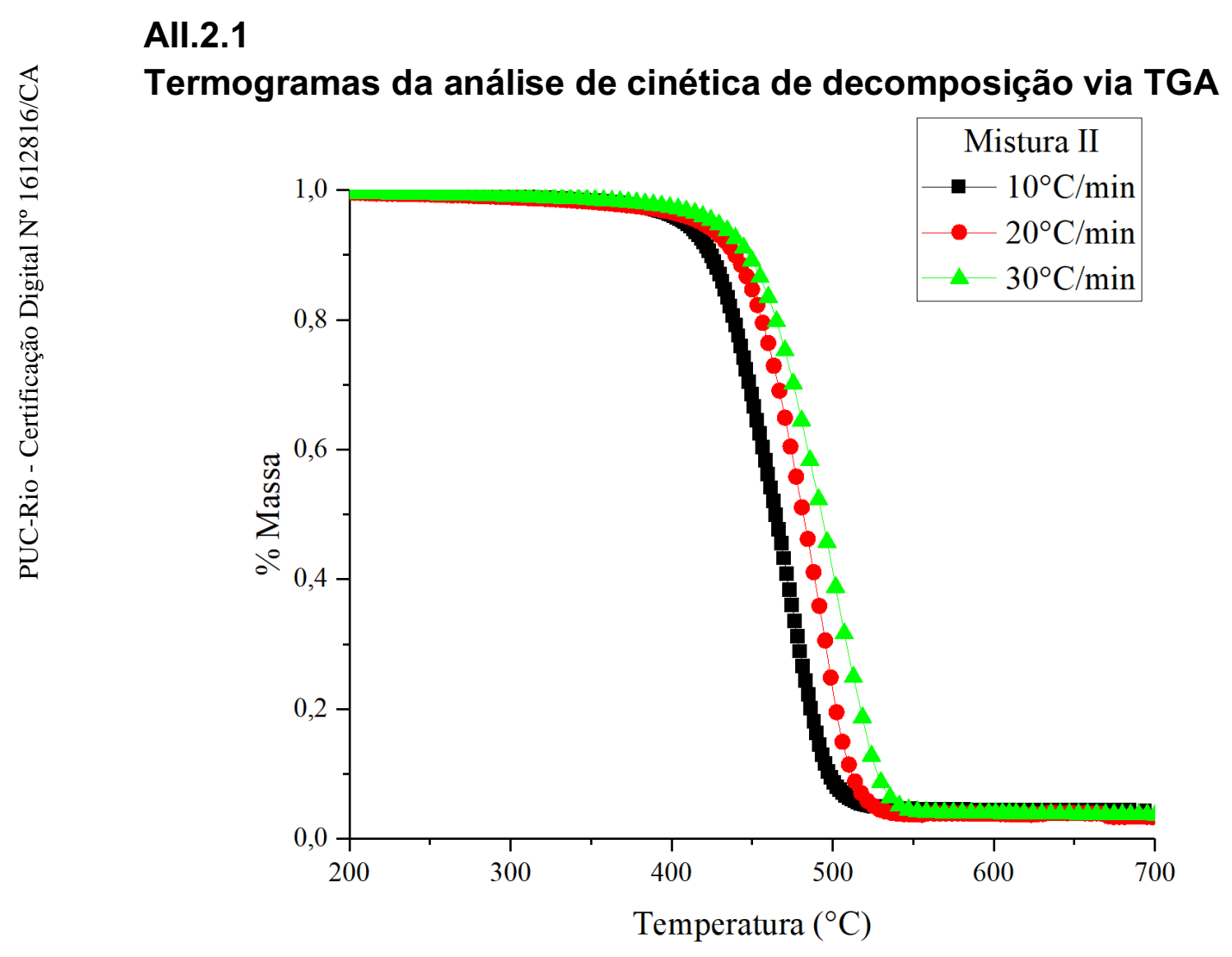

Figura AII.18: Termograma exibindo as curvas para as três taxas de aquecimento utilizadas para a mistura II 


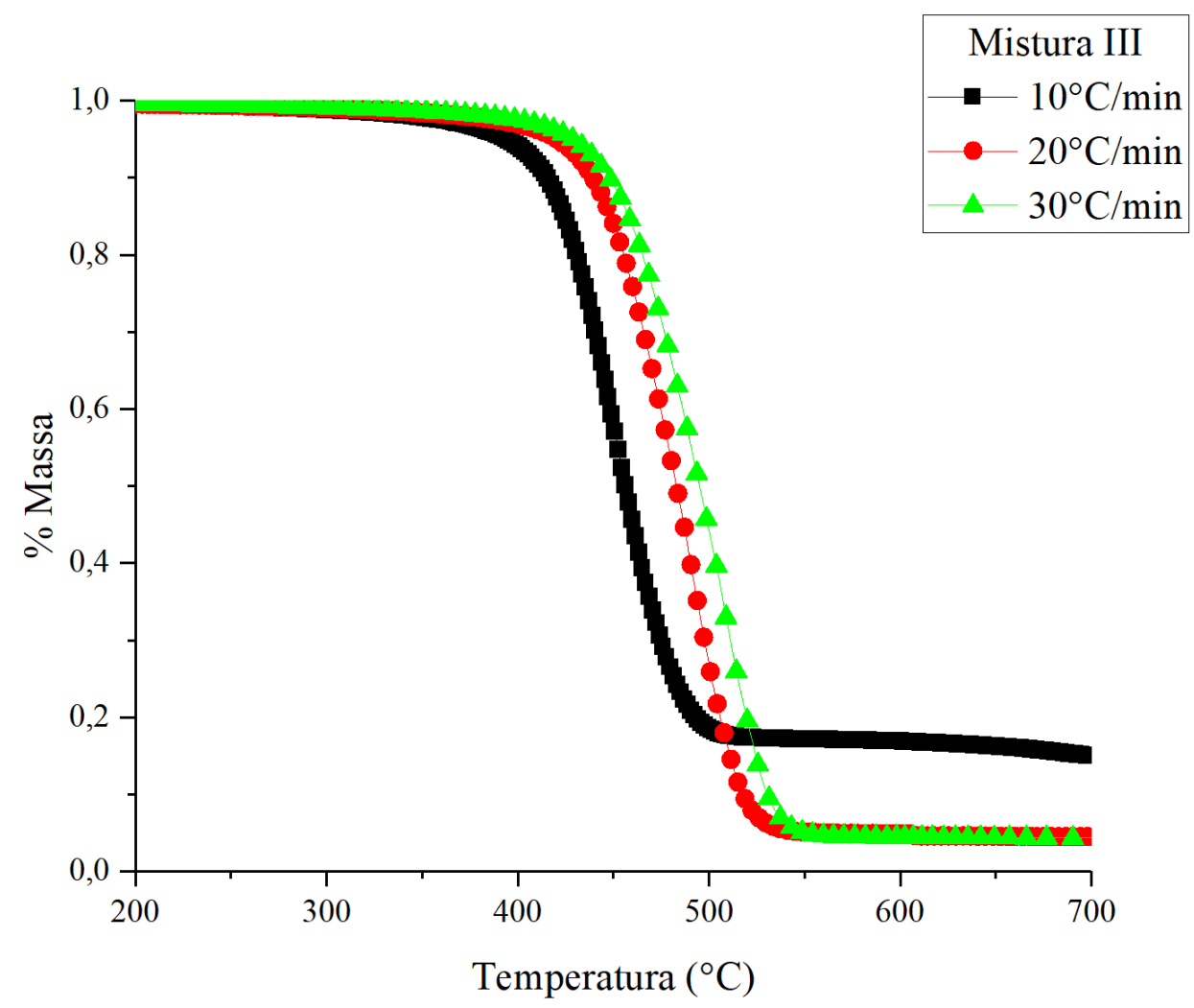

Figura AII.19:Termograma exibindo as curvas para as três taxas de aquecimento utilizadas para a mistura III

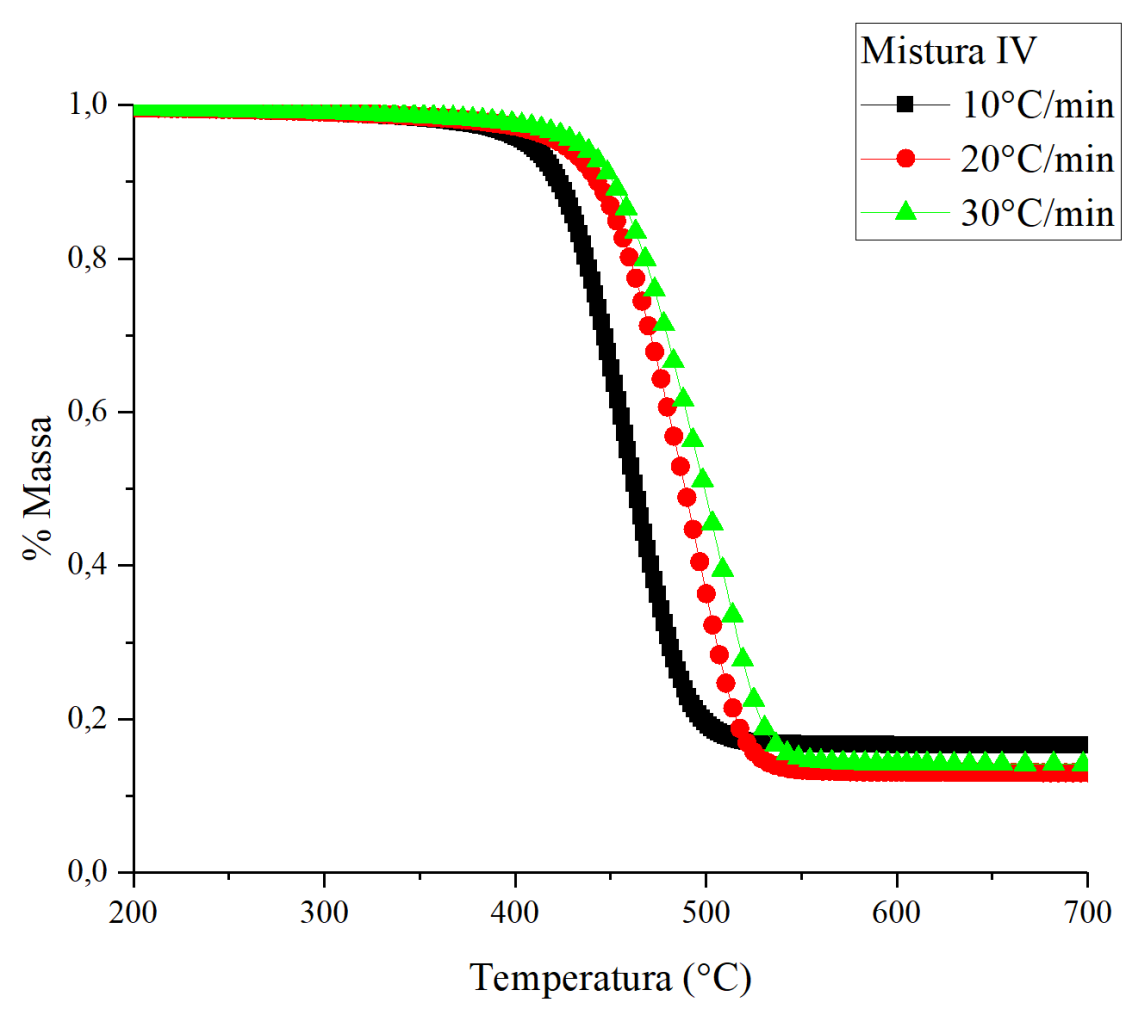

Figura AII.20: Termograma exibindo as curvas para as três taxas de aquecimento utilizadas para a mistura IV 


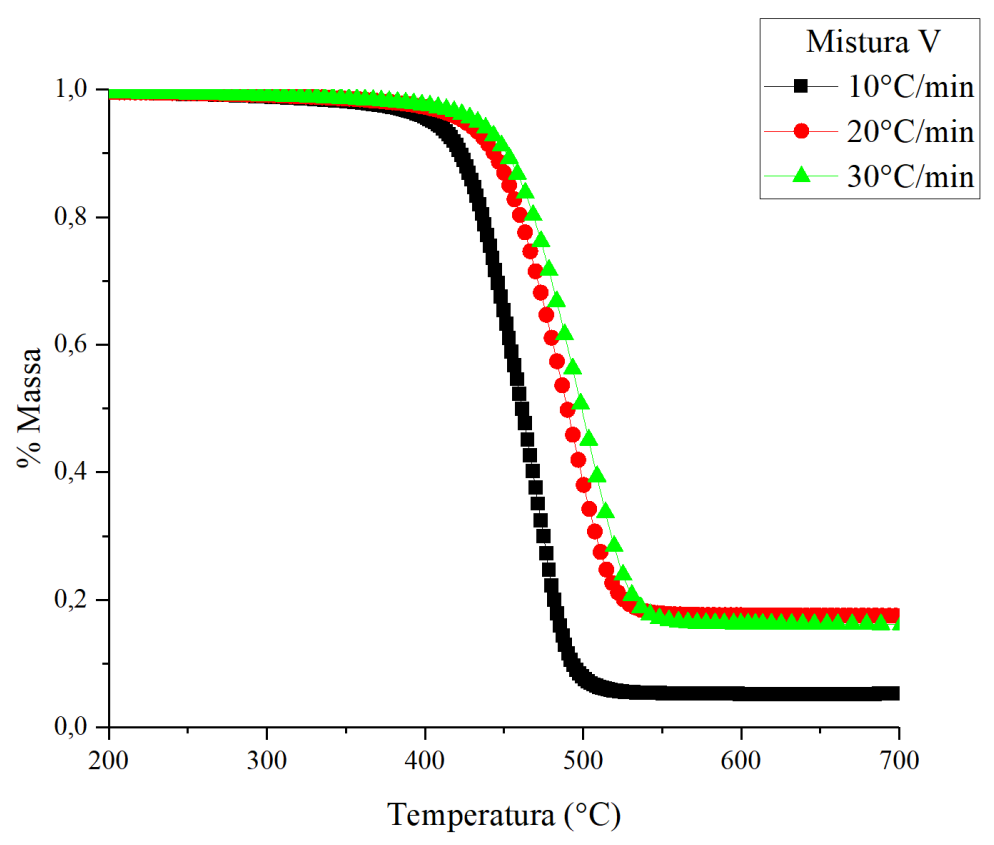

Figura AII.21: Termograma exibindo as curvas para as três taxas de aquecimento utilizadas para a mistura $\mathrm{V}$

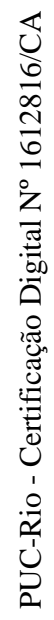

\section{All.2.2}

Níveis de degradação em função da taxa de aquecimento e temperatura

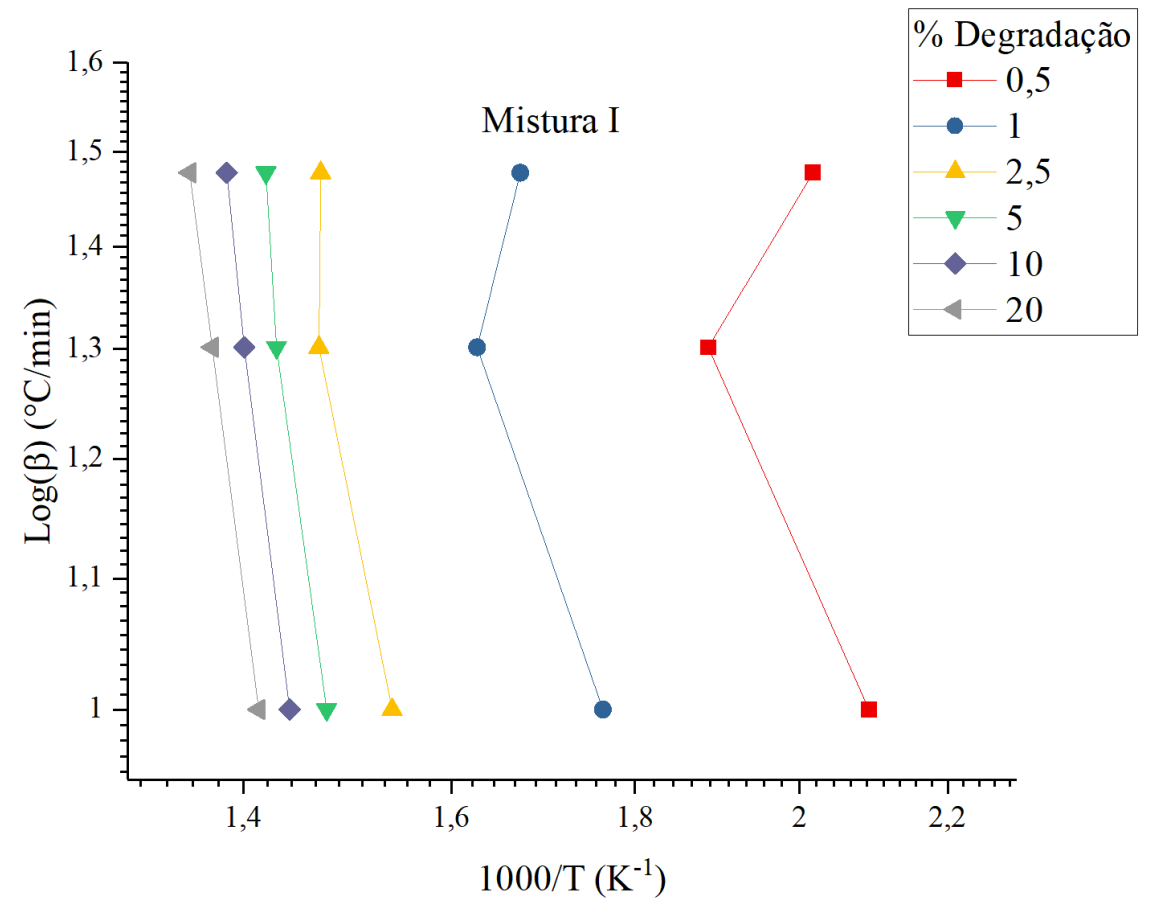

Figura AII.22: Gráfico dos níveis de degradação em função da taxa de aquecimento e temperatura. 


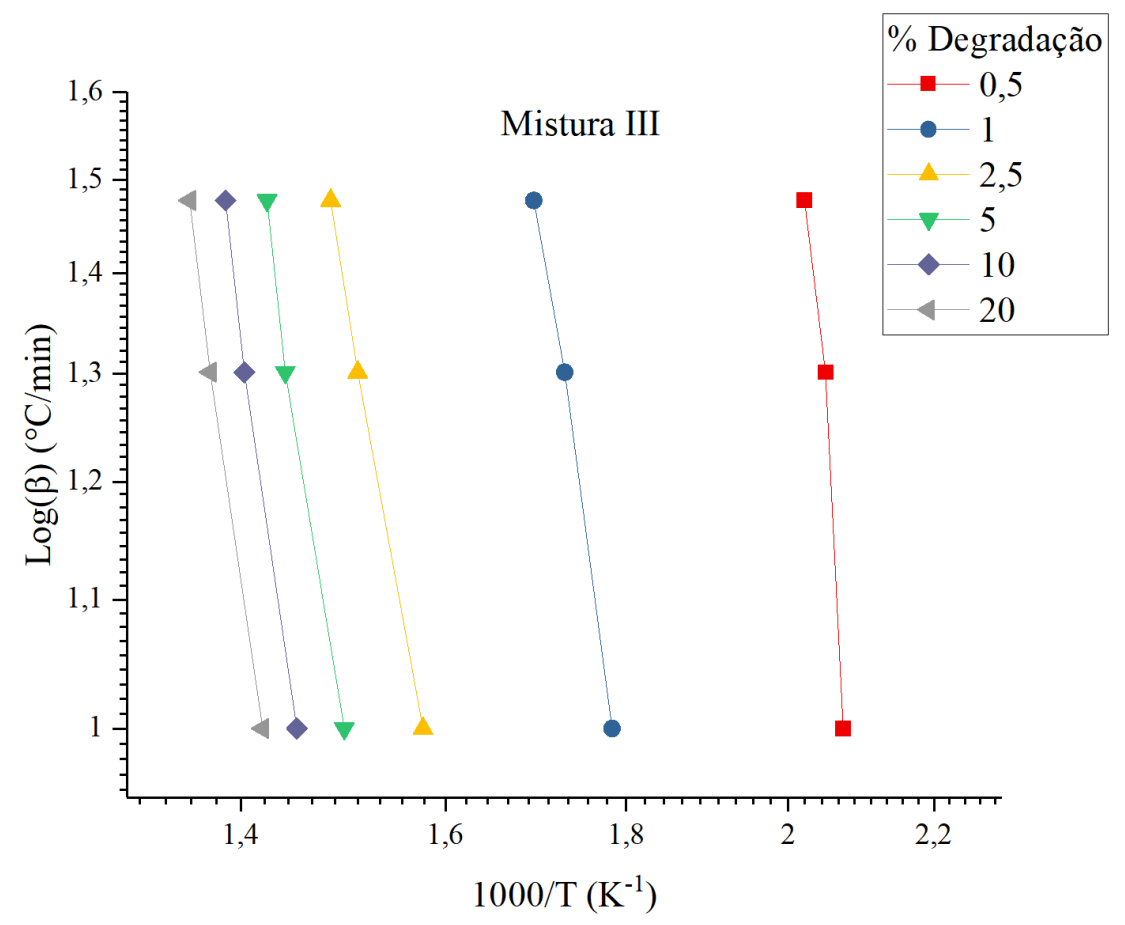

Figura AII.23: Gráfico dos níveis de degradação em função da taxa de aquecimento e temperatura.

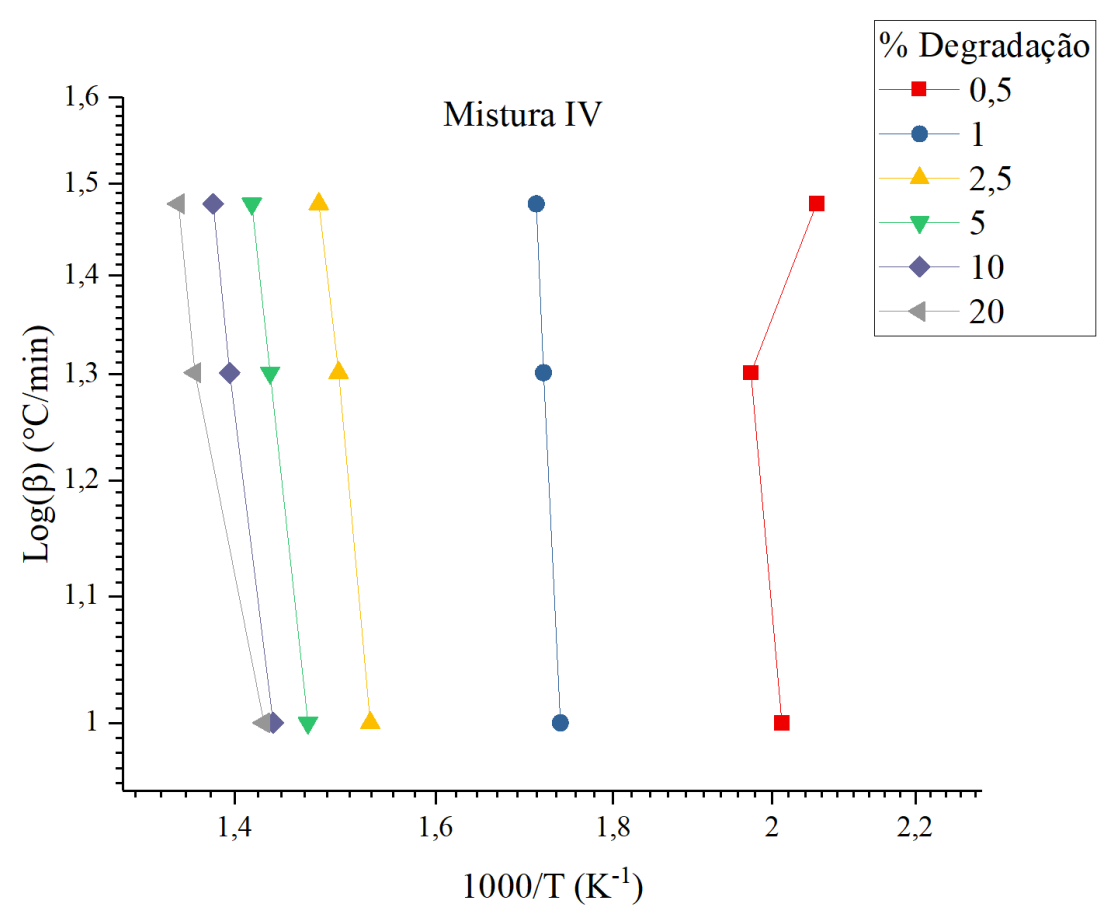

Figura AII.24: Gráfico dos níveis de degradação em função da taxa de aquecimento e temperatura. 


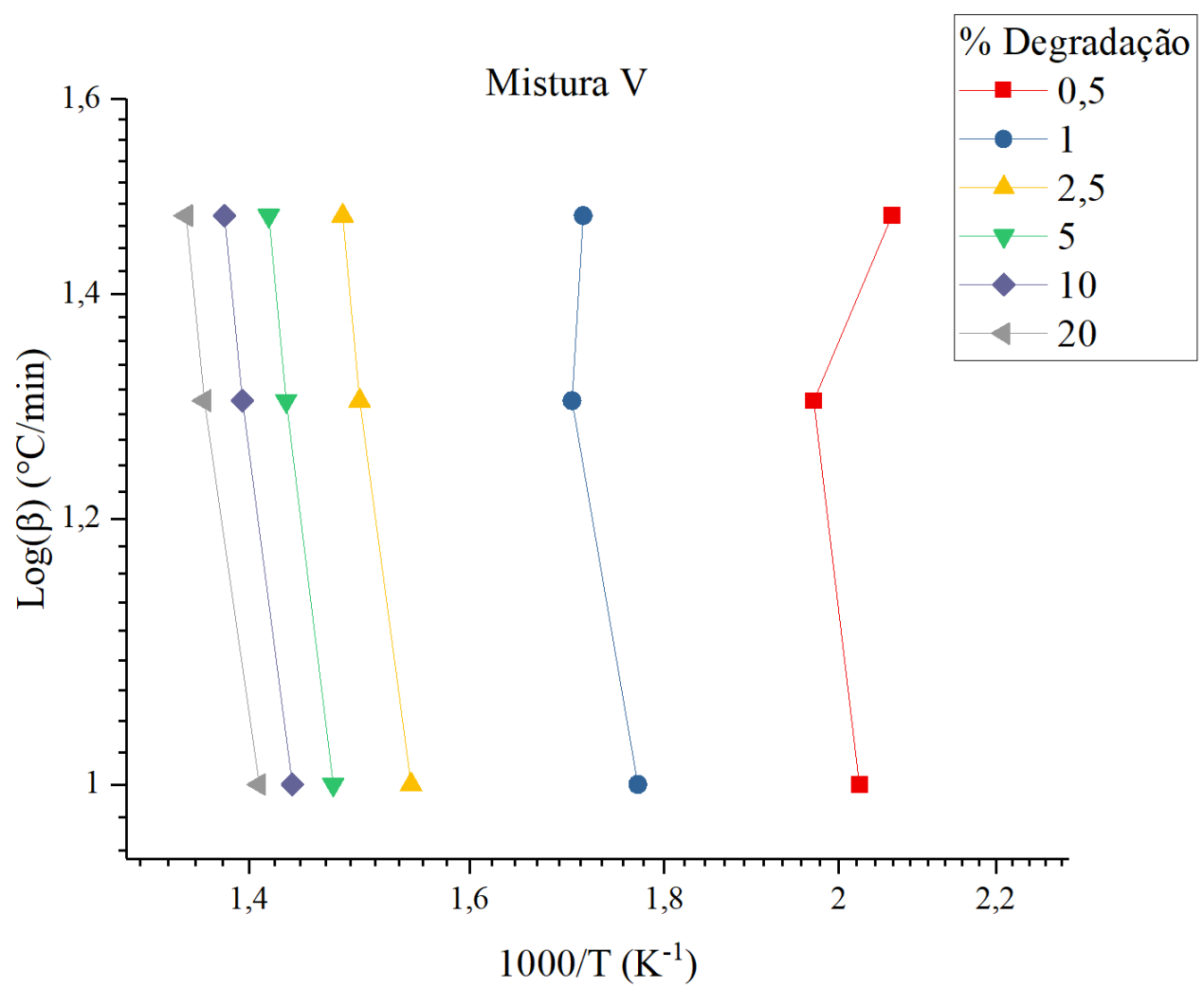

Figura AII.25: Gráfico dos níveis de degradação em função da taxa de aquecimento e temperatura. 